\title{
WestVirginiaUniversity
}

THE RESEARCH REPOSITORY @ WVU

Graduate Theses, Dissertations, and Problem Reports

2006

\section{Parametric sensitivity analysis of microscrews}

Zachary F. Witzgall

West Virginia University

Follow this and additional works at: https://researchrepository.wvu.edu/etd

\section{Recommended Citation}

Witzgall, Zachary F., "Parametric sensitivity analysis of microscrews" (2006). Graduate Theses, Dissertations, and Problem Reports. 1956.

https://researchrepository.wvu.edu/etd/1956

This Thesis is protected by copyright and/or related rights. It has been brought to you by the The Research Repository @ WVU with permission from the rights-holder(s). You are free to use this Thesis in any way that is permitted by the copyright and related rights legislation that applies to your use. For other uses you must obtain permission from the rights-holder(s) directly, unless additional rights are indicated by a Creative Commons license in the record and/ or on the work itself. This Thesis has been accepted for inclusion in WVU Graduate Theses, Dissertations, and Problem Reports collection by an authorized administrator of The Research Repository @ WVU. For more information, please contact researchrepository@mail.wvu.edu. 


\title{
Parametric Sensitivity Analysis of Microscrews
}

Zachary F. Witzgall

Thesis Submitted to the College of Engineering and Mineral Resources

At West Virginia University In Partial Fulfillment of the Requirements For the Degree of

\author{
Master of Science \\ in \\ Mechanical Engineering \\ Victor H. Mucino, Ph.D., Chair \\ James E. Smith, Ph.D. \\ Kenneth H. Means, Ph.D. \\ Department of Mechanical and Aerospace Engineering
}

Morgantown, WV

2006

Keywords: Parametric Sensitivity, Microscrews, Finite Element Analysis 


\section{Abstract}

\section{Parametric Sensitivity Analysis of Microscrews}

By Zachary F Witzgall

The research and development of a popular, publicly available microscrew system required an analysis of fastener strength. This analysis was performed using a Finite Element Analysis (FEA) program. ANSYS was used to model and stress the fasteners through various loading schemes. A simplified model was constructed due to limitations in model size.

The analysis required key parameters to be changed slightly. These parameters were socket depth and socket diameter. Changing these parameters had a substantial affect on the strength of the fastener.

Torque and rotation to tension analyses were performed on the microscrew to determine the validity of the ANSYS computation results. This data also provided complimentary information on the mechanics of a threaded assembly. 


\section{Table of Contents}

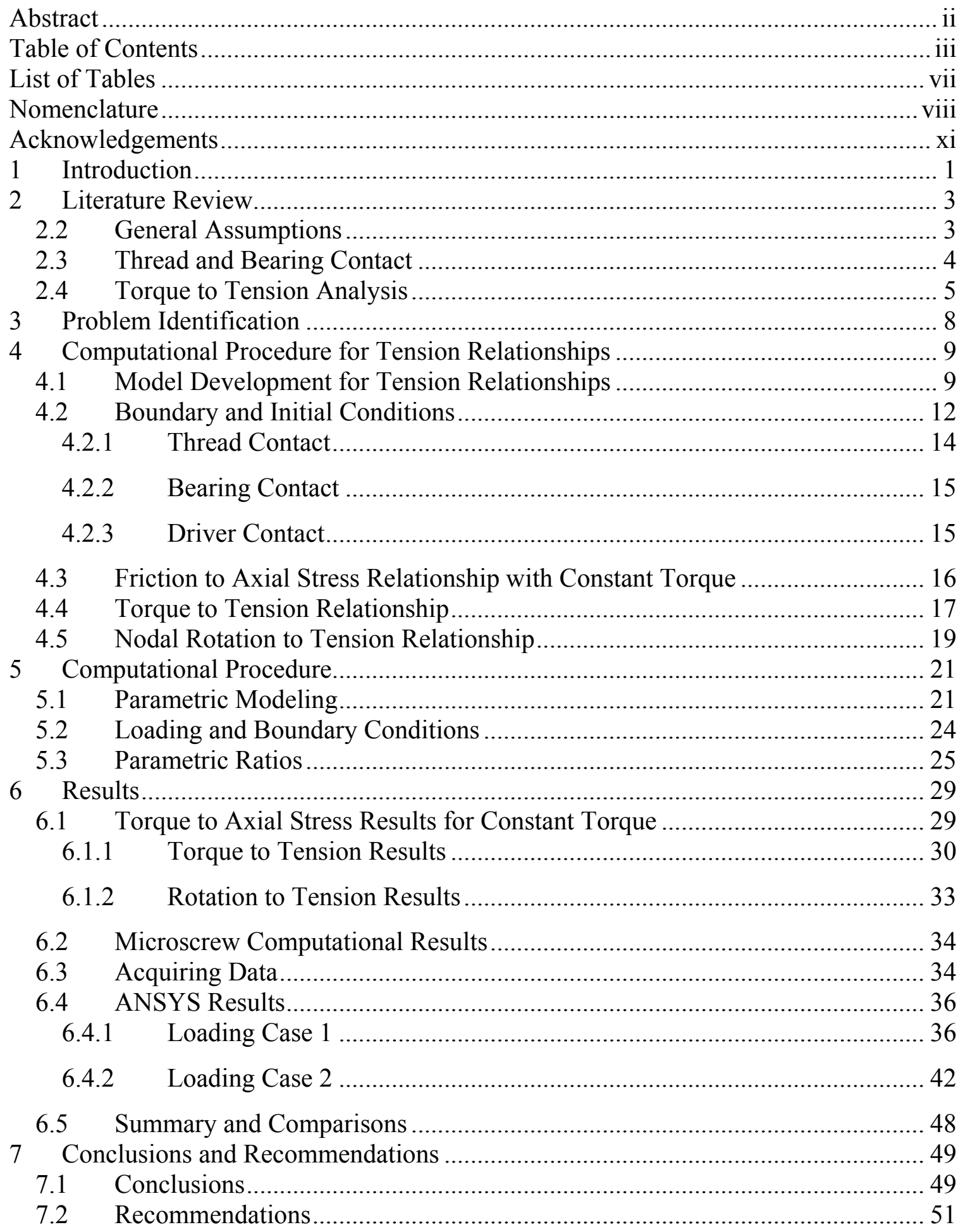




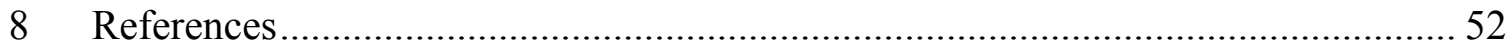

Appendix A $\quad$ APDL Code for Parametric Sensitivity................................5 54

Appendix B Von Mises Plots from the Parametric Sensitivity.....................64

Appendix C Microscrew Schematic....................................... 73 


\section{List of Figures}

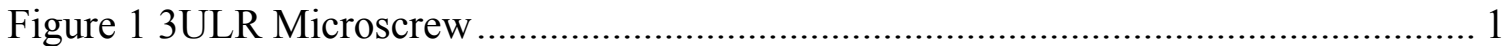

Figure 2 Thread Load Comparison [6] ...................................................................... 5

Figure 3 Relationship between axial bolt stress and nut rotation angle [7] ...................... 7

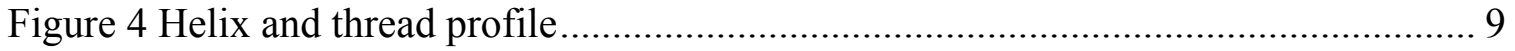

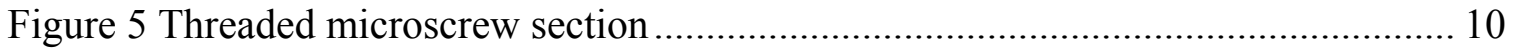

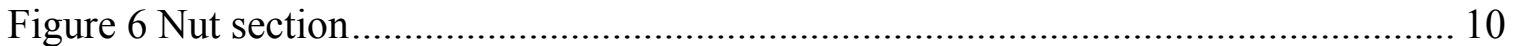

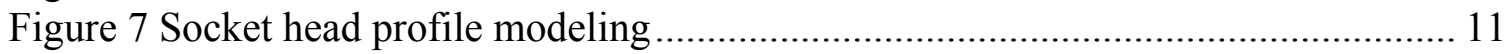

Figure 8 Microscrew head after profile subtraction................................................. 11

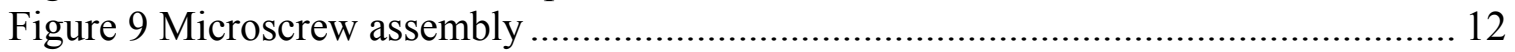

Figure 10 Diagram of beam elements attached to solids on microscrew driver ............... 13

Figure 11 Solids with boundary conditions on bottom element ..................................... 14

Figure 12 Cut away of thread and bearing contact .................................................... 15

Figure 13 Driver and head contact surfaces with hidden head .................................... 16

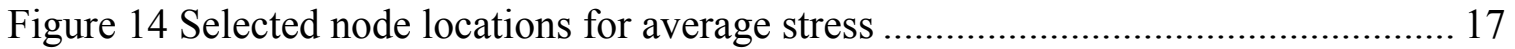

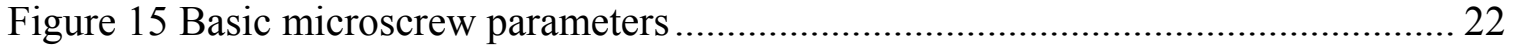

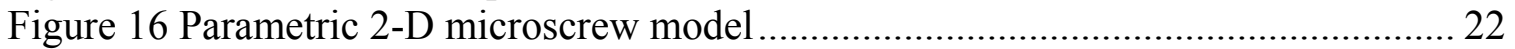

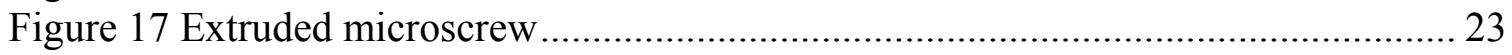

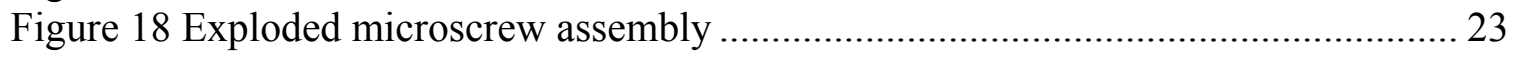

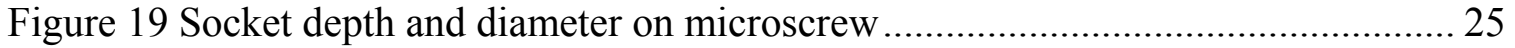

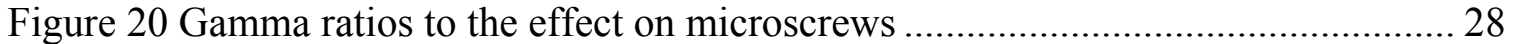

Figure 21 Maximum von Mises stress in cross section for $\mu=0.7$............................ 29

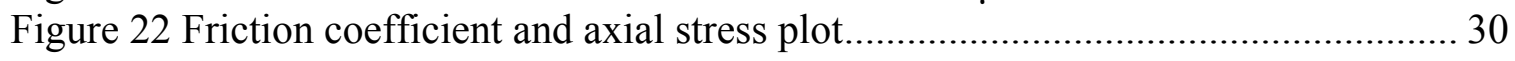

Figure 23 Torque to tension relationship for constant friction coefficients..................... 31

Figure 24 Calculated torque to tension relationship for constant friction coefficients.... 32

Figure 25 Rotation to tension for constant friction coefficients ..................................... 33

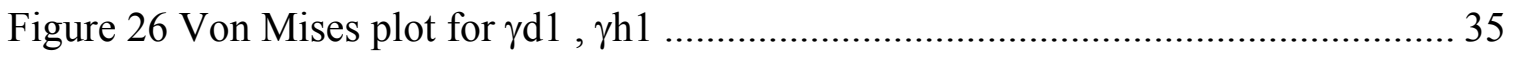

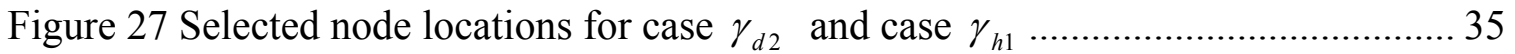

Figure 28 Percentage of max stress for $\gamma_{h}$ for Constant $\gamma_{d 1}$ for load case 1 ................... 37

Figure 29 Percentage of max stress for $\gamma_{h}$ for Constant $\gamma_{d 2}$ for load case 1 .................. 37

Figure 30 Percentage of max stress for $\gamma_{h}$ for Constant $\gamma_{d 3}$ for load case 1 .................. 38

Figure 31 Percentage of max stress for $\gamma_{d}$ for Constant $\gamma_{h 1}$ for load case 1 ................... 39

Figure 32 Percentage of max stress for $\gamma_{d}$ for Constant $\gamma_{h 2}$ for load case 1 ................ 39

Figure 33 Percentage of max stress for $\gamma_{d}$ for Constant $\gamma_{h 3}$ for load case 1 ................ 40

Figure $34 \gamma_{d}$ and $\gamma_{h}$ against percentage of max stress at the Microscrew Fillet for load

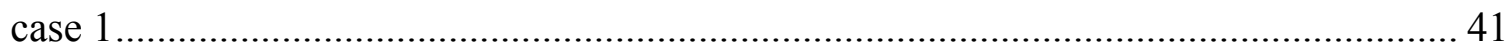

Figure $35 \gamma_{d}$ and $\gamma_{h}$ against percentage of max stress at the Microscrew Head for load

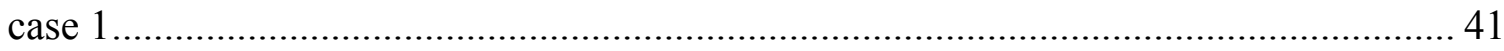

Figure 36 Percentage of stress for $\gamma_{h}$ for Constant $\gamma_{d 1}$ for load case 2 2....................... 43

Figure 37 Percentage of stress for $\gamma_{h}$ for Constant $\gamma_{d 2}$ for load case 2 ........................ 43 
Figure 38 Percentage of stress for $\gamma_{h}$ for Constant $\gamma_{d 3}$ for load case 2 $\ldots \ldots \ldots \ldots \ldots \ldots \ldots \ldots \ldots . . . . . . . .44$

Figure 39 Percentage of stress for $\gamma_{d}$ for Constant $\gamma_{h 1}$ for load case 2 $\ldots \ldots \ldots \ldots \ldots \ldots \ldots \ldots \ldots . . . . . . . . . .45$

Figure 40 Percentage of stress for $\gamma_{d}$ for Constant $\gamma_{h 2}$ for load case $2 \ldots \ldots \ldots \ldots \ldots \ldots \ldots \ldots . . . .45$

Figure 41 Percentage of stress for $\gamma_{d}$ for Constant $\gamma_{h 3}$ for load case 2 ....................... 46

Figure $42 \gamma_{d}$ and $\gamma_{h}$ against percentage of max stress at the Microscrew Fillet for load

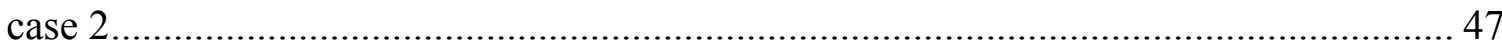

Figure $43 \gamma_{d}$ and $\gamma_{h}$ against percentage of max stress at the Microscrew Head for load

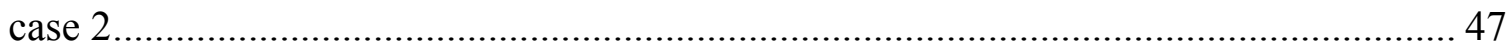

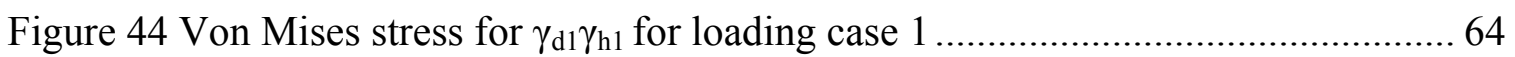

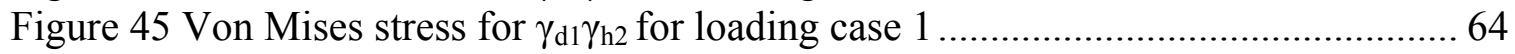

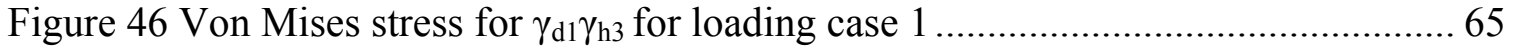

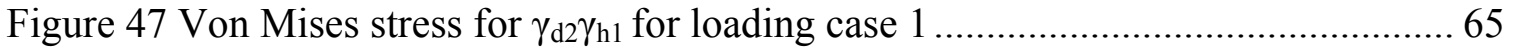

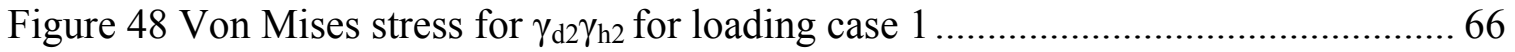

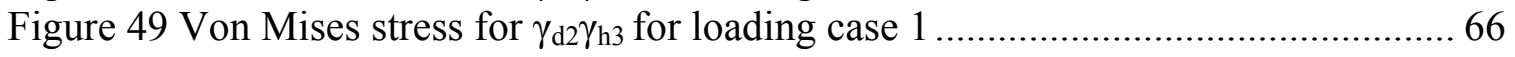

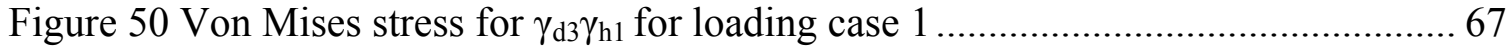

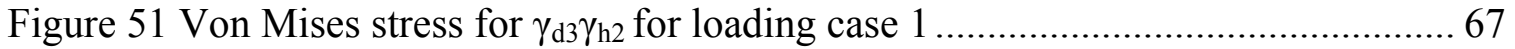

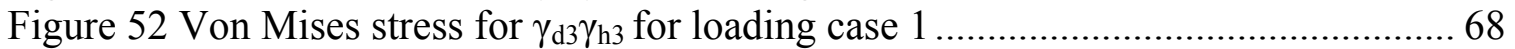

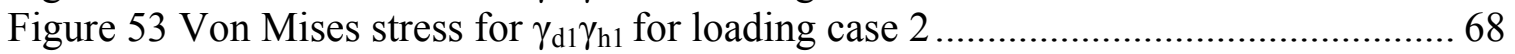

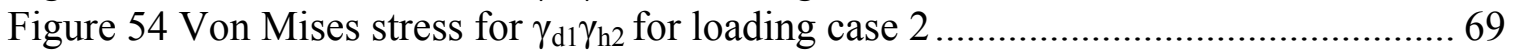

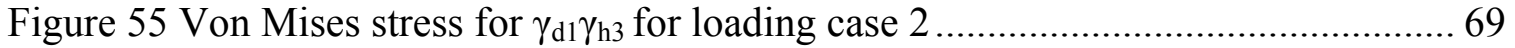

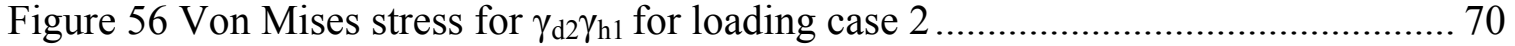

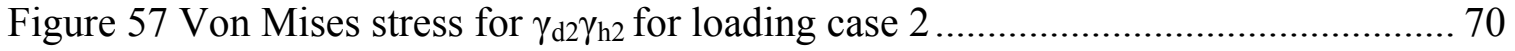

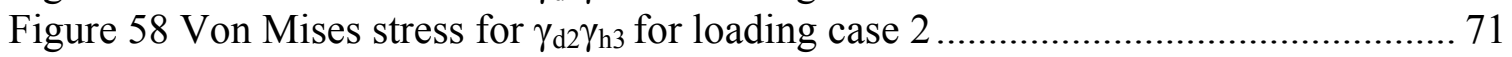

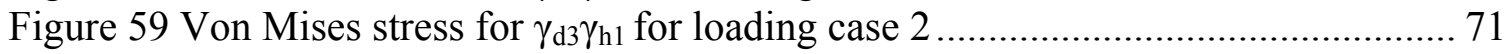

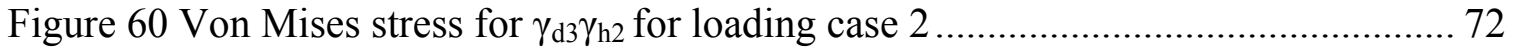

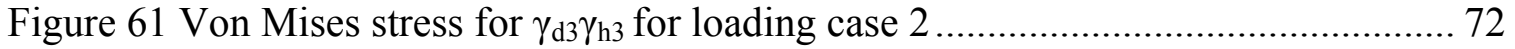

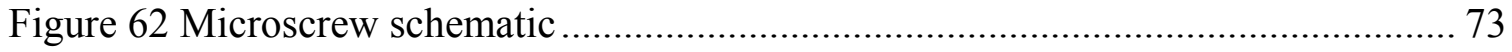




\section{List of Tables}

Table 1 Friction coefficients of materials [10] ........................................................... 7

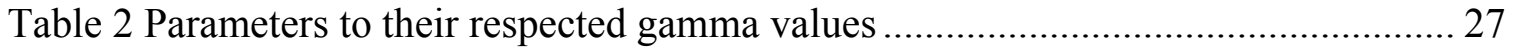

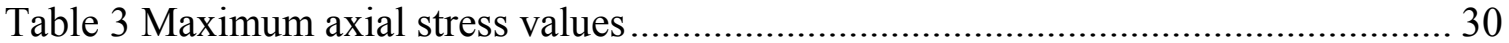

Table 4 Tension from torque at friction coefficients ................................................. 31

Table 5 Calculated Tension from torque at friction coefficients .................................... 32

Table 6 Tension from rotation at friction coefficients ............................................... 33

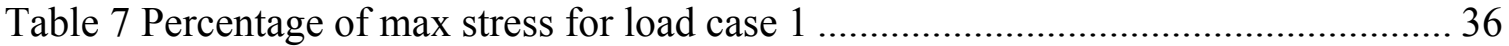

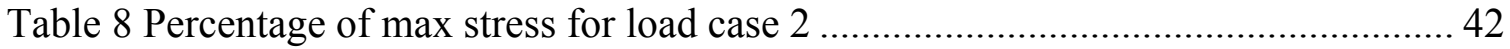




\section{Nomenclature}

\section{$\underline{\text { English }}$}

\begin{tabular}{|c|c|}
\hline APDL & ANSYS Programmable Design Language \\
\hline $\mathrm{c}$ & Constant relating torque to axial stress \\
\hline $\mathrm{d}$ & shank diameter \\
\hline$d^{\prime}$ & socket diameter \\
\hline$d$ & bolt diameter \\
\hline$d_{m}$ & bolt mean diameter \\
\hline DOF & Degree of Freedom \\
\hline $\mathrm{f}$ & Thread friction coefficient \\
\hline$f_{c}$ & Collar friction coefficient \\
\hline$F_{i}, F$ & Bolt preload \\
\hline Gamma & See Greek $\gamma$ \\
\hline $\mathrm{h}$ & Socket depth \\
\hline $\mathrm{H}$ & Socket height \\
\hline in-lbs & Torque value, Inch-Pounds \\
\hline$i n^{2}$ & Area in square inches \\
\hline Lbs & Force value, Pounds \\
\hline $\mathrm{K}$ & Torque coefficient \\
\hline Msi & Unit for Young's modulus in English units, One Million - $\frac{l b}{i n^{2}}$ \\
\hline $\mathrm{Mu}$ & See Greek $\mu$ \\
\hline
\end{tabular}




$\begin{array}{ll}\text { Psi } & \text { Unit of stress, } \frac{l b}{i n^{2}} \\ r_{b} & \text { Bearing radius } \\ r_{t} & \text { Effective thread radius } \\ S_{a x i a l} & \text { Percentage of max axial stress in psi } \\ \text { SEQV } & \text { Von Mises equivalent stress in psi } \\ \mathrm{T}, T & \text { Torque unit, in in-lbs } \\ T_{b} & \text { Bearing torque } \\ T_{p} & \text { Pitch torque } \\ T_{t} & \text { Friction torque } \\ \mathrm{UNC} & \text { Unified Coarse (threads) }\end{array}$

\section{$\underline{\text { Greek }}$}

$\alpha$

$\gamma_{d}$

$\gamma_{h}$

$\lambda$

$\mu$

$\mu_{b}$

$\mu_{t}$
Thread profile angle, $30^{\circ}$

Ratio of shank and socket diameter

Ratio of head height and socket depth

Lead angle

Friction coefficient

Bearing friction

Thread friction 
$\underline{\text { Subscripts }}$

\begin{tabular}{|c|c|}
\hline$)_{1}$ & Value at case 1 \\
\hline & Value at case 2 \\
\hline$)_{3}$ & Value at case 3 \\
\hline
\end{tabular}




\section{Acknowledgements}

The author would like to express his appreciation to Professors Ken Means and James Smith for their guidance and support in completing this project. A special thanks is also given to Professor Victor Mucino for directly supervising this project.

The author would also like to thank his friends and family for their insight and encouragement. 


\section{Introduction}

Microscrews are fasteners that are on the scale of fractions of a millimeter. Due to their size, the microscrews are extremely delicate to assemble. During assembly, the head of the microscrew breaks away from the shank at the base of the socket. The result is the microscrew head with a hole in the shape of the socket that industry calls a "donut". The head of the 3ULR microscrew Figure 1 is unusually large in diameter with respect to the shank and typically has a smaller head height as compared to other fasteners. These combinations of characteristics in conjunction with their small size are believed to cause the failure. This failure is undesirable since it leaves the threaded screw component still engaged in the female threads and will need to be extracted.
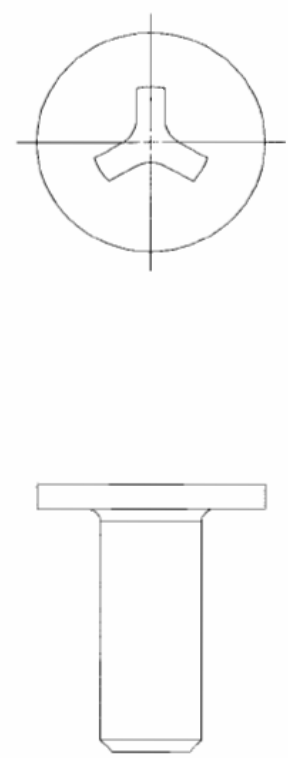

Figure 1 3ULR Microscrew

To develop an optimal head shape, Finite Element Analysis (FEA) was used to create a parametric sensitivity analysis of the microscrew. This type of analysis requires 
performing an analysis several times with small parameter changes and how these changes affect the strength of the microscrew [15]. Two parameters of the microscrew were thought to cause the type of failure described; socket depth and socket diameter. These two parameters, when their sizes were increased, leave a very small amount of material between the bottom of the socket and the fillet on the microscrew shank. The socket changes were put into parametric ratios, so that the socket changes have no units. The ratios were designed so that socket diameter was a function of shank diameter and socket depth was a function of head height.

The microscrew model was developed and analyzed using ANSYS. A program was also written in the ANSYS Programmable Design Language (APDL) that generated models with changes the socket geometries to save modeling time and. The program also kept the models consistent in that only the two parameters previously described would be changed.

To determine the loading conditions on the microscrew during assembly, a torque-totension model was created. Subsequently, an analysis can be done that compares rotation of the microscrew to axial tension. The results from these analyses gave an approximation of the load that was applied to the microscrew for the sensitivity analysis. The torque and rotation analyses also gave critical information on the behavior of a microscrew during assembly. This analysis also validated the results given ANSYS when compared against the calculated values of torque to tension. 


\section{Literature Review}

This chapter provides a background of previous research about bolts and bolted joints which pertain and introduce the main analysis of microscrews. Most of the previous research done relates to the behavior of the fastener in direct tension, and the affect of axial loading in the bolt threads. The studies completed by other researchers provide a good basis on which assumptions can be made and analyses created.

\subsection{General Assumptions}

Previous research suggests a threaded connection assuming all materials are linearly elastic. This assumption will work for preliminary results, but unrealistic stresses can occur in the bolted assembly and should be noted. The primary reason for this is that there is no defined yielding or ultimate stress, and the material stresses infinitely. Multilinear material properties can closely resemble a stress-strain curve for steel or any material that is ductile. Since it is assumed that the microscrew will be assembled into some type of bulkhead or blank of material instead of a nut, recommendations from [4] are used to model a nut as a cylindrical element or a "cornerless nut "Imperfections in the nut and bolt are ignored and both nut and bolt are assumed isotropic and homogeneous [6].

The model generate is a very simplified version of a standard bolted assembly. This simplification is a direct result of the limited ANSYS University Intermediate license available at West Virginia University. The model is kept small enough to remain in the 
limits of the 32,000 nodes or 32,000 elements allowed by this license. Elements are created when a model is divided up into a mesh of finite volumes, or elements. Nodes are points in which adjacent elements come into contact. The limit of element and node numbers in a model was also experienced by [9] on their three-dimension analysis. The model was simplified to compensate for this limit but the full result they desired was not achieved.

\subsection{Thread and Bearing Contact}

Interaction between the mating threads and the bearing surface of the head and the clamped part of the microscrew is a factor that needs to be addressed when creating the analysis. [6] experimented in ANSYS with different means of interaction. The first is the "glue" function, which occurs when two volumes are glued so that the parts cannot separate or slide with respect to each other. Secondly, coupling is applied to the same bolted joint. Coupling is in essence a derivative of gluing in which nodes are forced to take the same displacement in the specified nodal direction. Finally, contact elements create general contact between volumes or surface-to-surface contact through the ANSYS Contact Wizard. The results of these methods can be found in Figure 2, where the load between engaged threads is more evenly distributed. The FEM analysis with contact elements is more realistic than that of the glued and coupled methods and is consistent with experimental measurements. 


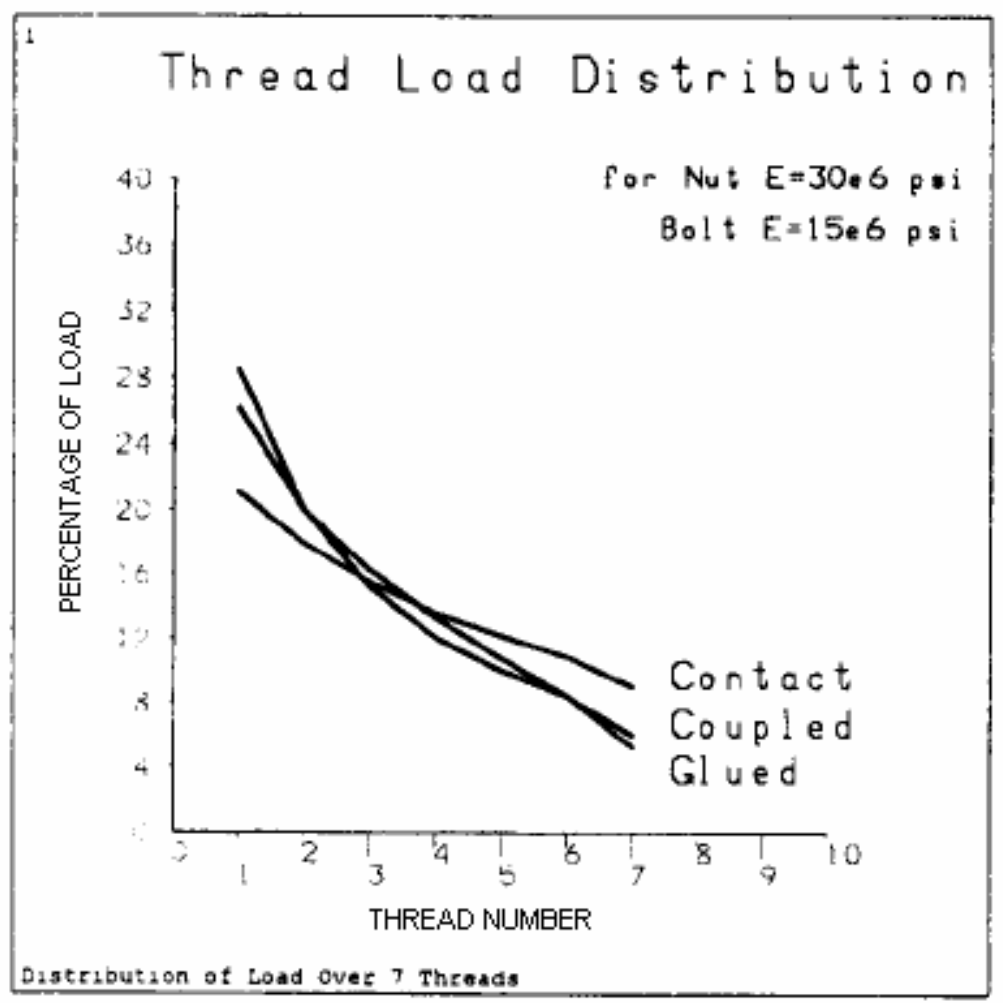

Figure 2 Thread Load Comparison [6]

Neither gluing nor coupling will allow a threaded mechanism to work, which is why contact elements are the primary choice of elements used for the type of surface interaction needed. The main advantage of contact elements over the other methods is that friction can be included and modified easily.

\subsection{Torque to Tension Analysis}

To better understand the mechanics of the fastener, it is useful to develop a relationship between torsion and axial bolt tension. Tightening torque $\mathrm{T}$ is the summation 
of pitch torque $T_{p}$, Torque required to overcome friction $T_{t}$, and the bearing friction of the head to surface contact $\mathrm{T}_{\mathrm{b}}$ in equation 2.1 [14]

$$
T=T_{p}+T_{t}+T_{b}
$$

The pitch torque is defined as

$$
T_{p}=\frac{p}{2 \pi} F
$$

Where $p$ is the thread pitch and $F$ is the bolt pretension. Torque to overcome friction [14] is defined as

$$
T_{t}=\frac{\mu_{t} r_{t}}{\cos \beta} F
$$

Where $\mu_{t}$ is the coefficient of friction between the mating threads, $r_{t}$ effective contact radius between threads and $\beta$ is half the thread profile angle of $30^{\circ}$ for standard threads. Torque to overcome the bearing friction [14] is defined as

$$
T_{b}=\mu_{b} r_{b} F
$$

Where $\mu_{b}$ is the coefficient of friction between the bearing surfaces of the fastener head and $r_{b}$ is the affecting bearing radius.

Equation 2.2 is a general approximation of the relationship between torque and tension. The calculated values are compared to the values from the models solved by ANSYS. Since the coefficient of friction varies between materials and differs from static and kinetic conditions as shown in Table 1, plots can be constructed of torque versus tension for several different values of friction coefficients. 
Table 1 Friction coefficients of materials [10]

\begin{tabular}{||l|c|c||}
\hline \multicolumn{1}{|c|}{ Material Combination } & $\begin{array}{c}\text { Static Coefficient of } \\
\text { Friction }\end{array}$ & $\begin{array}{c}\text { Kinetic Coefficient of } \\
\text { Friction }\end{array}$ \\
\hline Steel on Steel & 0.80 & 0.42 \\
\hline Aluminum on Aluminum & 1.05 & 1.40 \\
\hline Aluminum on Steel & 0.61 & 0.47 \\
\hline Cast Iron on Cast Iron & 1.10 & 0.15 \\
\hline Cast Iron on Steel & 0.40 & 0.23 \\
\hline Aluminum on Cast Iron & 1.10 & -- \\
\hline Bolt Thread on Nut Thread & - & 0.15 \\
\hline
\end{tabular}

Likewise, an angle of twist to tension analysis can be done, and compared to several different values of friction coefficients. This relationship of axial stress or load compared to the nut angle of twist [6] can provide useful information in this analysis as well as any other nut rotation angle control systems. Figure 3 shows the numerical results with plastic deformation.

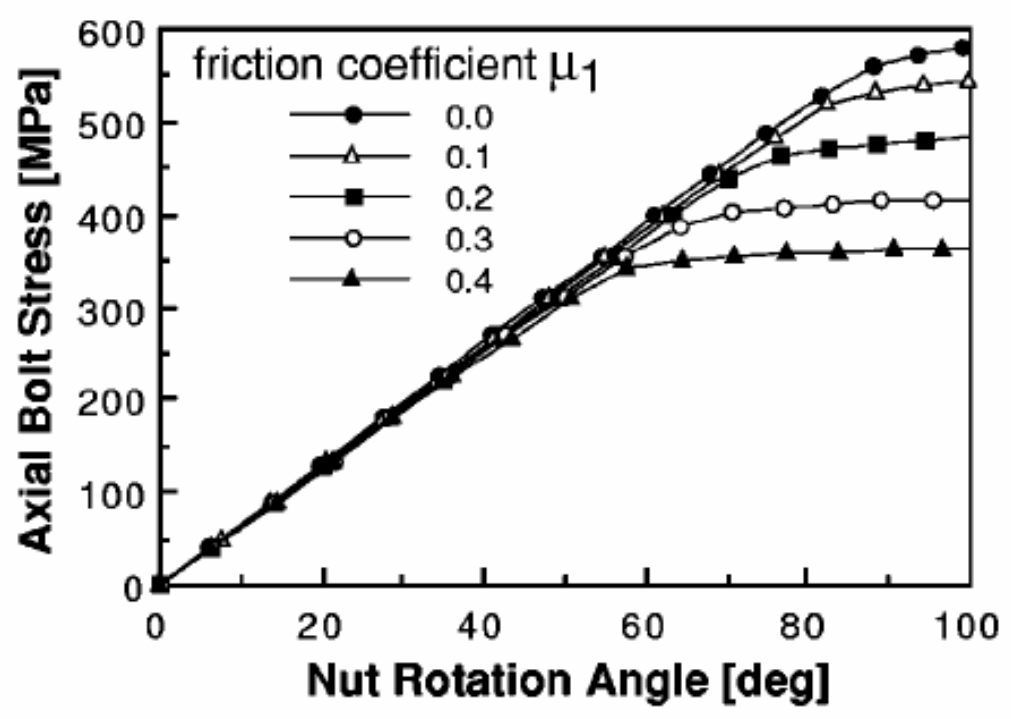

Figure 3 Relationship between axial bolt stress and nut rotation angle [7] 


\section{Problem Identification}

Microscrews tend to fail prematurely during the assembly process. The failure is located in the head to shank connection which causes the head to separate from the shank. The resultant piece that breaks free is called a "donut" since the head separates from the shank around the socket. ANSYS can provide an FEM analysis on the socket geometry to maximize the torque to obtain optimal clamping force without failure. In addition, torque to tension and rotation to tension analyses will provide validation of the FEM results and complimentary information about the mechanics of a threaded fastener. 


\section{Computational Procedure for Tension Relationships}

This chapter analyzes the torque to tension relationships and rotation to tension relationship in a selected fastener. The models are generated through the ANSYS modeling software, meshed and nodal displacements are solved. These nodal displacements can then be transferred into stress by the use Hooke's Law. For the analysis of the model, the geometry was based upon dimensions of a one inch diameter bolt with eight threads per inch. This bolt has fairly simple dimensions and should be sufficient for a torque and rotation to tension analysis. Percentage of maximum stress is defined as the value of one is equal to $100 \%$ of the maximum value.

\subsection{Model Development for Tension Relationships}

The model is created starting with a helix generated by offset keypoints. Lines are connected to these keypoints in a cylindrical coordinate system and the triangular area of the thread pattern shown in Figure 4.

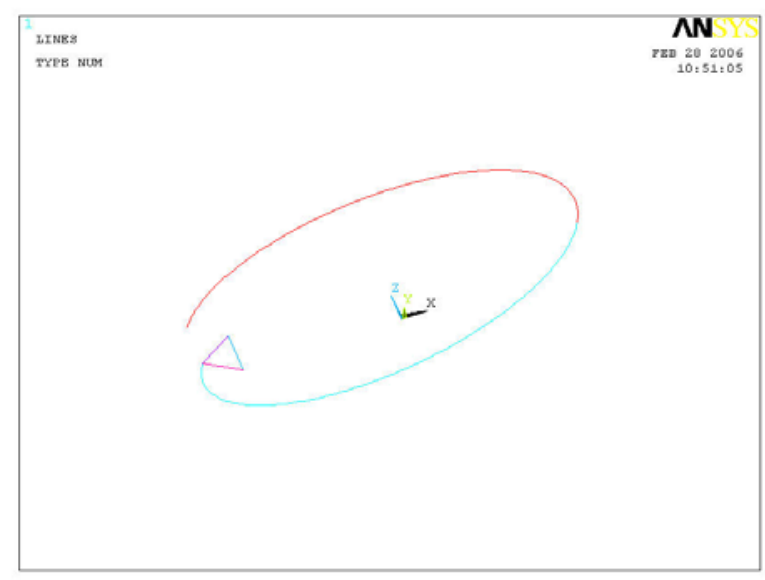

Figure 4 Helix and thread profile 
The thread area is extruded around the helix, and then the shank is added as shown in Figure 5. Only one thread is generated so that an axial load will result from an input torque. Load distribution throughout the threads is not required, since the primary failure mode in question is the head separation.

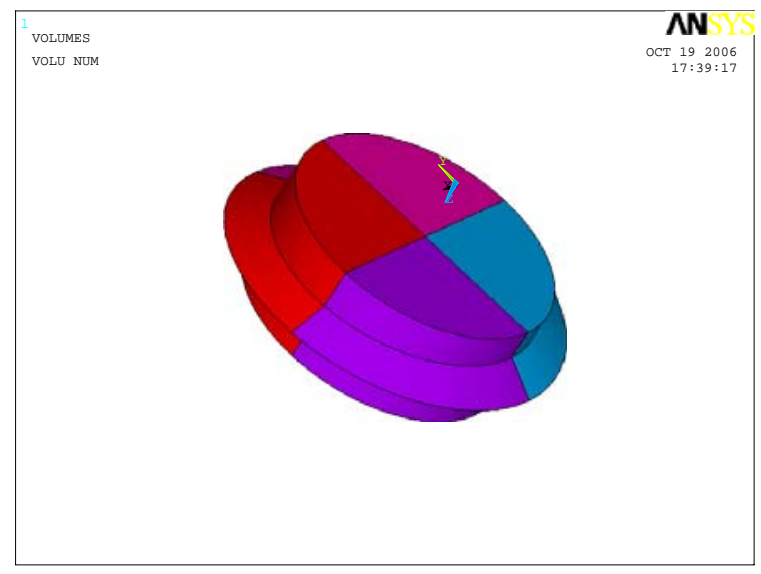

Figure 5 Threaded microscrew section

Modeling of the nut is done the same as the screw; however the thread triangle is reversed, creating the pattern of the female thread in Figure 6. With this inverted thread profile, a nut body can be added.

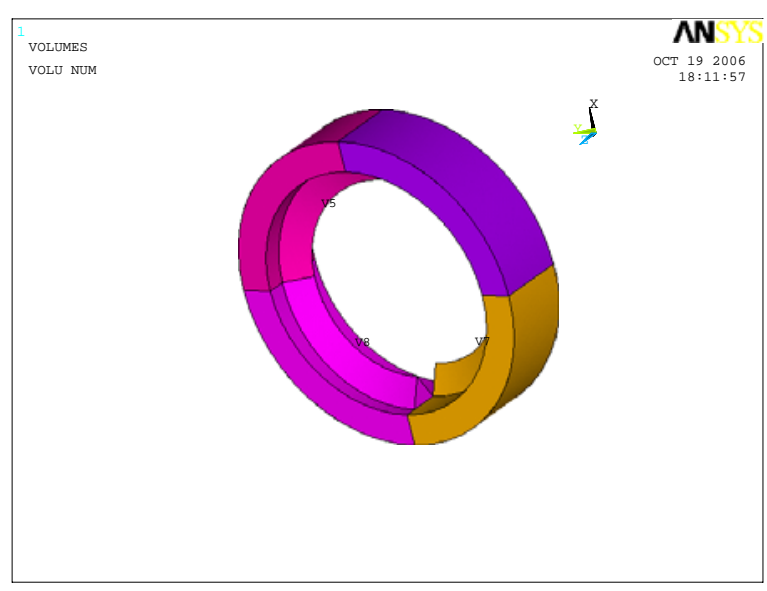

Figure 6 Nut section 
This concludes the threaded mechanism of the fastener assembly. For the head geometry, three cylinders with radius, R3, based off of the socket radius, R1, are created on the same plane. Figure 7 demonstrates the cylinders are offset by 120 degrees about points on a circle of radius $\mathrm{R} 2$, and are created along with a center cylinder with a depth $\mathrm{d}$ of the socket.

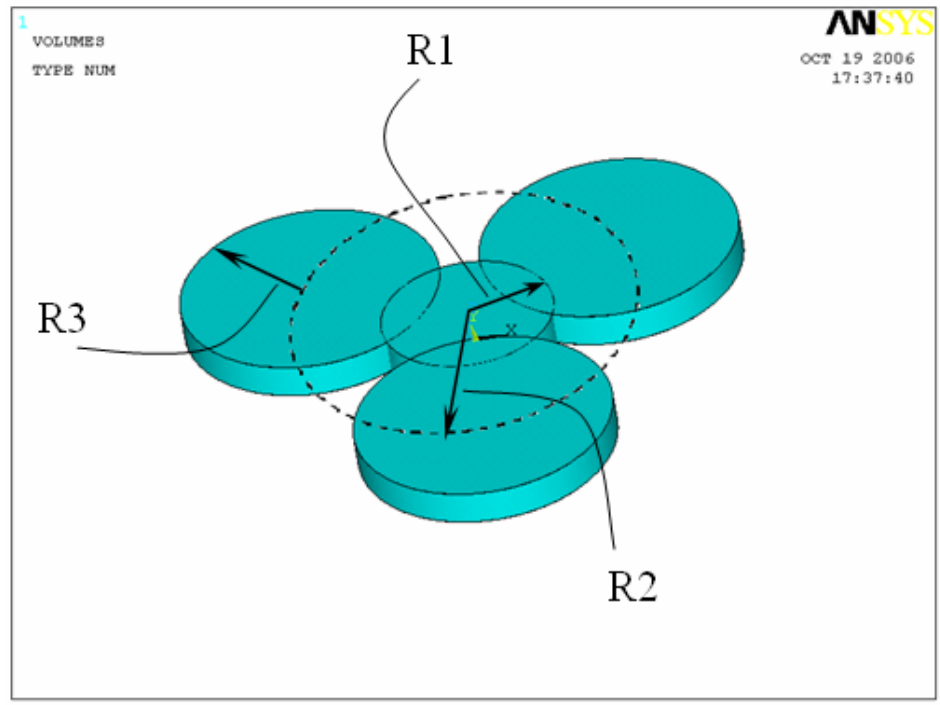

Figure 7 Socket head profile modeling

Figure 8 shows the geometry of the head with height $\mathrm{H}$ after the socket head profile is subtracted to form the shape of the socket.

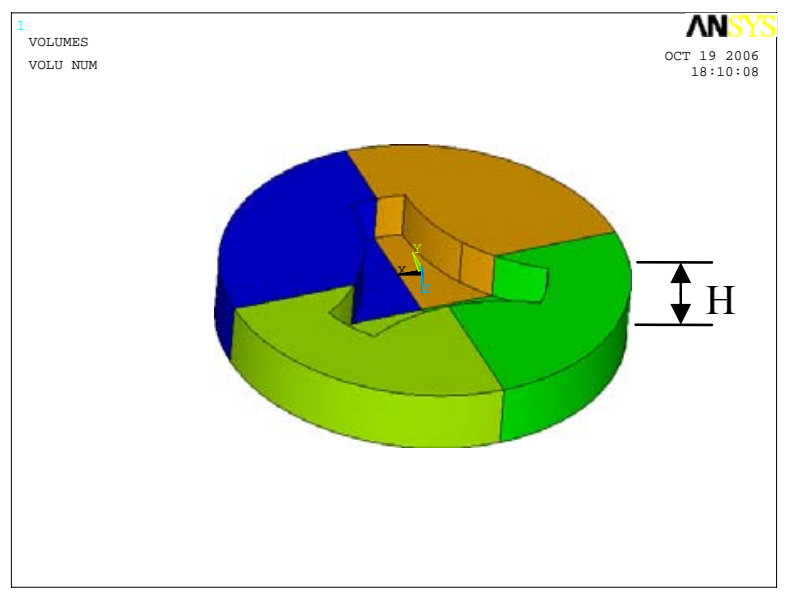

Figure 8 Microscrew head after profile subtraction 
A driver mechanism is created in the same fashion as Figure 7 and is used to apply the torque or angle of twist to the microscrew. The head and screw shank are combined and the entire microscrew assembly can be analyzed shown in Figure 9. Note that the entire model has been divided into four sections. This is done so the inner parts of the microscrew can be analyzed by selecting any of these sections.

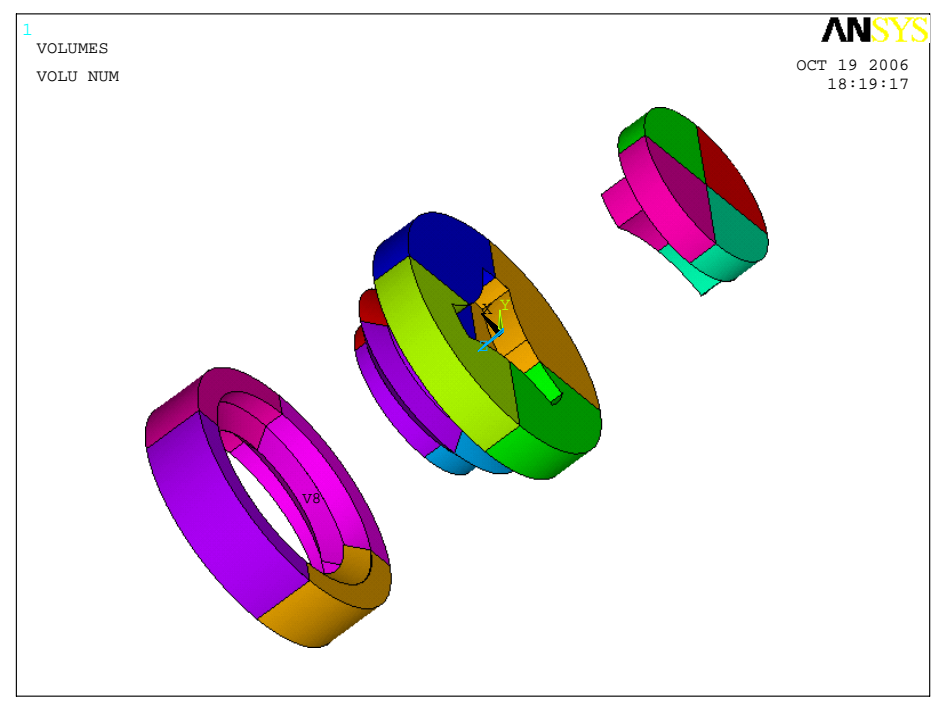

Figure 9 Microscrew assembly

\subsection{Boundary and Initial Conditions}

The microscrew model is meshed with SOLID45 elements and the material properties of steel are assigned since it is a common material. Boundary and initial conditions are then applied to the model. For this analysis, torque or rotation is applied to the driver by means of BEAM4 elements. SOLID45 elements are defined by eight nodes, each with three degrees of freedom (DOF). Beam elements need to be created as shown in Figure 10 since they provide six degrees of freedom about their nodes. 


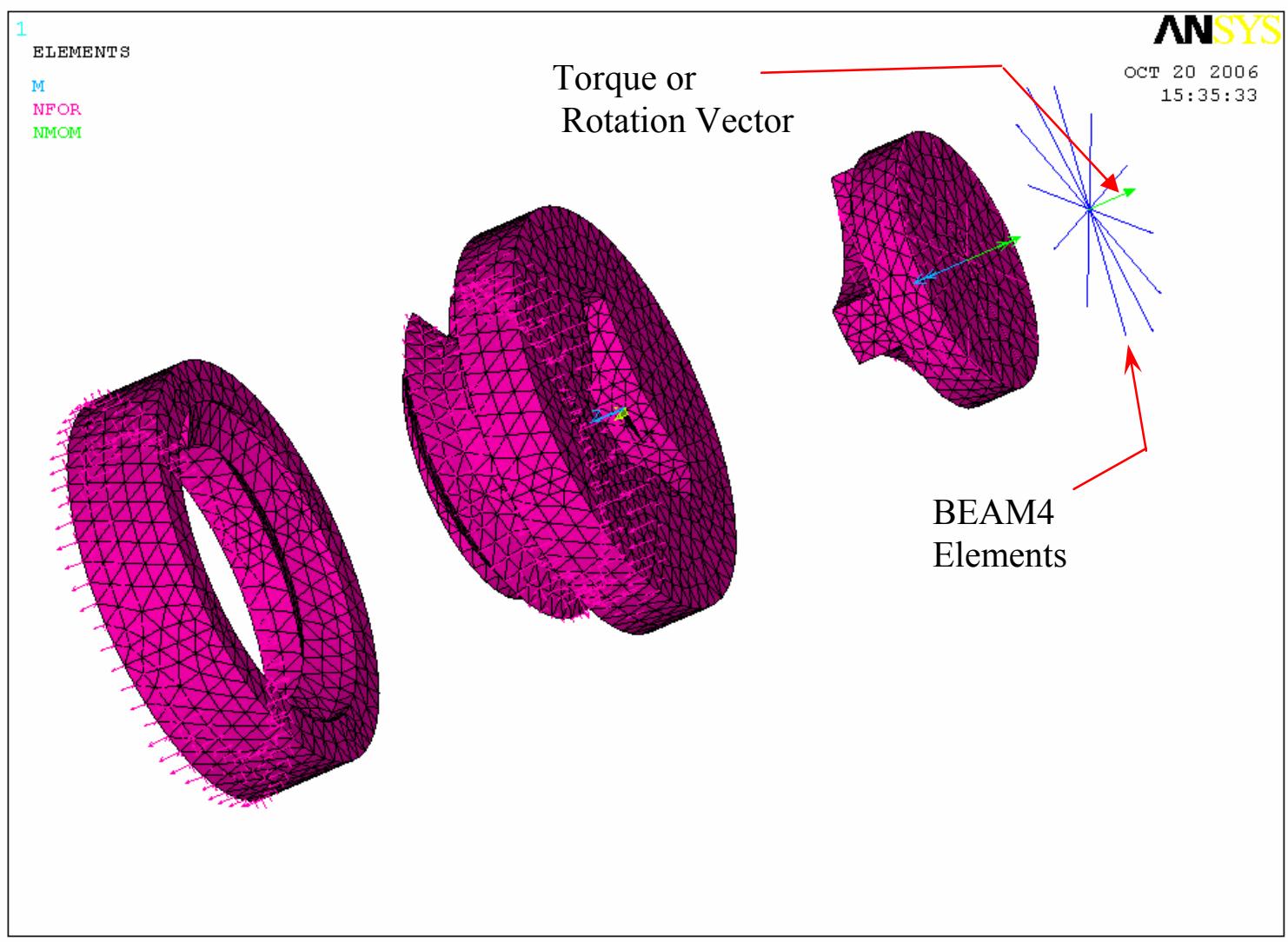

Figure 10 Diagram of beam elements attached to solids on microscrew driver

These beam elements are assigned a Young's Modulus of $30 \times 10^{10} \mathrm{psi}$ so that they can be assumed rigid. The beam elements are created through nodes at the end of the driver and real constants are set to give the beam elements a cross sectional area for increased stiffness. The nut in this situation is to remain fixed shown in Figure 11, simulating assembly into a bulkhead or blank of material with mating threads. The bottom surface of the nut is fixed with all degrees of freedom. 


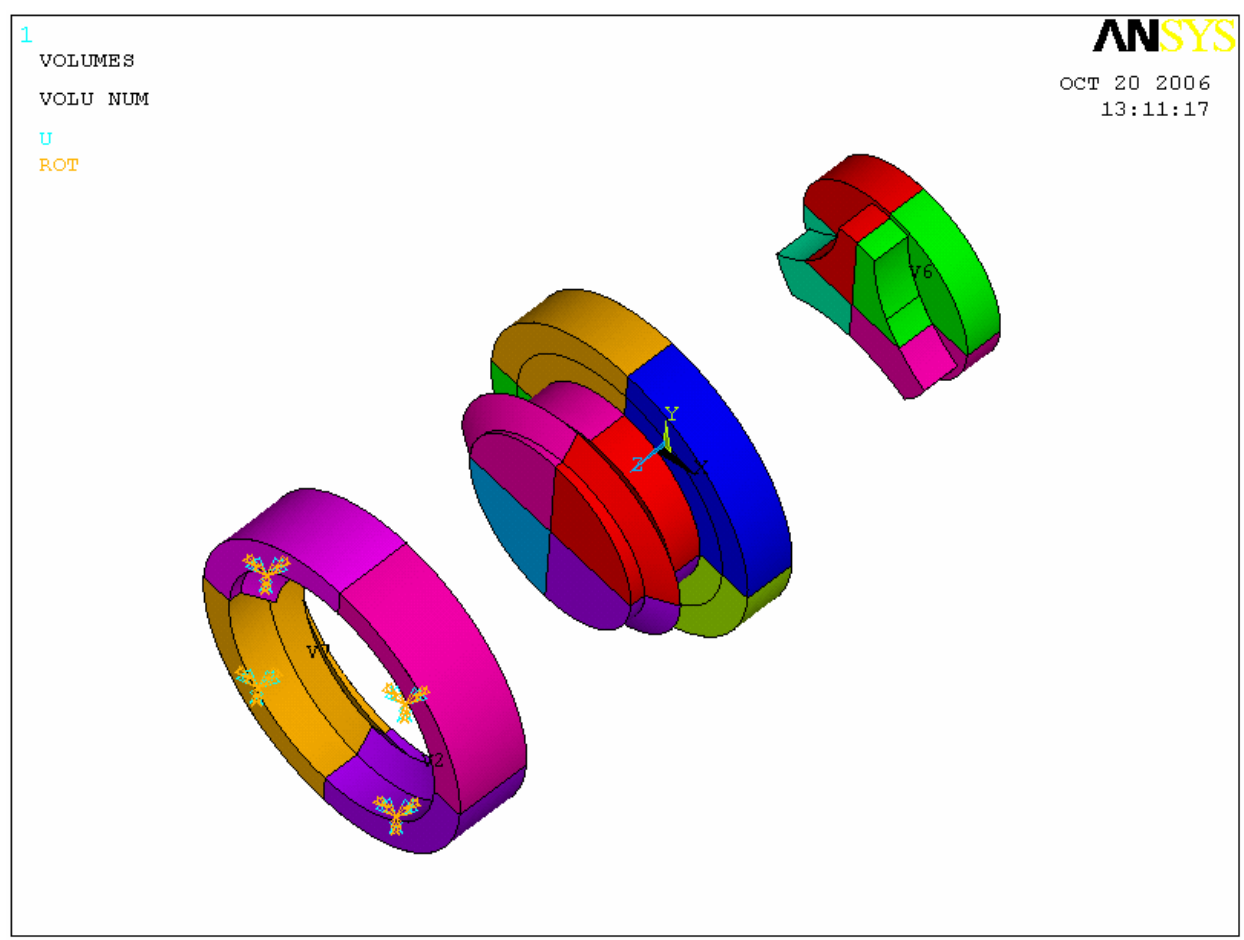

Figure 11 Solids with boundary conditions on bottom element

\subsubsection{Thread Contact}

Thread contact is created through the contact wizard in the ANSYS Main Menu. Contact elements are the best means in which to create the surface to surface contact since friction can be introduced. Axial stress in the microscrew is desired to create a tension, so the surfaces that come into contact during tightening are selected for the contact elements Figure 12. Through the Contact Wizard, target and contact elements are created and a coefficient of friction for this model is assigned. The main focus was on the stress in the transition between the head and the shank. Only one thread was modeled to generate the axial force from a torque. This method is to keep the computational requirements low due to license limitations. 


\subsubsection{Bearing Contact}

To create axial loading in the threaded assembly, bearing contact must be created. The bearing surface is created between the bottom surface of the microscrew head and the top of the nut Figure 12.

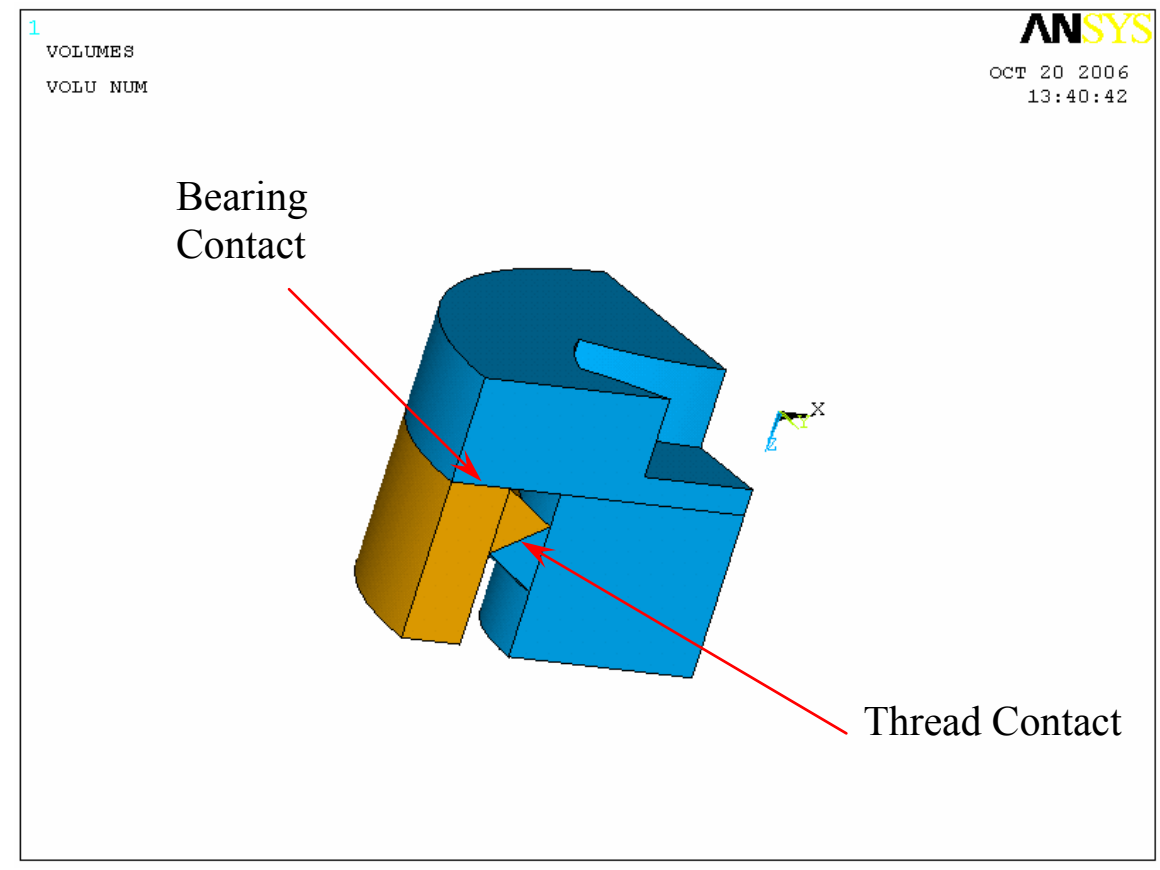

Figure 12 Cut away of thread and bearing contact

The friction for this contact surface is set to the same value as the threaded connection assuming that the microscrew material and the part being clamped are of the same material.

\subsubsection{Driver Contact}

Torque or rotation is applied to the driver and is transmitted to the microscrew. The contact for this system is defined as the parts that are needed only for tightening are in contact shown by Figure 13. 


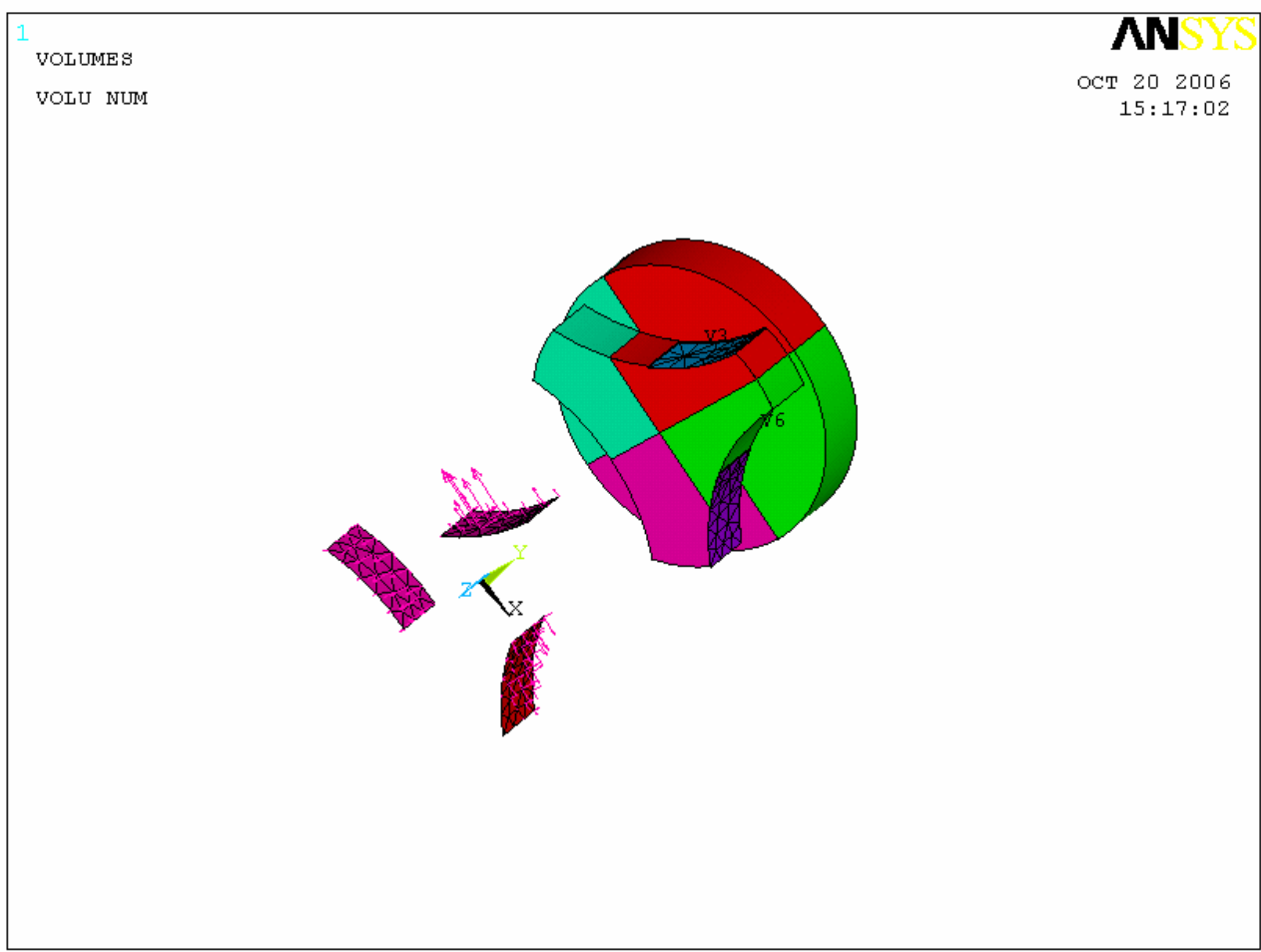

Figure 13 Driver and head contact surfaces with hidden head

\subsection{Friction to Axial Stress Relationship with Constant Torque}

The load to the assembly is applied at the center of the beam elements shown in Figure 10. The axial stress generated by the torque will vary for different coefficients of friction. Friction values can be changed through the material properties without resetting the contact elements. Friction coefficients were selected from $\mu=0$ to $\mu=0.9$ with increments of 0.1 units. For this analysis, a constant arbitrary torque of 1000 in-lbs was applied and a plot of friction coefficient to axial stress is created. To acquire the average stress for a tension value, the model is sectioned into four volumes and nodes are selected across the axial cross section. Figure 14 shows the selected nodes. 


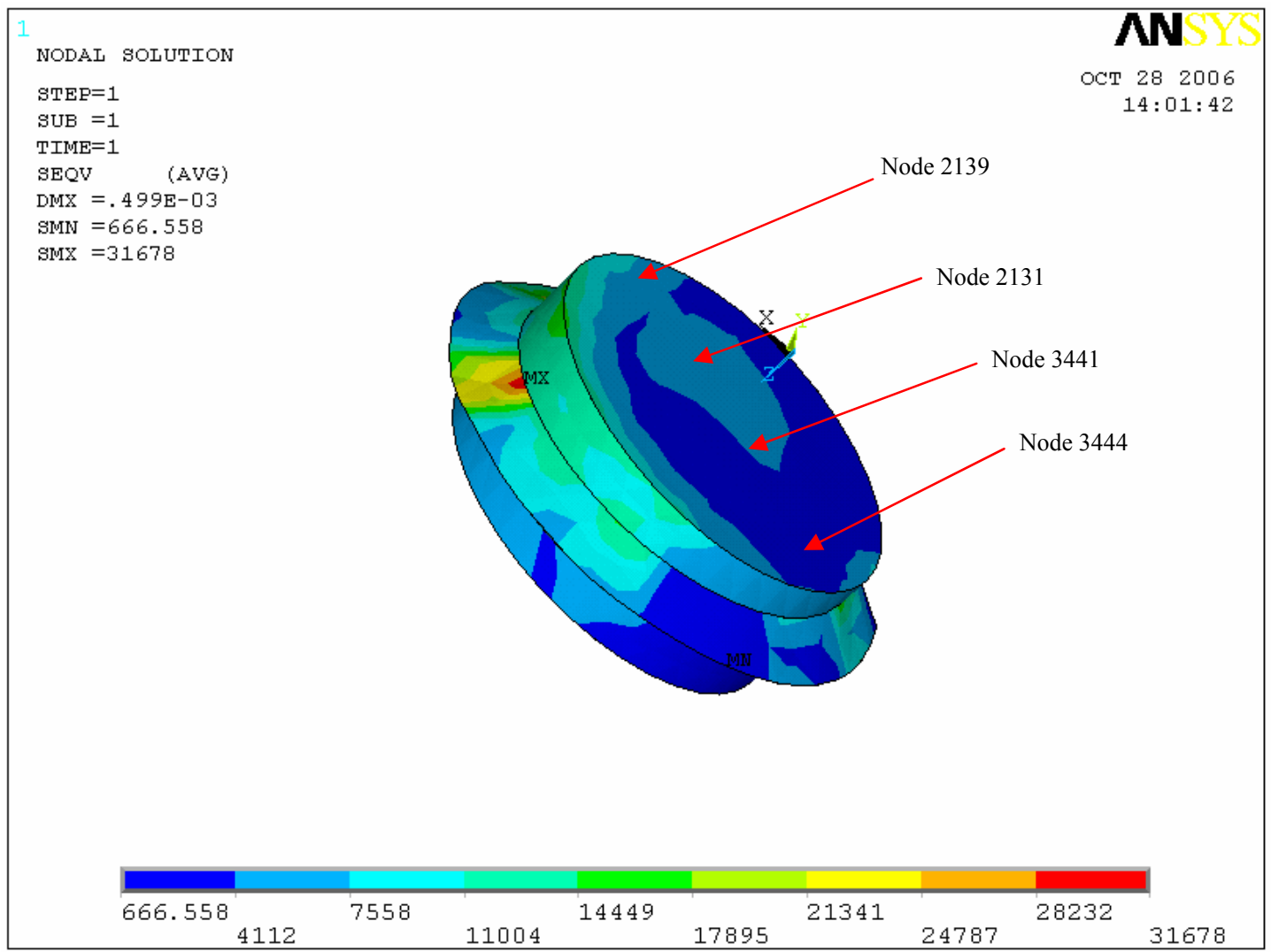

Figure 14 Selected node locations for average stress

\subsection{Torque to Tension Relationship}

The model for the Tension relationship is identical to the method presented by 4.3 . For each analysis, the friction coefficient is held constant and 100, 250, 500 and a maximum of 1000 units of torque were applied. The coefficients of friction are increased from $\mu=0$ to $\mu=0.5$ with increments of 0.1 and an addition value at $\mu=0.05$. This extra value is added as a result of the large difference in load found between $\mu=0$ and $\mu=0.1$. Torque increments were given the produced a tension on the screw shank. The objective was to establish a relationship or trend between applied torque and the tension that was 
generated. The use of contact elements and friction makes the system nonlinear and this incremental approach was used with linear elastic material.

Stress is used to determine tension from the cross section as described in Chapter 4.3. Nodes along the cross section, Figure 14 are listed with their corresponding von Mises stress. This stress $\sigma$ is associated with Hooke's law and load, $P$ is calculated from equation $4.1[16]$.

$$
\sigma=\frac{P}{A}
$$

The diameter of the screw, $\mathrm{D}=0.7834936491$, was determined through the Check Geometry option in ANSYS. This dimension is a result from the shank diameter being the same value as the root diameter. Cross sectional area can now be calculated from equation $4.2[16]$

$$
A=\frac{\pi D^{2}}{4}
$$

The tension $T$ derived from the von Mises stress in the cross section from ANSYS are compared to the theoretical calculations from the torque to tension formula in equation $4.3[16]$.

$$
T=K F_{i} d
$$

The bolt in which the microscrew was model from is a one inch - eight threads per inch $(1 "-8)$ bolt with major diameter $d$ of 1 inch. Torque coefficient, $K[16]$ is determined from equation 4.4 .

$$
K=\left(\frac{d_{m}}{2 d}\right)\left(\frac{\tan \lambda+f \sec \alpha}{1-f \tan \lambda \sec \alpha}\right)+0.625 f_{c}
$$


The friction in the threads $f$ is assumed equal to the collar friction $f_{c}$ and the thread profile angle $\alpha$, is $30^{\circ}$ for standard threads. The mean diameter $d_{m}$ for the $1 "-8$ bolt is determined from equation 4.5 .

$$
d_{m}=d-\frac{p}{2}
$$

where the pitch $p$ for the bolt is 0.125 . Lead $l$ for this analysis is equal to thread pitch $p$ for a single-start threaded assembly which created the following relation for lead angle, $\lambda$ equation 4.6 [18]

$$
\lambda=\frac{l}{\pi d_{m}}=\frac{p}{\pi d_{m}}
$$

Solving equation 4.3 for preload $F_{i}$, equation 4.7 gives the theoretical relationship used in verify ANSYS computational results in equation 4.7.

$$
F_{i}=\frac{T}{K d}
$$

\subsection{Nodal Rotation to Tension Relationship}

A similar analysis is performed on the microscrew model similarly to Chapter 4.4 Torque to Tension Relationship. The same node of Figure 10 is used to apply a nodal rotation about the microscrew axis in place of a torque. For this analysis, a rotation of $0.5^{\circ}, 1^{\circ}, 3^{\circ}$ and $5^{\circ}$ was applied to the driver of the microscrew. The friction coefficient was set from $\mu=0$, to 0.5 with increments of 0.1 as well as an additional friction 
coefficient with value $\mu=0.05$ for consistency. Acquiring data points will be done in the same fashion as Figure 14. Values of rotation will be plotted against tension with lines of constant friction coefficient. The data from this analysis will be compared to the numerical calculations plotted by [6] in Chapter 6 . 


\section{Computational Procedure}

In this chapter the parametric sensitivity of the microscrew is described. In addition, the development of the microscrew model for the sensitivity analysis is discussed.

\subsection{Parametric Modeling}

The model for the sensitivity analysis is of different geometry than the models of Chapter 4 and has a different method of model generation. The model has no threads for axial loading, therefore an external load or pressure must be exerted on the microscrew model. This method is used to conserve elements for a finer mesh because of the 32,000 element limit in the ANSYS University Intermediate license. The model parameters come from a scaled up version microscrew schematic provided.

To ease the sensitivity analysis of the microscrew, a program written in the ANSYS Programmable Design Language (APDL) creates a microscrew model from user inputs. The inputs used to determine the model are socket diameter and socket depth. Other geometries, such as head height $H$ and shank diameter $d$, Figure 15 are kept constant. 

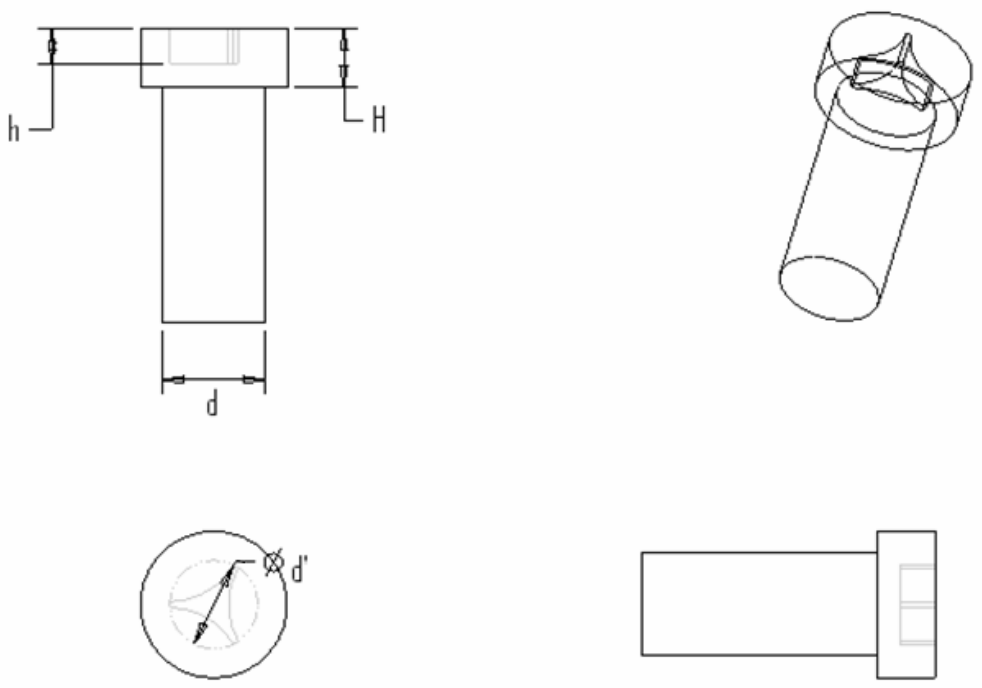

Figure 15 Basic microscrew parameters

The APDL program first generates the driver system identical to that of Chapter 4 . The program then creates keypoints in 2 dimensions, generating half of the microscrew.

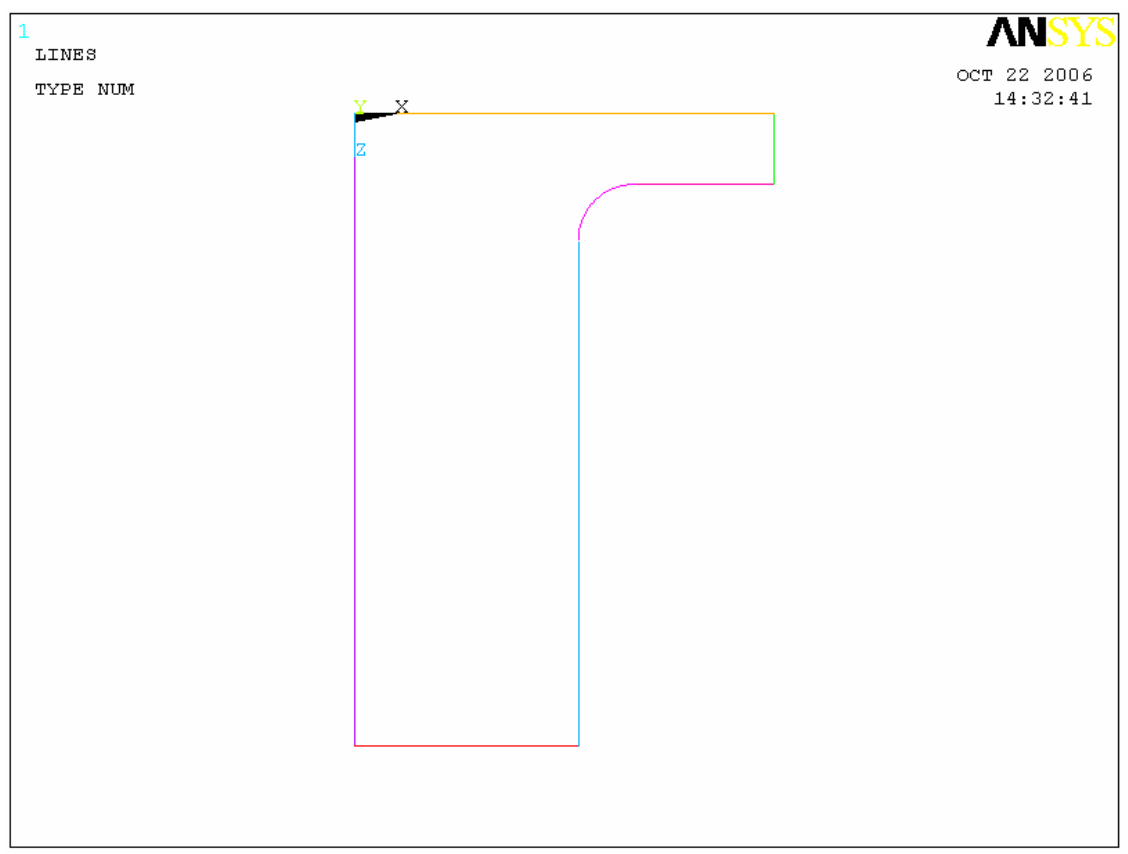

Figure 16 Parametric 2-D microscrew model 
Lines are attached to keypoints Figure 16, and an area is created by these lines for extrusion, Figure 17. Once the model is extruded around the axis of the microscrew, the socket can be created by subtracting the driver part from the microscrew head. A collar is added to simulate a fixed surface for bearing contact during assembly. This collar is fixed and contact elements between the collar and head in Figure 18 help to create the axial force on the microscrew.

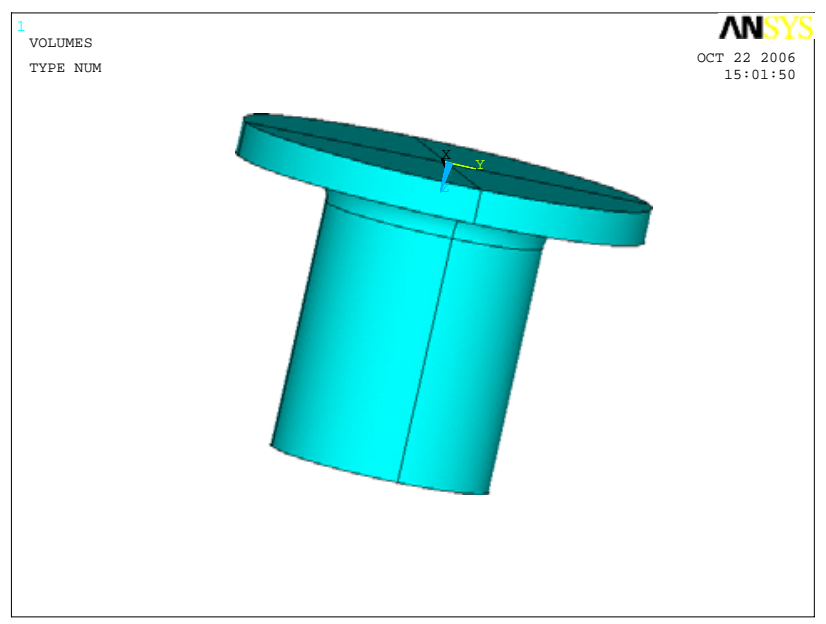

Figure 17 Extruded microscrew

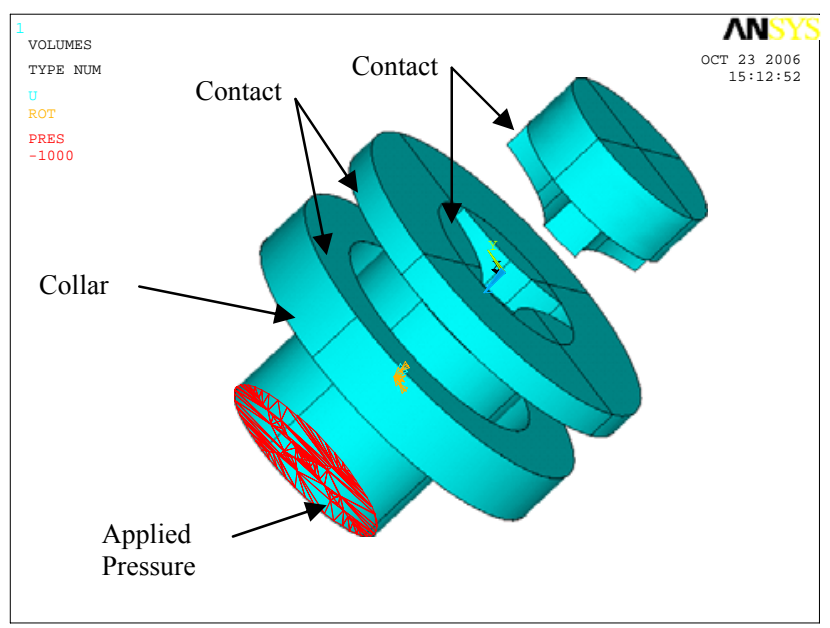

Figure 18 Exploded microscrew assembly 
The program is then set to mesh the model and apply the contact elements between the head and the driver, as well as applies any boundary conditions. Material properties, real constants and a user defined axial force are then automatically applied to the microscrew.

\subsection{Loading and Boundary Conditions}

For this parametric sensitivity analysis the threads are not modeled to save elements and simplify computation time. To simulate the threaded joint, a pressure is applied to the bottom of the microscrew shank. DOF constraints are applied to allow only displacement as a result of the axial load. A boundary condition is applied to resist motion in all degrees of freedom on the bottom surface of the collar. Contact elements between the collar and microscrew containing a friction coefficient of $\mu=0.4$, Figure 18 simulate a bearing friction as would be found in a threaded assembly. The torque is applied with a value of 1000 units and 2000 units of axial force to the driver. For an additional analysis, these values are double to better understand the mechanics of the microscrew. The axial force value is based on the findings of the analyses of Chapter 4. Torque and pressure in the analysis will remain constant to provide a consistent relationship. Due to the unknown changes is node numbers from the various configurations, manual selection of the beam elements is required as well as the

placement of the torque. This is done by selecting all nodes at the top area of the driver, plotting the nodes and creating the elements through nodes. 


\subsection{Parametric Ratios}

The parameters most likely to cause the donut failure, Figure 19, in the head are the diameter of the microscrew socket $d$ ' and the depth of the socket $h$. These are key parameters in causing stress concentrations from the star-shape of the 3ULR microscrew design.

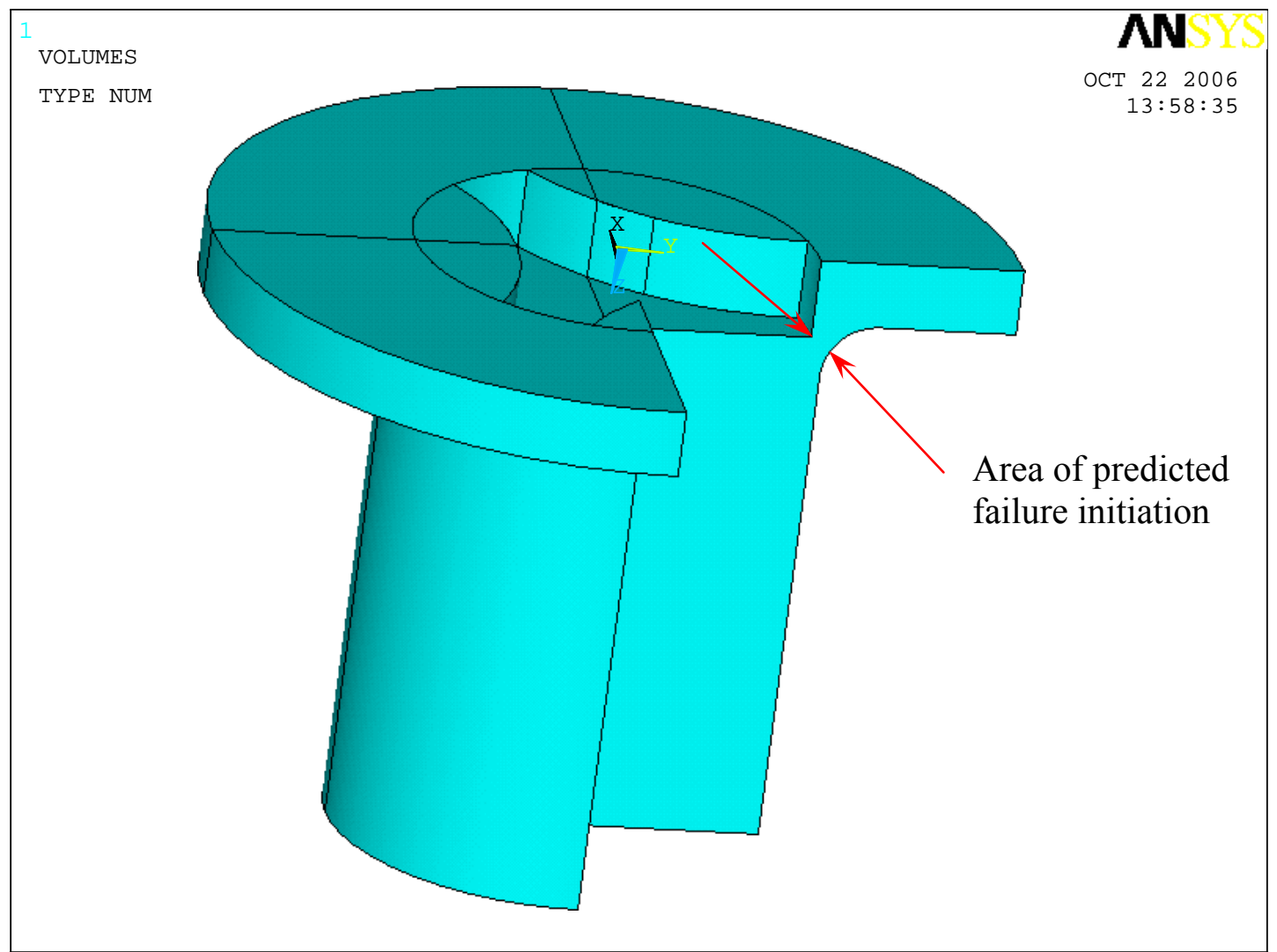

Figure 19 Socket depth and diameter on microscrew

The parameters of interest can be described as ratios in which can be changed to analyze the effects on the system. Socket diameter is compared against the shank 
diameter; an increase in socket diameter with a constant shank diameter will cause a decrease in the distance from the socket to the fillet. This same situation occurs when the socket depth is increased beyond the head height. In both cases, the socket approaches a geometry in which it will approach the fillet shown in Figure 19 causing stress concentrations that can lead to failure.

Once the comparisons of the parameters have been reached, the ratios can then be set up for the sensitivity analysis. They are defined as equation 5.1

$$
\gamma_{d}=\frac{d}{d^{\prime}}
$$

where equation 5.1 describes the ratio of shank diameter $d$ and socket diameter $d$ '.

$$
\gamma_{h}=\frac{H}{h}
$$

Equation 5.2 describes the ratio of head height $H$, and socket depth $h$.

For the analysis, nine different parametric models are solved in ANSYS. Shank diameter and head height are kept constant with values correspond to a scaled up version of the schematics provided. Shank diameter is set to 0.8 units and head height is set to 0.25 units. The system of units in ANSYS is determined by the Young's Modulus, which is assumed steel in English units of 30 Msi. Gamma ratios are derived from their relation to the proximity to the fillet in Table 2 . 
Table 2 Parameters to their respected gamma values

\begin{tabular}{|c|c|c|c|c|}
\hline Set & $\mathrm{d}^{\prime}$ & $\gamma_{\mathrm{d}}$ & $\mathrm{h}$ & $\gamma_{\mathrm{h}}$ \\
\hline 1 & 0.75 & 1.067 & 0.20 & 1.250 \\
2 & 0.75 & 1.067 & 0.25 & 1.000 \\
3 & 0.75 & 1.067 & 0.30 & 0.833 \\
4 & 0.80 & 1.000 & 0.20 & 1.250 \\
5 & 0.80 & 1.000 & 0.25 & 1.000 \\
6 & 0.80 & 1.000 & 0.30 & 0.833 \\
7 & 0.85 & 0.941 & 0.20 & 1.250 \\
8 & 0.85 & 0.941 & 0.25 & 1.000 \\
9 & 0.85 & 0.941 & 0.30 & 0.833
\end{tabular}

The first analysis includes geometries that begin a relatively safe distance between the socket while fillet. The socket depth is gradually increased from 0.2 units to 0.3 units, Figure 20a - Figure 20c. The second set, $\lambda_{d}=1$, where the socket diameter equals that of the shank diameter. The socket depth is gradually increased as before, Figure 20d Figure 20f. The socket diameter for the last set is set larger than the shank diameter, and socket depth is gradually increased until a worst-case scenario is reached. This scenario is when the socket is nearly piercing through the fillet, Figure $20 \mathrm{~g}$ - Figure $20 \mathrm{i}$. 


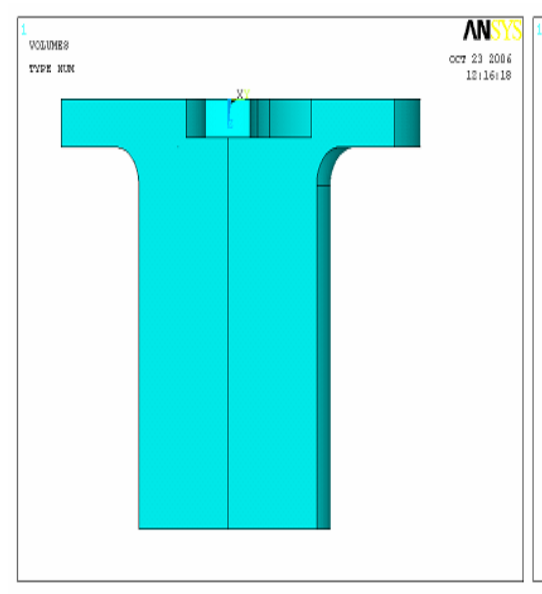

a) $\gamma_{d 1}$ and $\gamma_{h 1}$

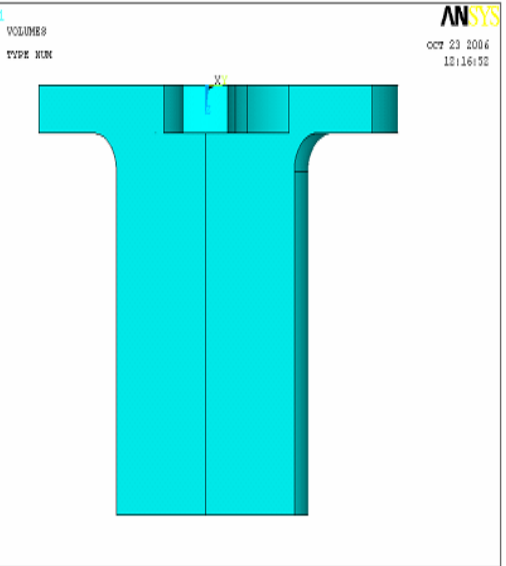

b) $\gamma_{d 1}$ and $\gamma_{h 2}$

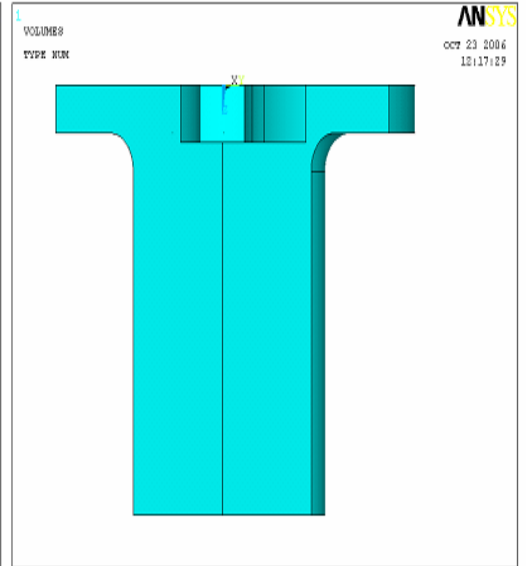

c) $\gamma_{d 1}$ and $\gamma_{h 3}$
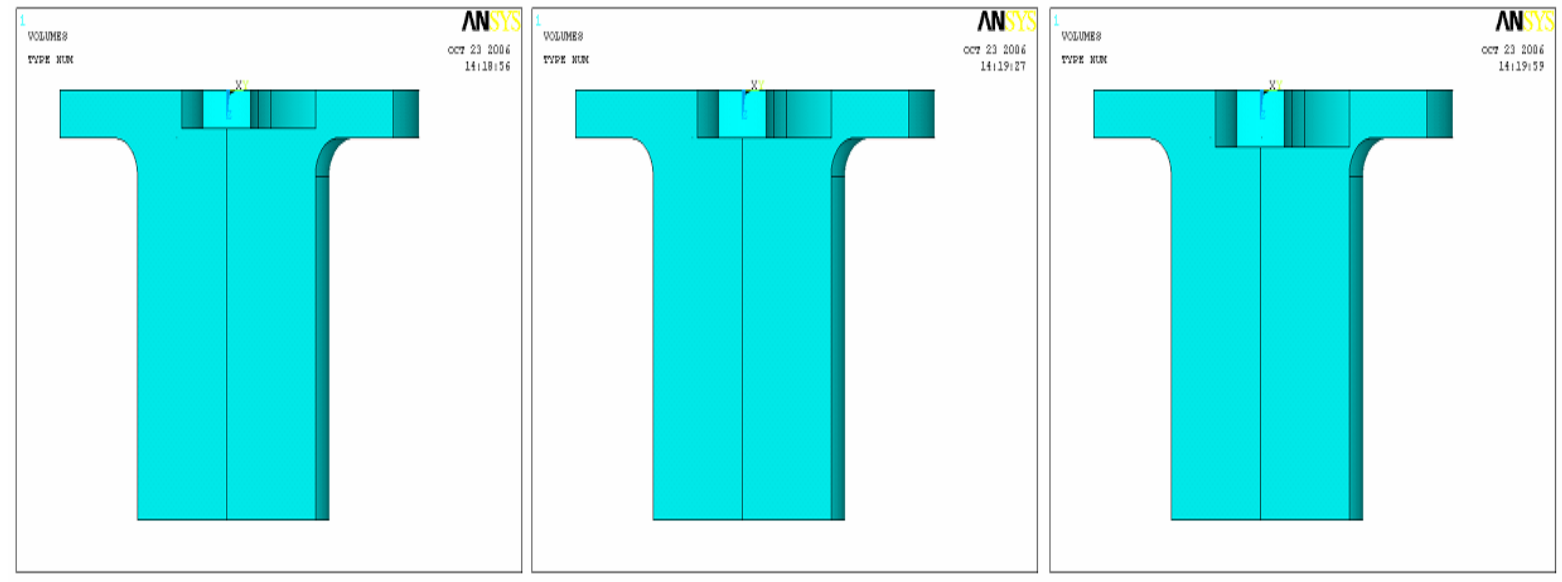

d) $\gamma_{d 2}$ and $\gamma_{h 1}$

e) $\gamma_{d 2}$ and $\gamma_{h 2}$

f) $\gamma_{d 2}$ and $\gamma_{h 3}$

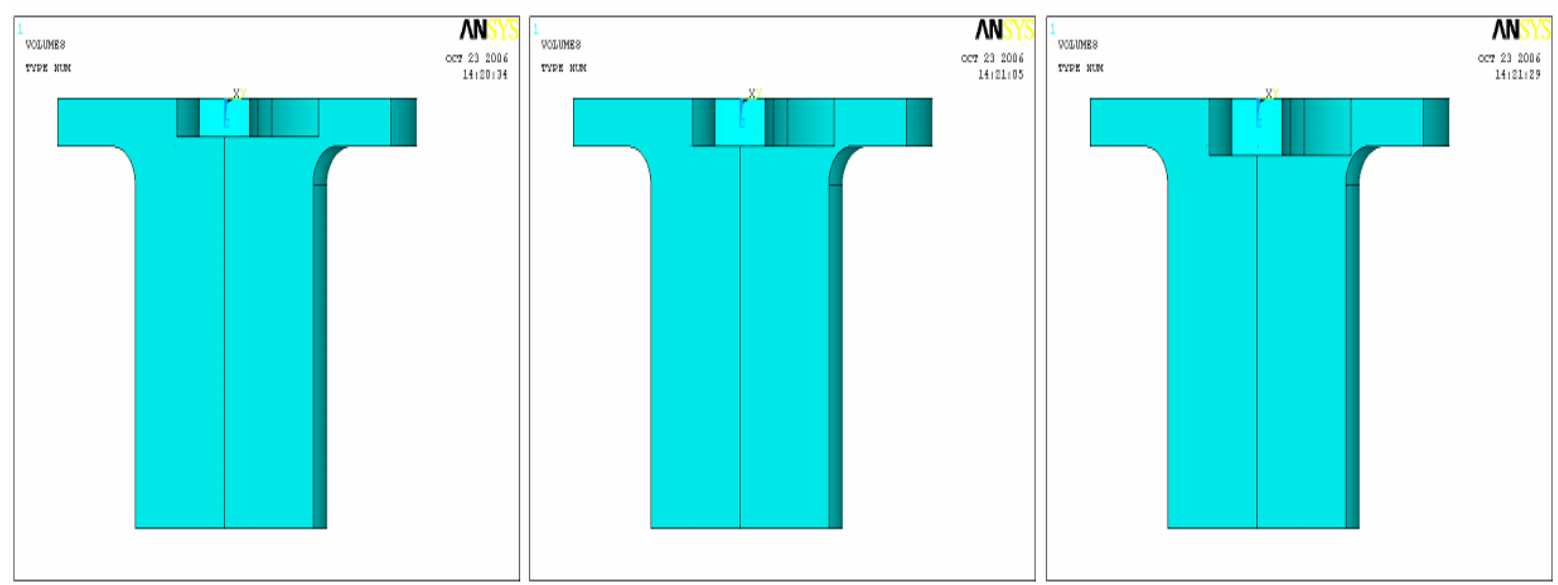

g) $\gamma_{d 3}$ and $\gamma_{h 1}$

h) $\gamma_{d 3}$ and $\gamma_{h 2}$

i) $\gamma_{d 3}$ and $\gamma_{h 3}$

Figure 20 Gamma ratios to the effect on microscrews 


\section{Results}

This chapter will discuss the results of the torque and nodal rotation to tension analysis as and parametric sensitivity analysis. This analysis was computational in nature and validity will be checked against theoretical calculations and other comparisons.

\subsection{Torque to Axial Stress Results for Constant Torque}

The load to the assembly is applied at the center of the beam elements in Figure 10. The axial stress generated by the torque will vary for different coefficients of friction for a bolt with a diameter of 1 inch and 8 threads per inch. Once this base model is established, the friction values can be changed through the material properties without resetting the contact elements. Friction coefficients were selected from $\mu=0$ to $\mu=0.9$ with increments of 0.1 units. For this analysis, a constant torque of 1000 in-lbs was applied to create a plot of axial stress versus friction coefficient. Axial stress values were taken from the cross section of the shank, Figure 21.

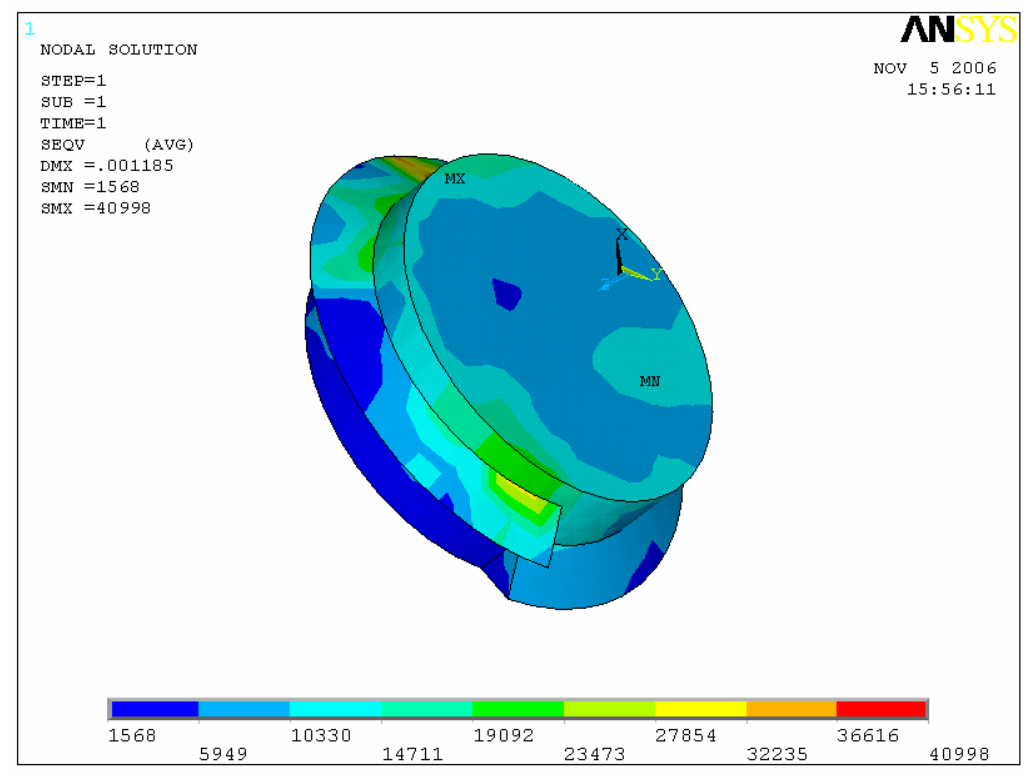

Figure 21 Maximum von Mises stress in cross section for $\boldsymbol{\mu}=\mathbf{0 . 7}$ 
Table 3 shows the values of friction and axial stress.

Table 3 Maximum axial stress values for given friction coefficients

\begin{tabular}{|c|c|c|}
\hline Sample & $\begin{array}{c}\text { Coefficient } \\
\text { of Friction }\end{array}$ & Stress \\
\hline 1 & 0.00 & 50449 \\
\hline 2 & 0.01 & 43650 \\
\hline 3 & 0.05 & 26683 \\
\hline 4 & 0.10 & 18095 \\
\hline 5 & 0.20 & 12370 \\
\hline 6 & 0.30 & 10263 \\
\hline 7 & 0.40 & 9435 \\
\hline 8 & 0.50 & 9041 \\
\hline 9 & 0.60 & 8933 \\
\hline 10 & 0.70 & 8784 \\
\hline 11 & 0.80 & 8582 \\
\hline 12 & 0.90 & 8354 \\
\hline
\end{tabular}

These values are plotted in Excel, illustrated in Figure 22.

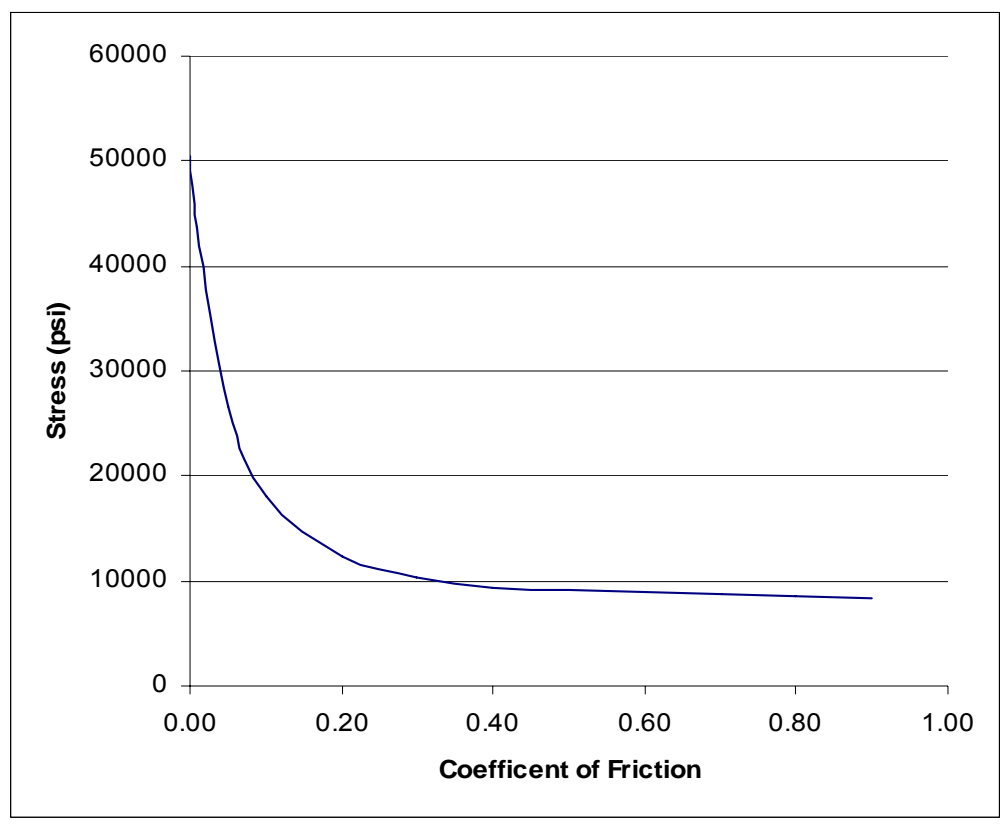

Figure 22 Friction coefficient and axial stress plot

\subsubsection{Torque to Tension Results}

Once the procedure is determined to acquire tension in the microscrew, a relationship between torque and tension can be established. Average stress along the cross sectional 
area was recorded from the four points as described in Chapter 4.3. The average stress, along with the area of the cross section is used to determine a force or tension by Hooke's law. The tension values computed from the average von Mises stress as given by ANSYS are found in Table 4.

Table 4 Tension from torque at friction coefficients

\begin{tabular}{|c|c|c|c|c|c|c|c|c|}
\hline & \multicolumn{7}{|c|}{$\%$ of Max Tension } \\
\hline & & $\mu=0$ & $\mu=0.05$ & $\mu=0.1$ & $\mu=0.2$ & $\mu=0.3$ & $\mu=0.4$ & $\mu=0.5$ \\
\hline \multirow{6}{*}{ 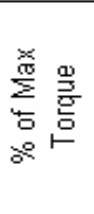 } & 0.00 & 0.00 & 0.00 & 0.00 & 0.00 & 0.00 & 0.00 & 0.00 \\
\hline & 10.00 & 20.21 & 8.45 & 8.20 & 8.00 & 8.04 & 8.10 & 8.16 \\
\hline & 25.00 & 34.27 & 16.34 & 12.23 & 10.22 & 9.92 & 9.97 & 9.46 \\
\hline & 50.00 & 62.08 & 28.20 & 19.81 & 14.00 & 12.50 & 12.36 & 12.17 \\
\hline & 75.00 & 82.29 & 40.39 & 27.49 & 19.09 & 16.26 & 15.69 & 14.95 \\
\hline & 100.00 & 100.00 & 52.89 & 35.87 & 24.52 & 20.34 & 18.70 & 17.92 \\
\hline
\end{tabular}

The values are then plotted to understand the affect of friction on the tension of a bolt under loading in Figure 23.

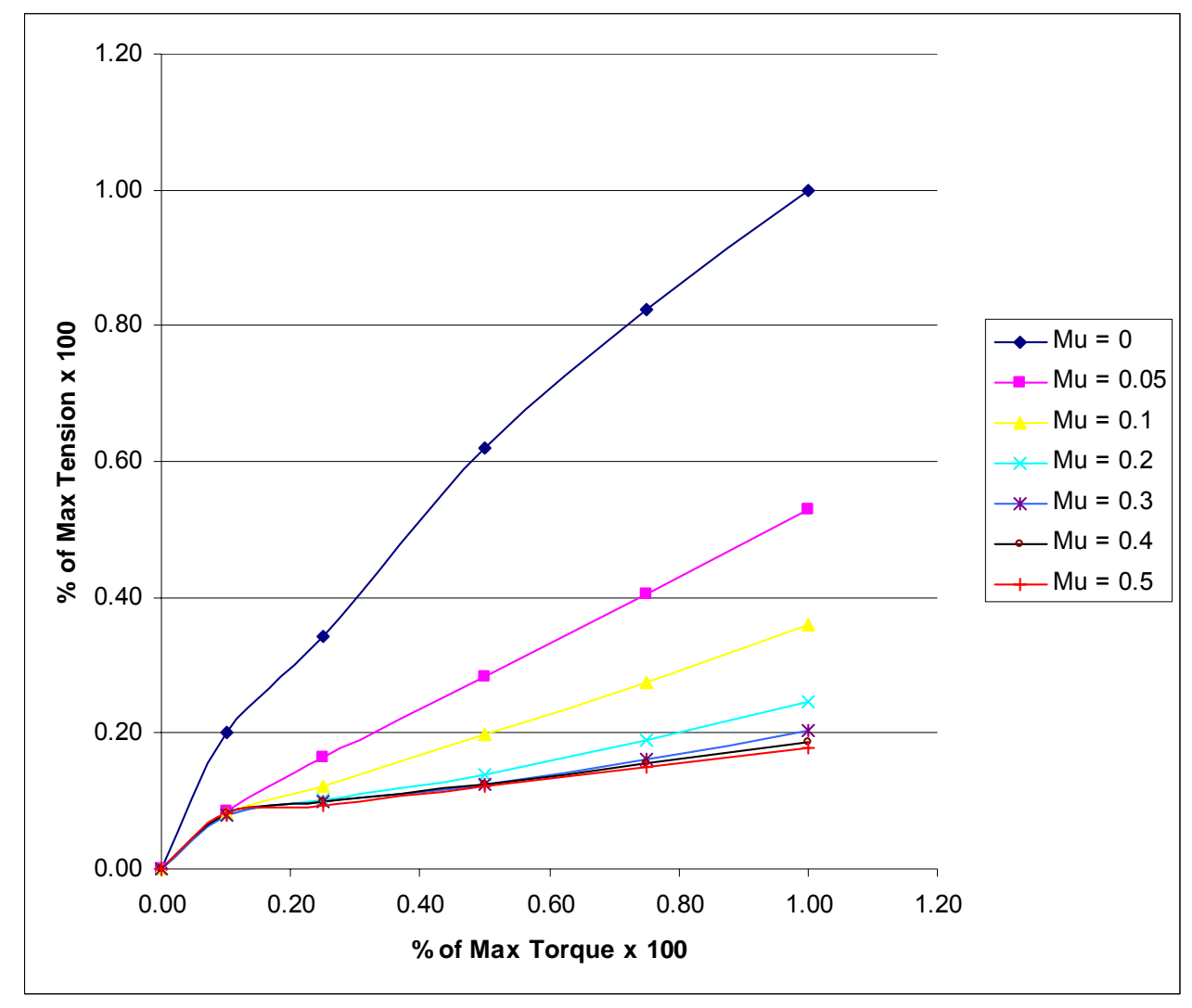

Figure 23 Torque to tension relationship for constant friction coefficients 
To verify the data given from ANSYS, theoretical calculations from equation 4.7 are used for comparisons. These values in Table 5 are calculated from the same load steps and friction coefficients as the ANSYS comparisons.

Table 5 Calculated Tension from torque at friction coefficients

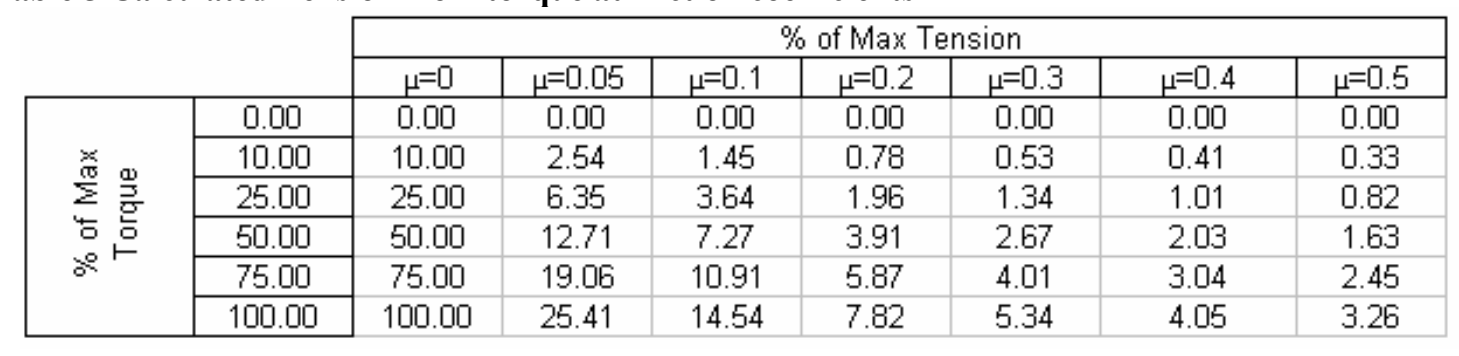

Similarly to Figure 23, the tension values for each value of friction are combined on the same plot in Figure 24.

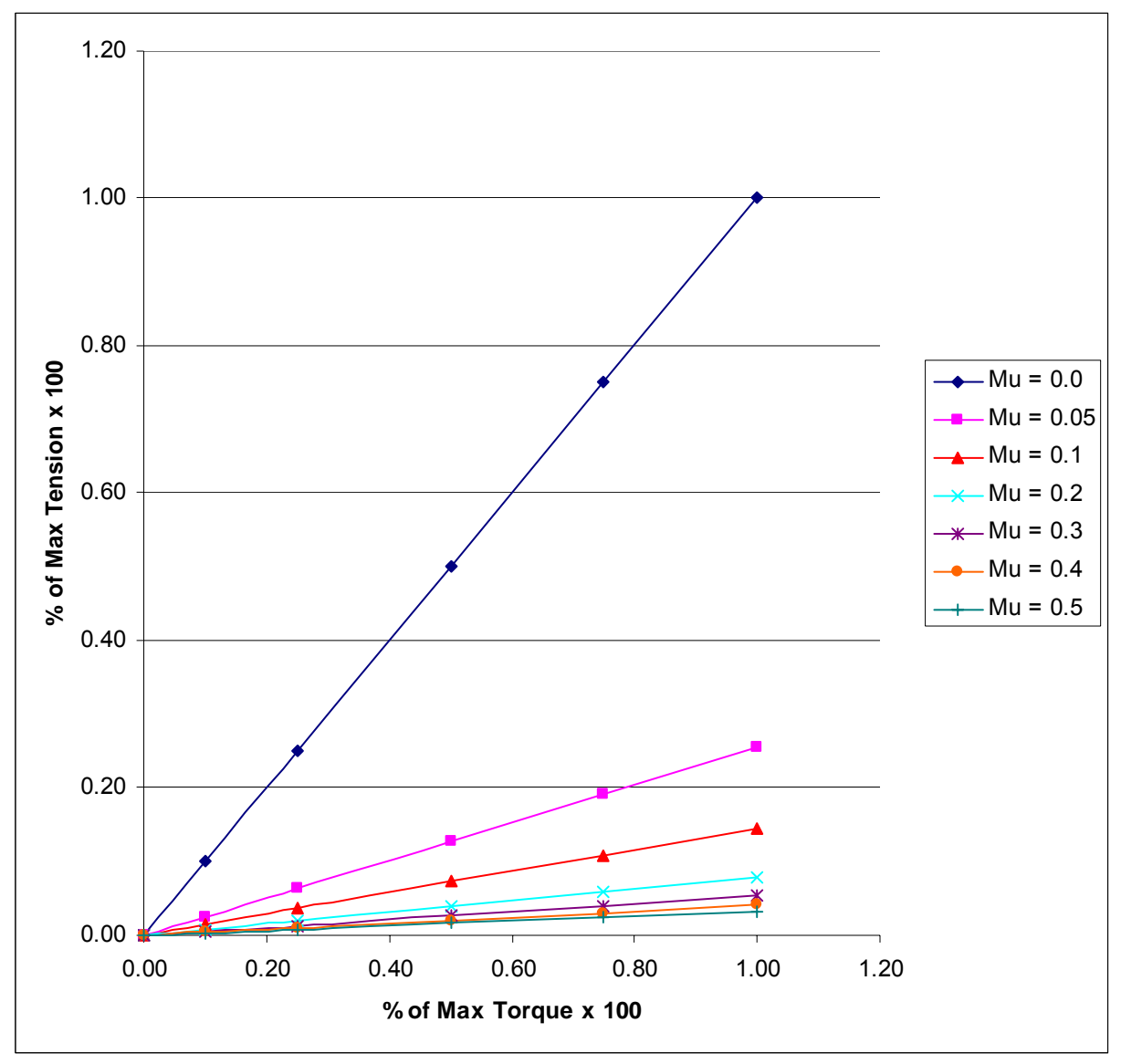

Figure 24 Calculated torque to tension relationship for constant friction coefficients. 


\subsubsection{Rotation to Tension Results}

The microscrew models are put through a nodal rotation simulation. The value of rotation and the corresponding values of tension are shown in Table 6 . The method for acquiring data remains the same as in Chapter 4.3.

Table 6 Tension from rotation at friction coefficients

\begin{tabular}{|c|c|c|c|c|c|c|c|c|}
\hline & \multicolumn{7}{|c|}{$\%$ of Max Tension } \\
\hline & & $\mu=0$ & $\mu=0.05$ & $\mu=0.1$ & $\mu=0.2$ & $\mu=0.3$ & $\mu=0.4$ & $\mu=0.5$ \\
\hline \multirow{5}{*}{ 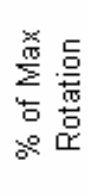 } & 0.0 & 0.00 & 0.00 & 0.00 & 0.00 & 0.00 & 0.00 & 0.00 \\
\hline & 10.0 & 10.86 & 11.31 & 11.85 & 13.26 & 14.85 & 16.61 & 18.45 \\
\hline & 20.0 & 15.79 & 16.07 & 16.70 & 18.36 & 20.60 & 23.24 & 25.96 \\
\hline & 60.0 & 37.86 & 38.33 & 39.56 & 43.81 & 49.51 & 56.06 & 62.67 \\
\hline & 100.0 & 64.99 & 64.68 & 66.00 & 71.45 & 80.26 & 90.05 & 100.00 \\
\hline
\end{tabular}

Once these values in Table 6 are plotted, they are compared against the findings of [6]. Their findings consist of a plot from numerical calculations of nut rotation angle to axial bolt stress with loadings into the plastic region. The results from the nodal rotation simulations can be found in Figure 25.

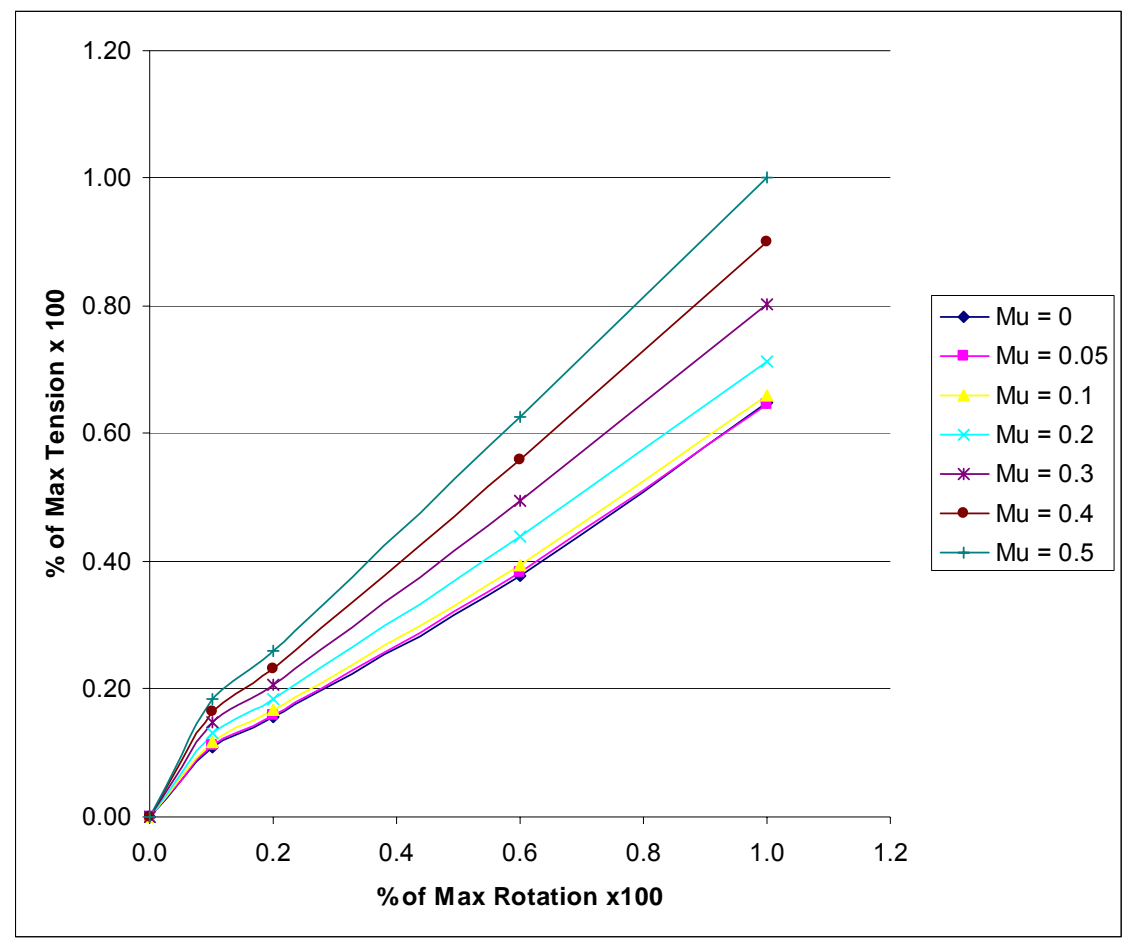

Figure 25 Rotation to tension for constant friction coefficients 


\subsection{Microscrew Computational Results}

After the model variations were solved each with the same loadings and restraints, post processing is started. Stress in the fillet was a primary concern, but as the results were analyzed, high stress concentrations were found on the top of the head. These stresses were specifically located directly behind the area of contact between the driver and the head. These stresses will be addressed in Chapter 7 Conclusions.

\subsection{Acquiring Data}

The model was segmented into four sections with two planes; normal to the Xplane and Y-plane. This created the sections along the axis on the microscrew. The volume select option allows the particular volume that contains the area in question to be selected. This volume displays the close proximity between the socket and the fillet as shown in Chapter 4.0. From here, elements attached to this volume can be selected and the nodal solution can now be limited to this volume only. Von Mises equivalent stress is plotted for this volume segment and can be compared to each geometry change, Figure 26. 


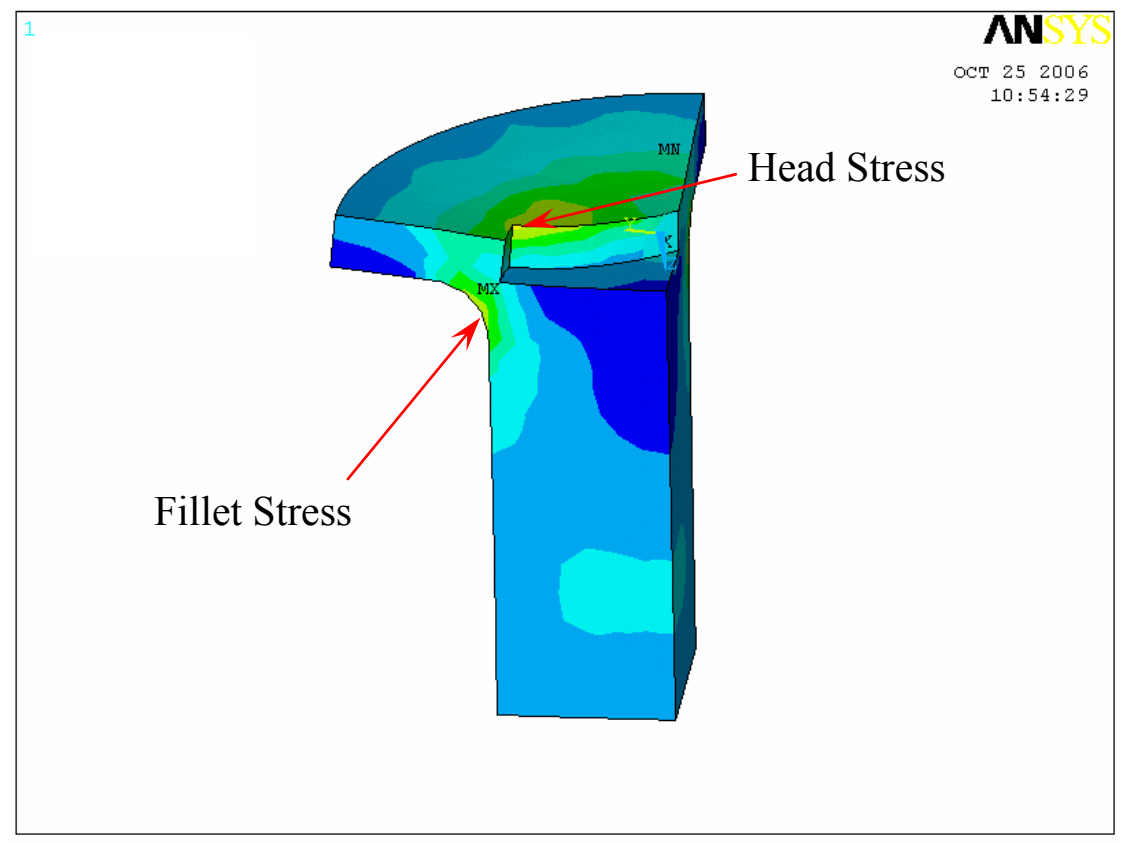

Figure 26 Von Mises plot for $\gamma \mathrm{d} 1, \gamma \mathrm{h} 1$

To acquire data concerning the stress in the region of the fillet and the area discussed on the head, nodes are selected in the region of the highest von Mises stress in Figure 27. These stresses are plotted and compared for each model variation.

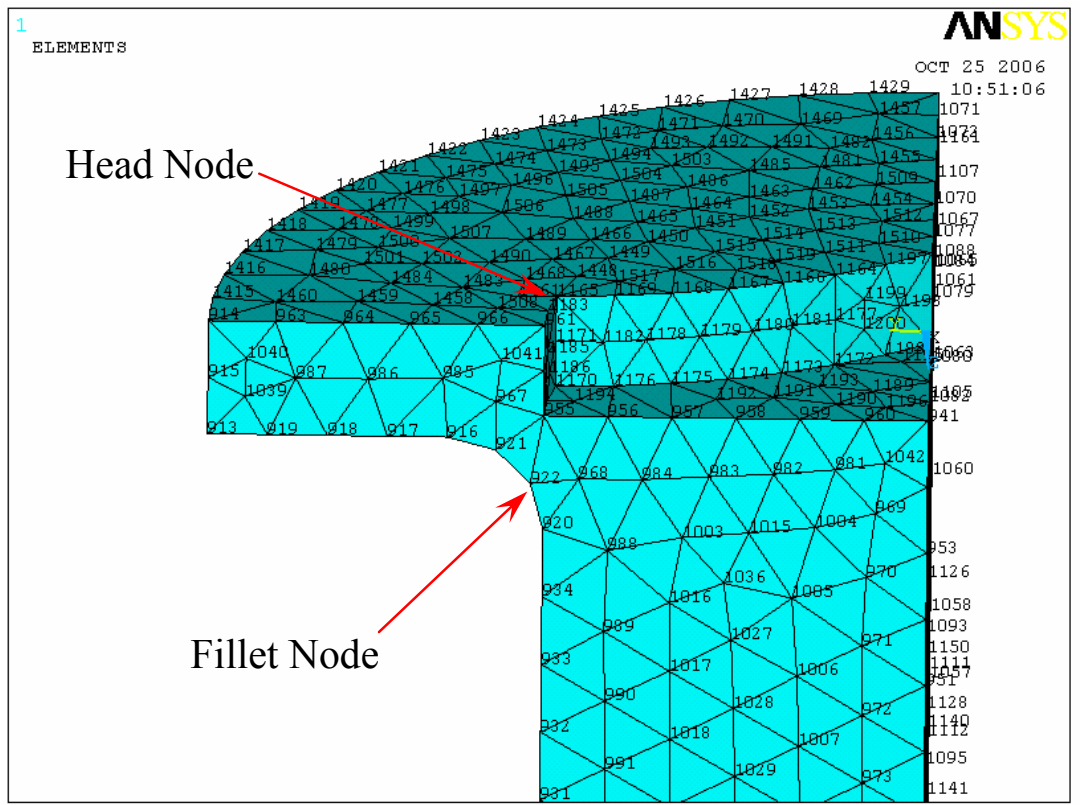

Figure 27 Selected node locations for case $\gamma_{d 2}$ and case $\gamma_{h 1}$ 


\subsection{ANSYS Results}

This chapter states the computational results as given by ANSYS. The two loading cases are described in Chapter 5.2.

\subsubsection{Loading Case 1}

Referencing Table 2, the $\gamma_{d}$ and $\gamma_{h}$ values are plotted with their corresponding stress values from an input torque of 1000 units and an axial force of 2000 units. Table 7 shows the corresponding stress value at the fillet and head nodes in question.

Table 7 Percentage of max stress for load case 1

\begin{tabular}{|c|c|c|}
\hline$\gamma_{\mathrm{d} 1} \%_{\mathrm{h} 1}$ & & $\%$ of Max Stress \\
\hline Fillet Node \# & 799 & 62.39 \\
\cline { 1 - 1 } Head Node \# & 1038 & 48.29 \\
\hline$\gamma_{\mathrm{d} 2} \%_{\mathrm{h} 1}$ & & \\
\cline { 1 - 1 } Fillet Node \# & 922 & 66.12 \\
\hline Head Node \# & 1165 & 46.71 \\
\hline$\gamma_{\mathrm{d} 3} \%_{\mathrm{h} 1}$ & & \\
\cline { 1 - 1 } Fillet Node \# & 937 & 59.77 \\
\hline Head Node \# & 1179 & 45.39 \\
\hline
\end{tabular}

\begin{tabular}{|c|c|c|}
\hline$\gamma_{\mathrm{d} 1} \%_{\mathrm{h} 2}$ & & $\%$ of Max Stress \\
\hline Fillet Node \# & 804 & 64.86 \\
\cline { 1 - 1 } Head Node \# & 1041 & 47.87 \\
\hline$\gamma_{\mathrm{d} 2} \%_{\mathrm{h} 2}$ & & \\
\cline { 1 - 1 } Fillet Node \# & 936 & 70.55 \\
\hline Head Node \# & 1180 & 55.95 \\
\hline$\gamma_{\mathrm{d} 3} \%_{\mathrm{h} 2}$ & & \\
\hline Fillet Node \# & 940 & 66.99 \\
\hline Head Node \# & 1179 & 45.35 \\
\hline
\end{tabular}

\begin{tabular}{|c|c|c|}
\hline$\gamma_{\mathrm{d} 1} \mathrm{~h}_{3}$ & & $\%$ of Max Stress \\
\hline Fillet Node \# & 793 & 62.82 \\
\hline Head Node \# & 1019 & 47.39 \\
\hline$\gamma_{\mathrm{d} 2}$ \% $_{3}$ & & \\
\hline Fillet Node \# & 989 & 80.20 \\
\hline Head Node \# & 1219 & 52.35 \\
\hline$\gamma_{\mathrm{d} 3}$ \%h $_{3}$ & & \\
\hline Fillet Node \# & 964 & 100.00 \\
\hline Head Node \# & 1195 & 49.02 \\
\hline
\end{tabular}

These values are put into bar graphs for comparison, Figure 28- Figure 30. 


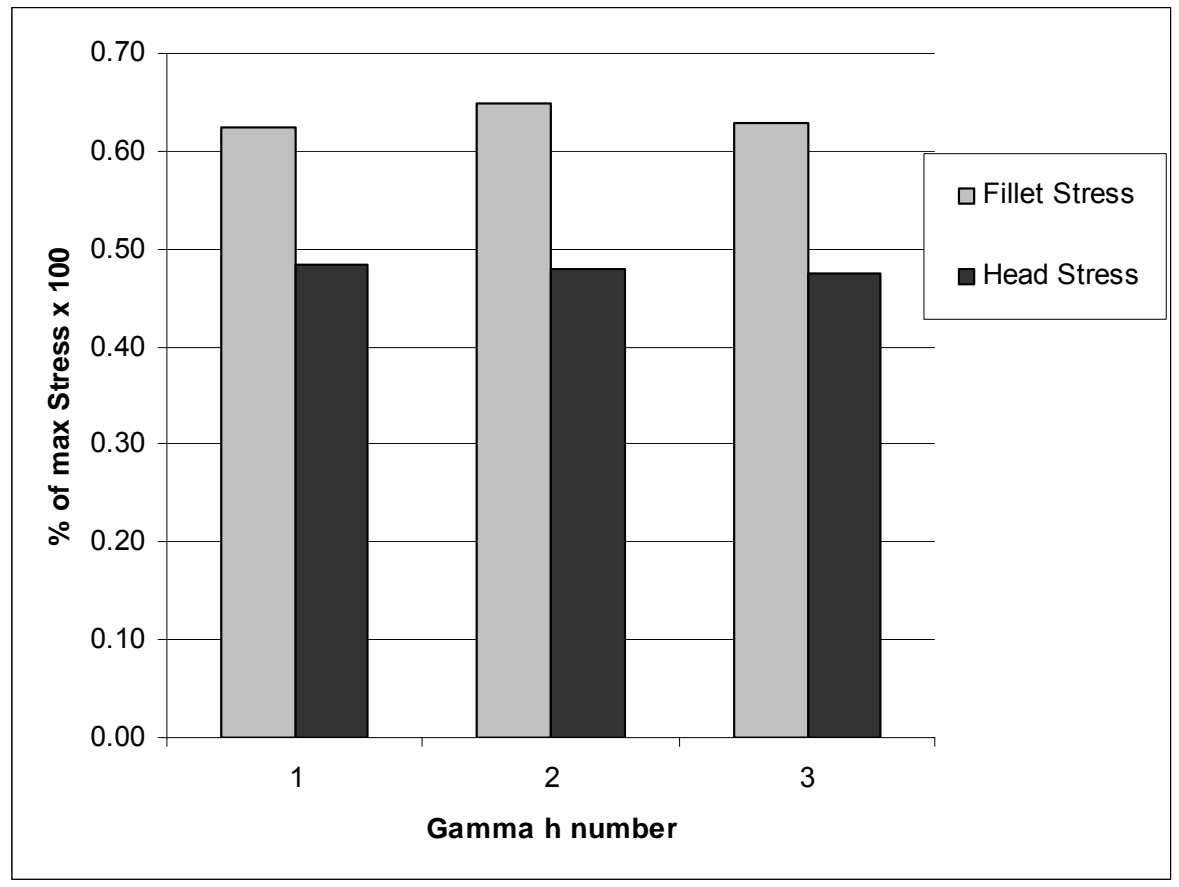

Figure 28 Percentage of max stress for $\gamma_{h}$ for Constant $\gamma_{d 1}$ for load case 1

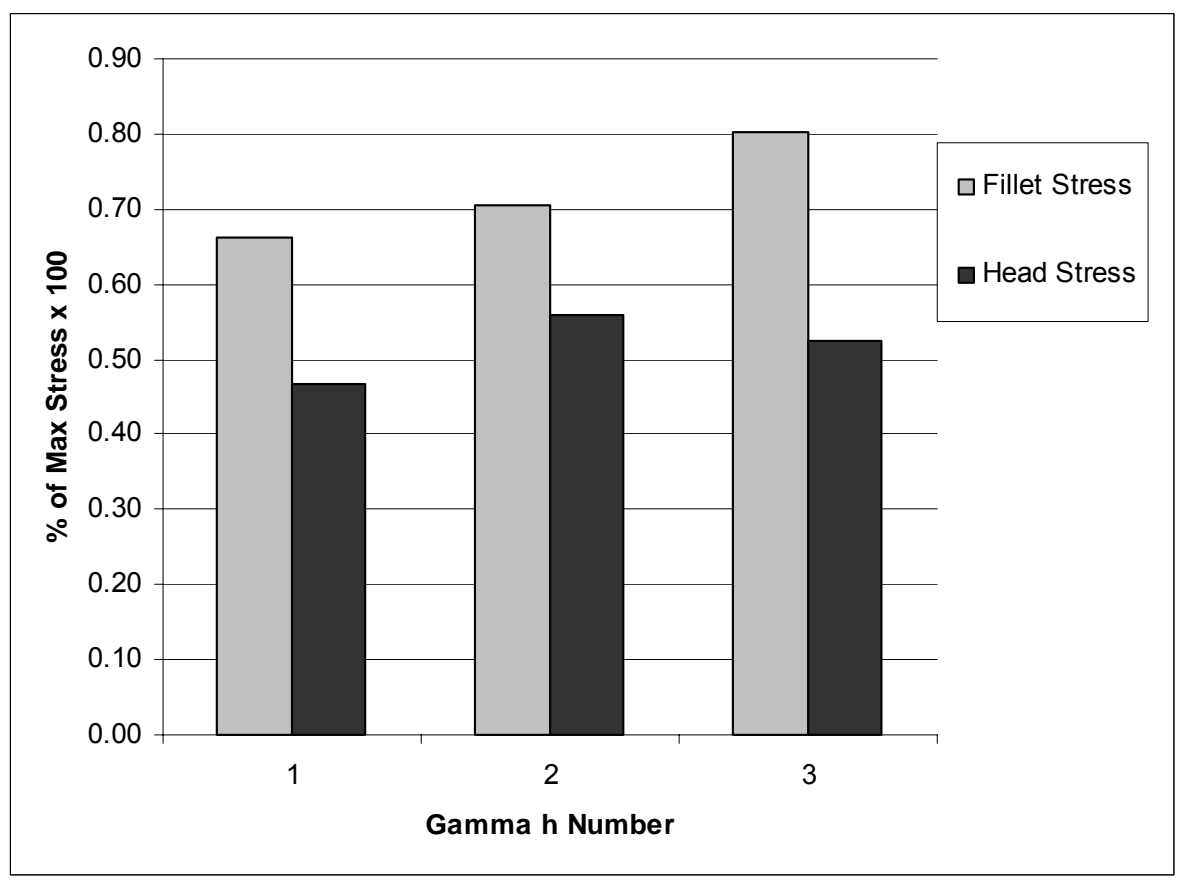

Figure 29 Percentage of max stress for $\gamma_{h}$ for Constant $\gamma_{d 2}$ for load case 1 


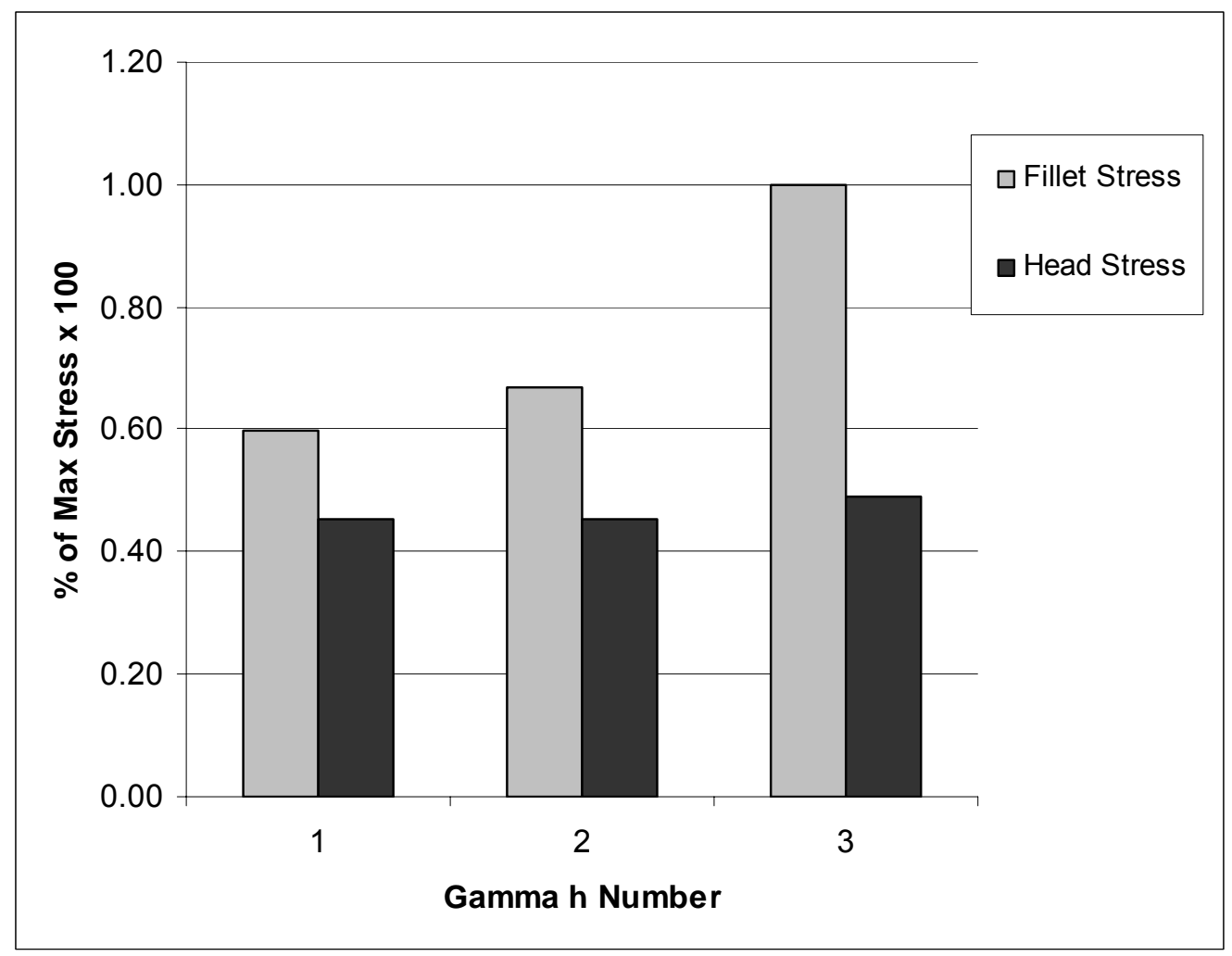

Figure 30 Percentage of max stress for $\gamma_{h}$ for Constant $\gamma_{d 3}$ for load case 1

Figure 28 - Figure 30 shows the stress as $\gamma_{h}$ increases, or as the socket depth varies from 0.2 units to 0.3 units with increments of 0.05 units while $\gamma_{d}$ remains constant for each case. Similarly, plots can be constructed for stress versus socket diameter as $\gamma_{d}$ increases from 0.75 units to 0.85 units with increments of 0.05 units while $\gamma_{h}$ remains constant for each case. Figure 31 - Figure 33 are plots of $\gamma_{d}$ versus stress for constant values of $\gamma_{h}$. 


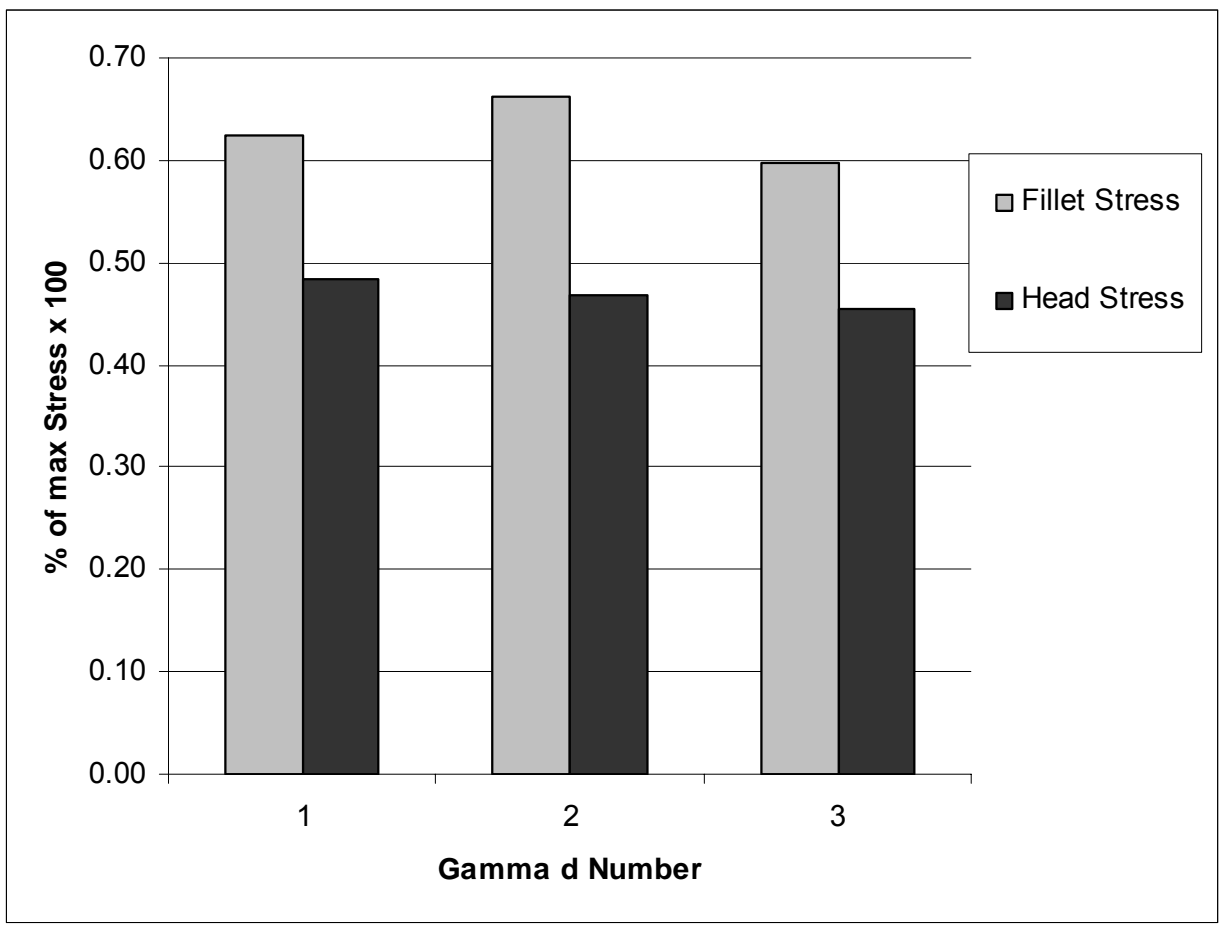

Figure 31 Percentage of max stress for $\gamma_{d}$ for Constant $\gamma_{h 1}$ for load case 1

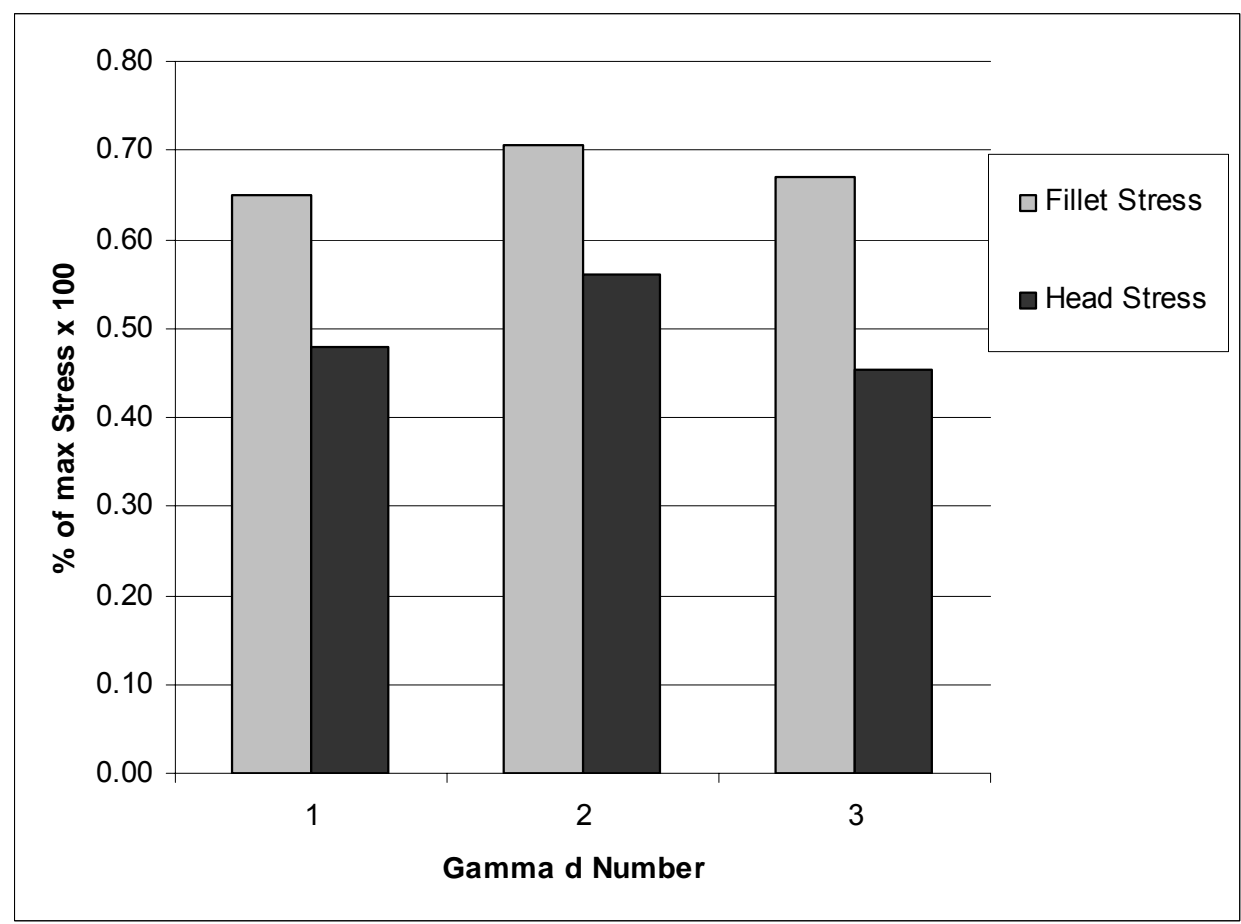

Figure 32 Percentage of max stress for $\gamma_{d}$ for Constant $\gamma_{h 2}$ for load case 1 


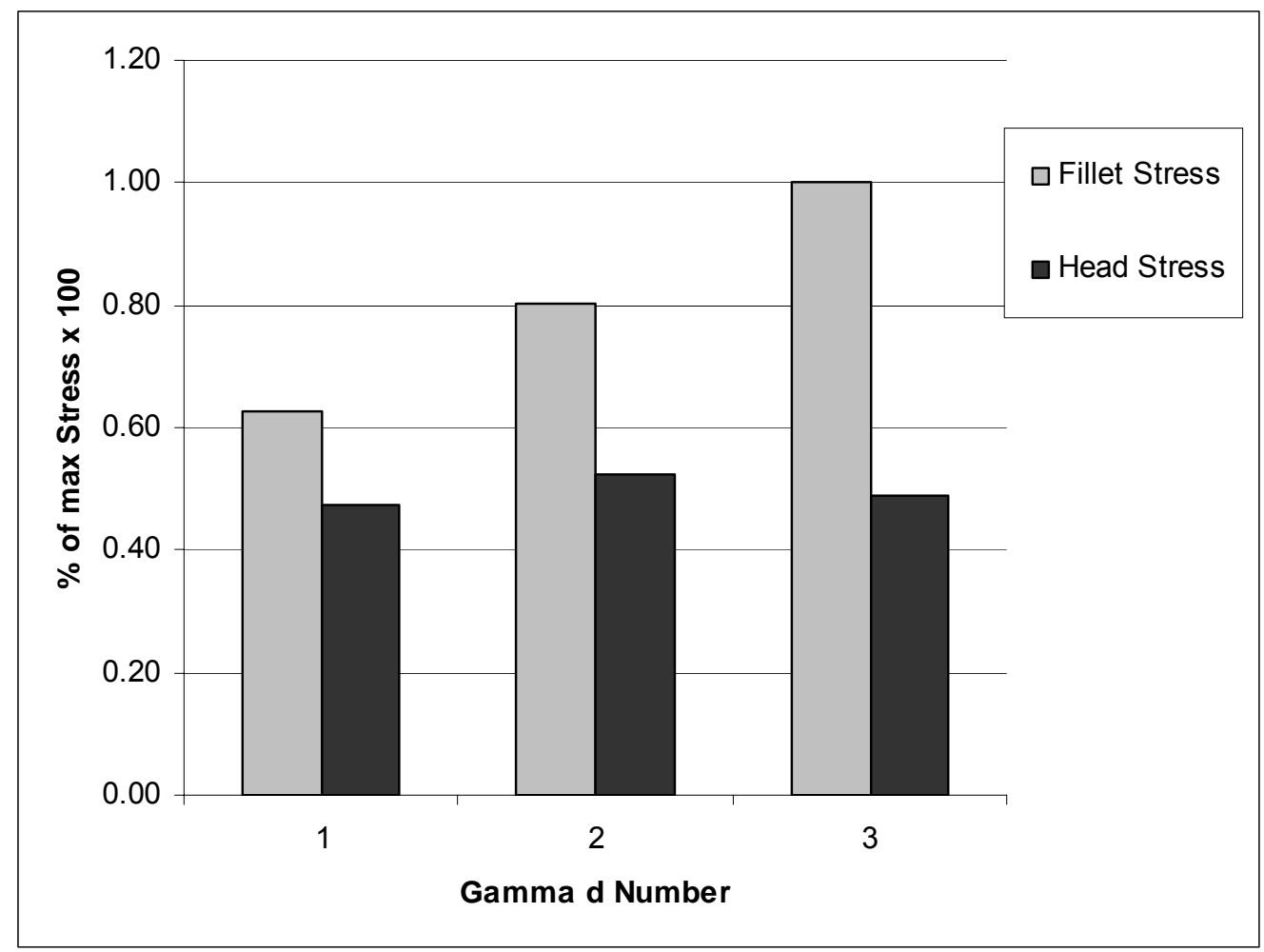

Figure 33 Percentage of max stress for $\gamma_{d}$ for Constant $\gamma_{h 3}$ for load case 1

Figure 28 through Figure 33 can be combined into surface plots to for a better understanding of the behavior of the microscrew under loading. The surface plot contains $\gamma_{d}$ and $\gamma_{h}$ values both plotted against their corresponding stresses in Figure 34. 


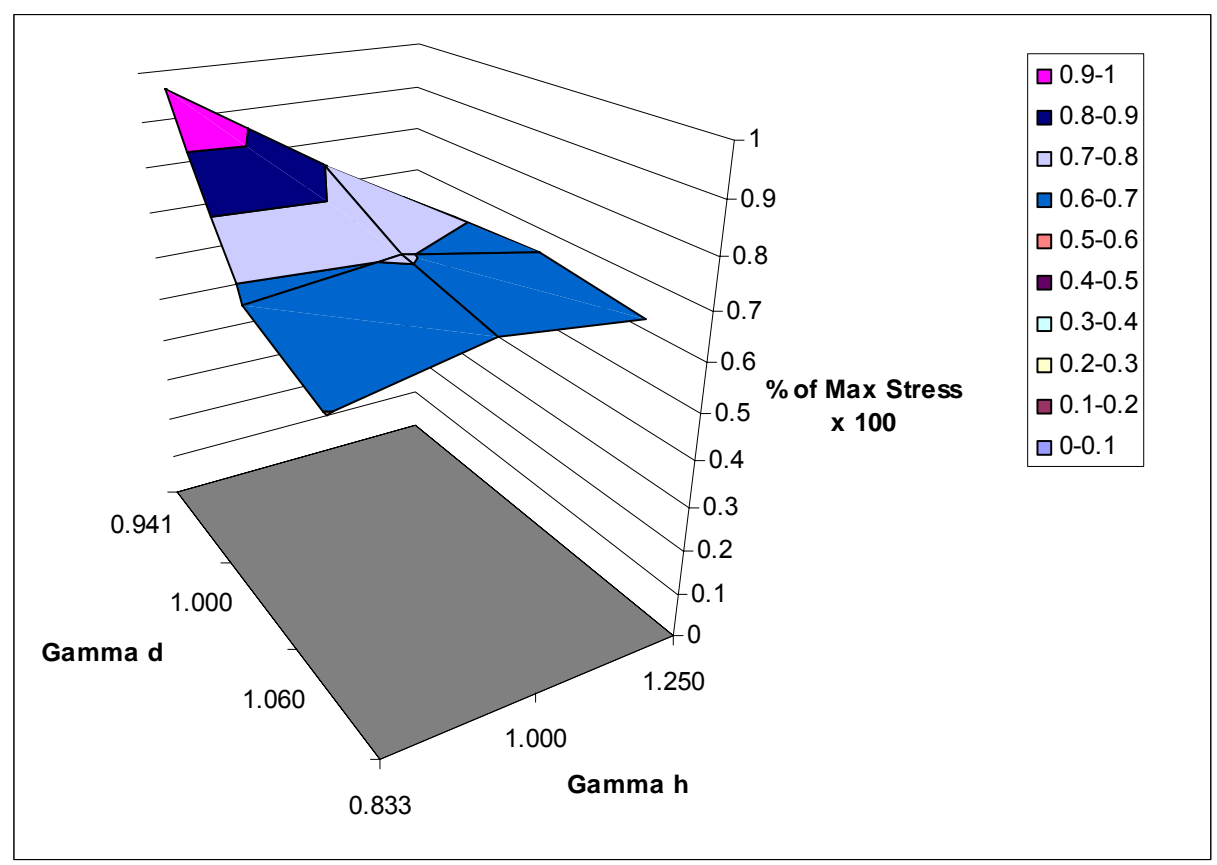

Figure $34 \gamma_{d}$ and $\gamma_{h}$ against percentage of max stress at the Microscrew Fillet for load case 1

A surface plot is created for the stress at the nodal location at the microscrew head in Figure 35.

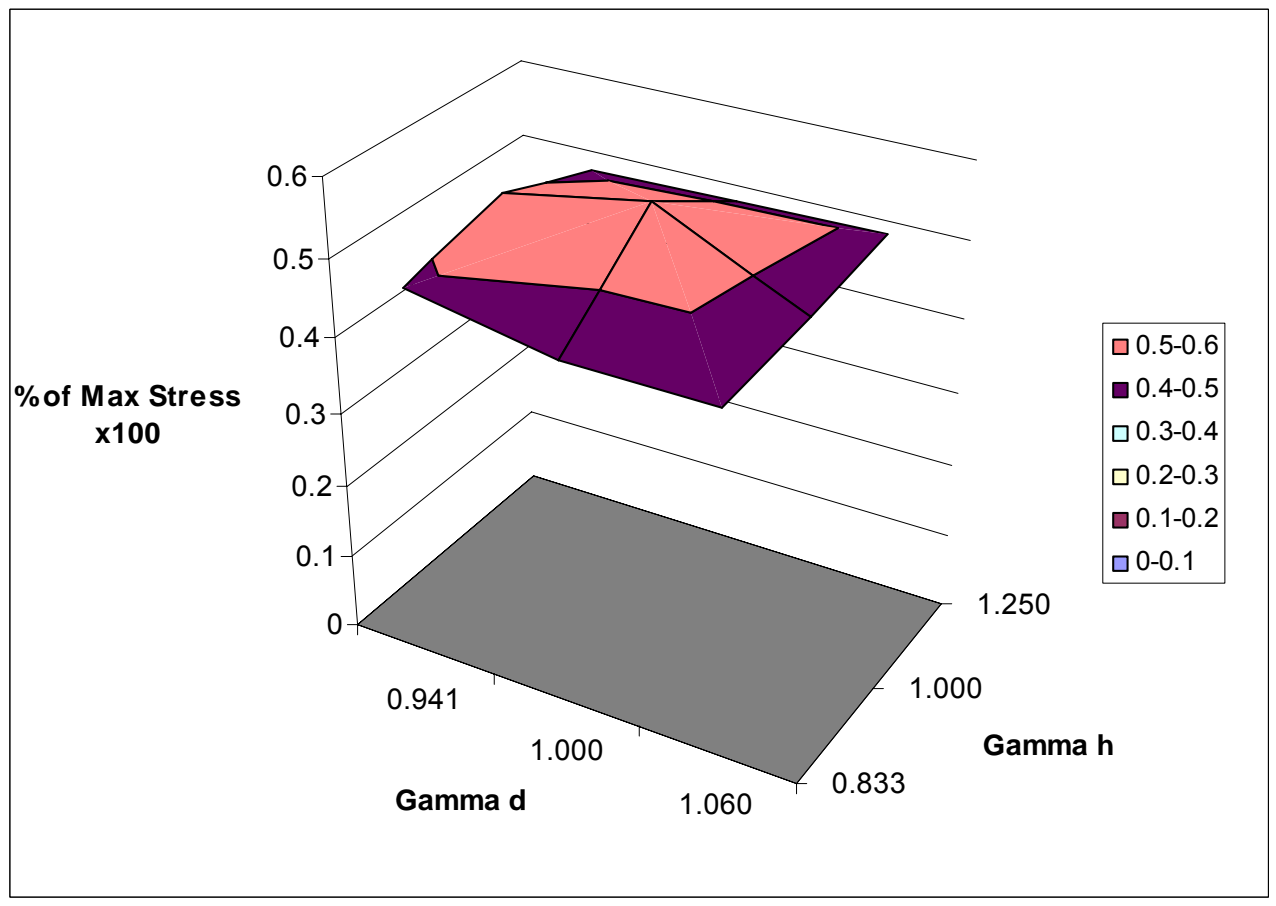

Figure $35 \gamma_{d}$ and $\gamma_{h}$ against percentage of max stress at the Microscrew Head for load case 1 


\subsubsection{Loading Case 2}

Referencing Table 2, $\gamma_{d}$ and $\gamma_{h}$ values are plotted with their corresponding stress values from an input torque increased from Chapter 6.4.1. Torque was doubled from 1000 in-lbs to 2000 in-lbs and axial force was also doubled from $2000 \mathrm{lbs}$ to $4000 \mathrm{lbs}$. This gives a better view of the mechanics of the microscrew for a change torque and axial loads. Table 8 shows the corresponding stress value at the fillet and head nodes in question.

Table 8 Percentage of max stress for load case 2

\begin{tabular}{|c|c|c|}
\hline$\gamma_{\mathrm{d} 1} \%_{\mathrm{h} 1}$ & & $\%$ of Max Stress \\
\hline Fillet Node \# & 799 & 63.36 \\
\hline Head Node \# & 1038 & 49.69 \\
\hline$\gamma_{\mathrm{d} 2} \%_{\mathrm{h} 1}$ & & \\
\hline Fillet Node \# & 922 & 66.59 \\
\hline Head Node \# & 1165 & 47.89 \\
\hline$\gamma_{\mathrm{d} 3} \%_{\mathrm{h} 1}$ & & \\
\hline Fillet Node \# & 937 & 74.50 \\
\hline Head Node \# & 1179 & 45.69 \\
\hline
\end{tabular}

\begin{tabular}{|c|c|c|}
\hline$\gamma_{\mathrm{d} 1} \mathrm{~h}_{2}$ & & $\%$ of Max Stress \\
\hline Fillet Node \# & 804 & 65.21 \\
\cline { 1 - 1 } Head Node \# & 1041 & 48.32 \\
\cline { 1 - 1 }$\gamma_{\mathrm{d} 2} \%_{\mathrm{h} 2}$ & & \\
\hline Fillet Node \# & 936 & 80.73 \\
\hline Head Node \# & 1180 & 56.46 \\
\hline$\gamma_{\mathrm{d} 3} \%_{\mathrm{h} 2}$ & & \\
\hline Fillet Node \# & 940 & 69.07 \\
\hline Head Node \# & 1179 & 49.20 \\
\hline
\end{tabular}

\begin{tabular}{|c|c|c|}
\hline$\gamma_{\mathrm{d} 1} \%_{\mathrm{h} 3}$ & & $\%$ of Max Stress \\
\hline Fillet Node \# & 793 & 63.31 \\
\cline { 1 - 1 } Head Node \# & 1019 & 48.39 \\
\hline$\gamma_{\mathrm{d} 2} \gamma_{\mathrm{h} 3}$ & & \\
\hline Fillet Node \# & 989 & 90.75 \\
\hline Head Node \# & 1219 & 52.80 \\
\hline$\gamma_{\mathrm{d} 3} \%_{\mathrm{h} 3}$ & & \\
\hline Fillet Node \# & 964 & 100.00 \\
\hline Head Node \# & 1195 & 49.45 \\
\hline
\end{tabular}

These values can be compared in bar graph similarly to Chapter 6.4.1 Loading Case 1. 


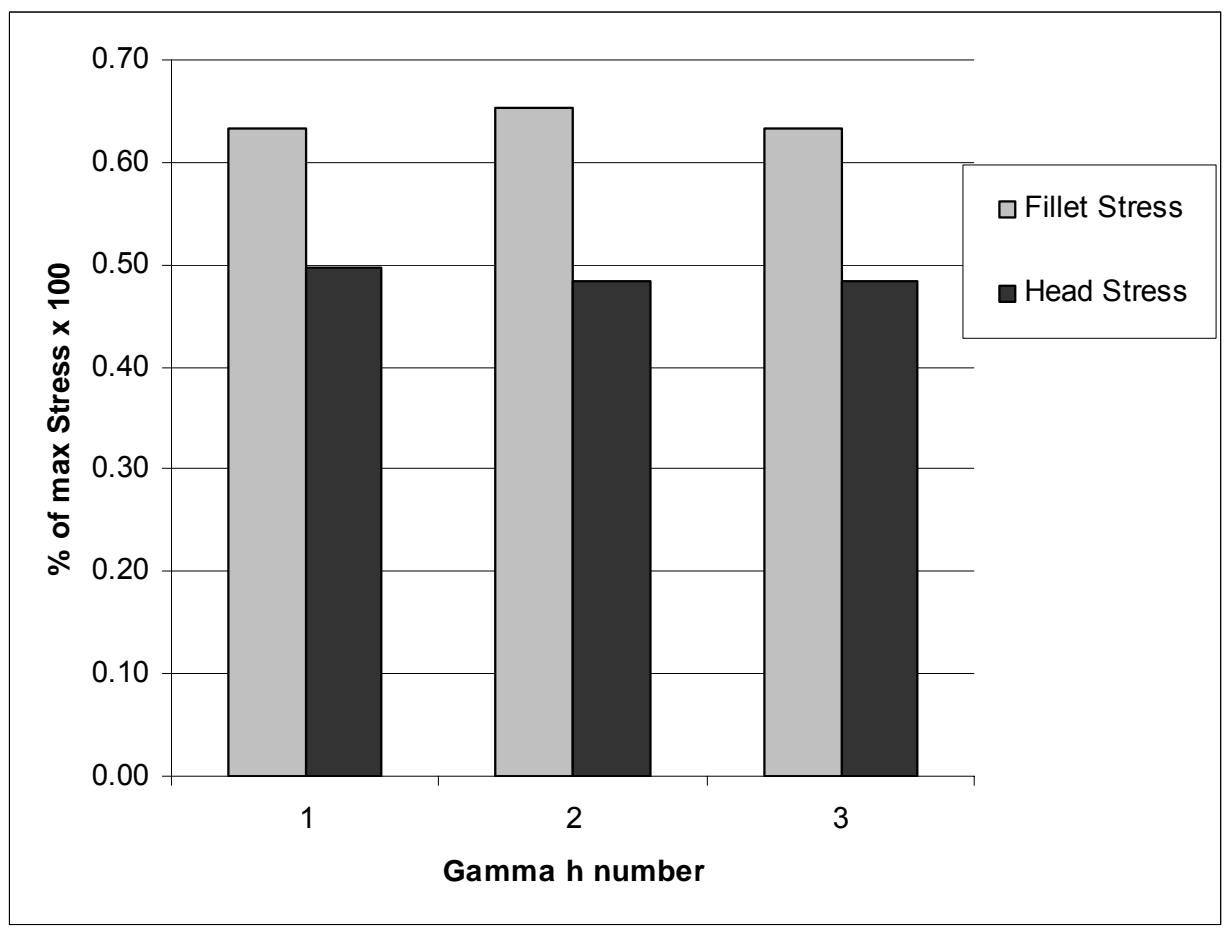

Figure 36 Percentage of stress for $\gamma_{h}$ for Constant $\gamma_{d 1}$ for load case 2

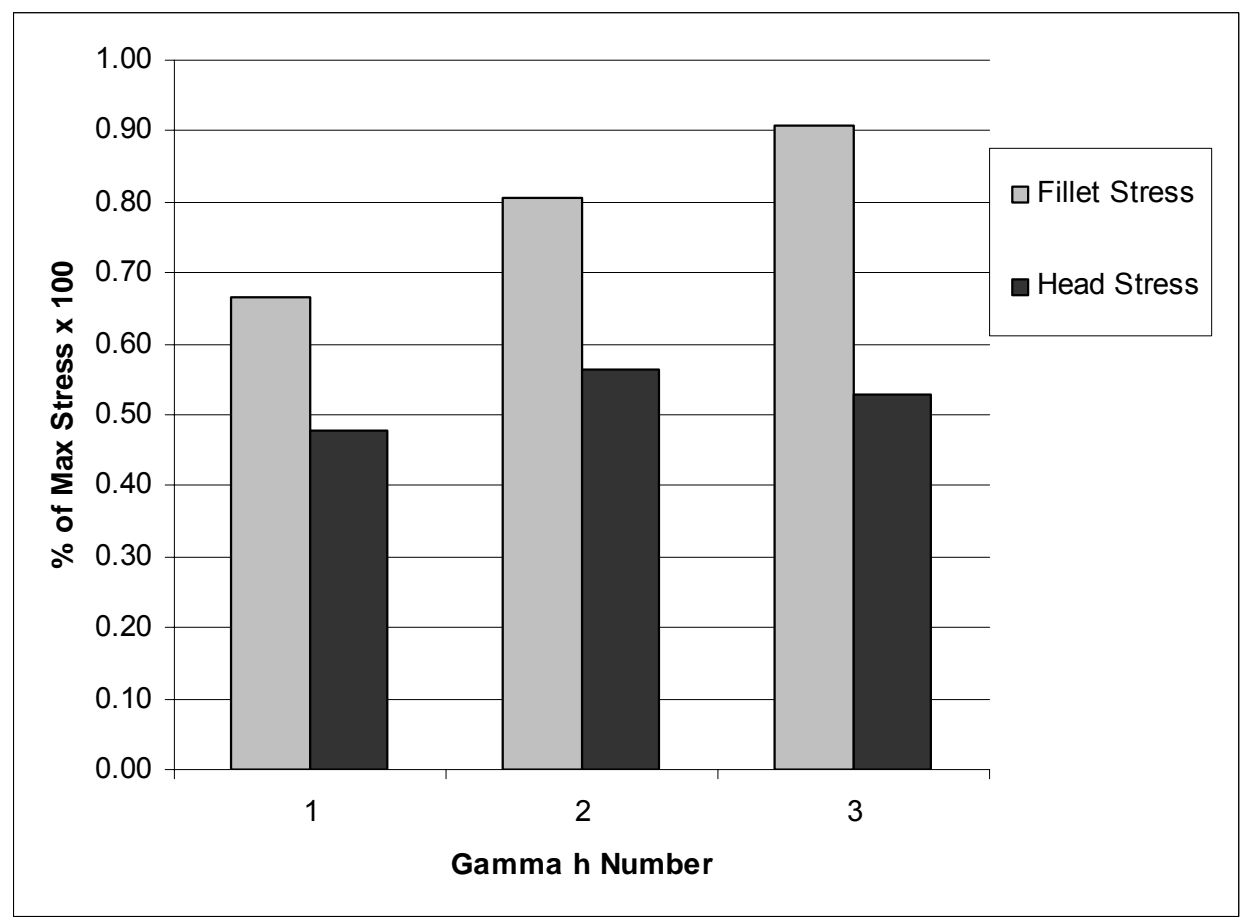

Figure 37 Percentage of stress for $\gamma_{h}$ for Constant $\gamma_{d 2}$ for load case 2 


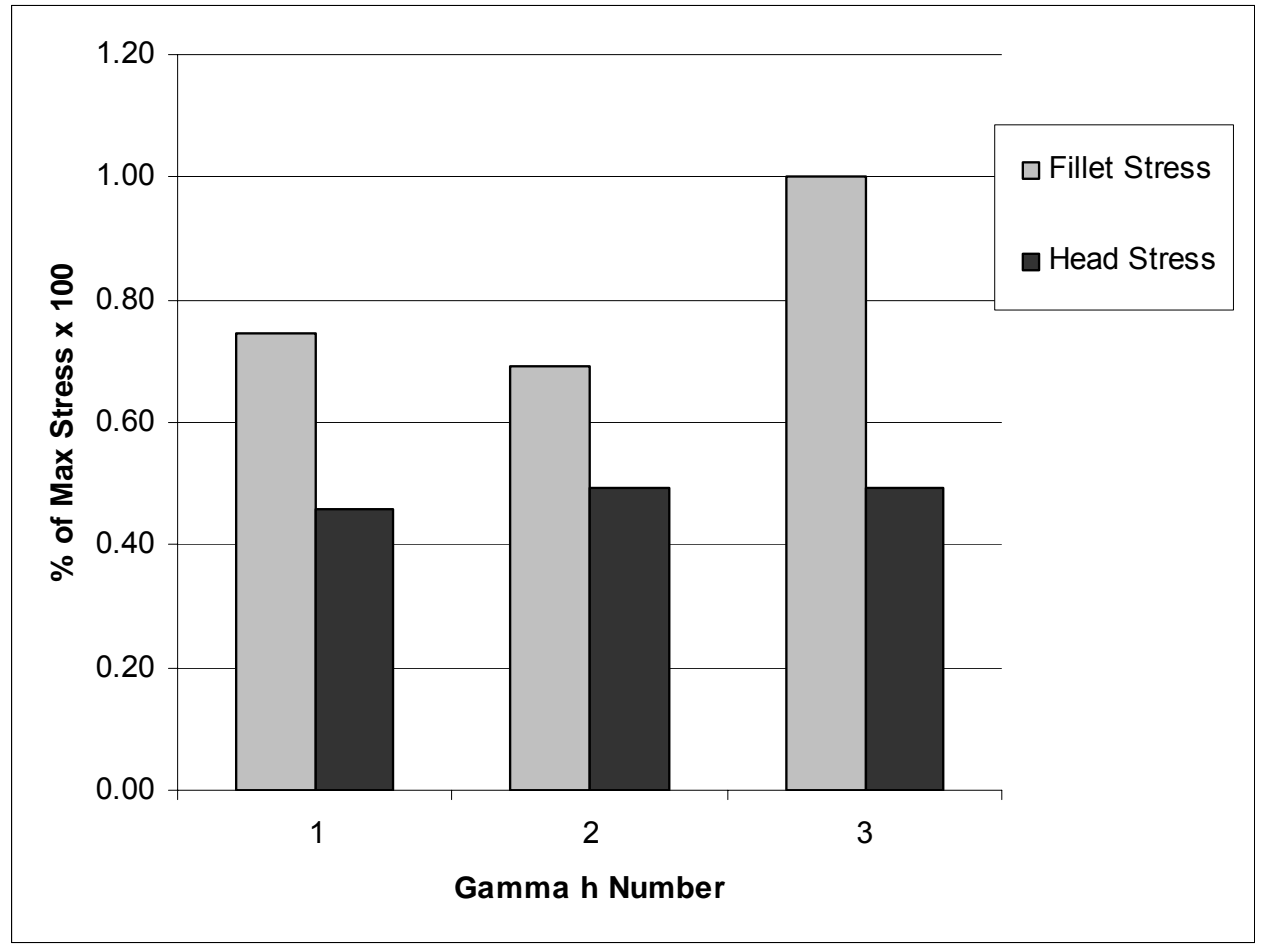

Figure 38 Percentage of stress for $\gamma_{h}$ for Constant $\gamma_{d 3}$ for load case 2

Similarly to Chapter 6.4.1 Loading Case 1, Figure 36 - Figure 38 show the stress as $\gamma_{h}$ increases, or as the socket depth varies from 0.2 units to 0.3 units while $\gamma_{d}$ remains constant for each case. Similarly, plots can be constructed for stress versus socket diameter as $\gamma_{d}$ increases from 0.75 units to 0.85 units while $\gamma_{h}$ remains constant for each case. Figure 39 - Figure 41 are plots of $\gamma_{d}$ versus stress for constant values of $\gamma_{h}$ for load case 2 . 


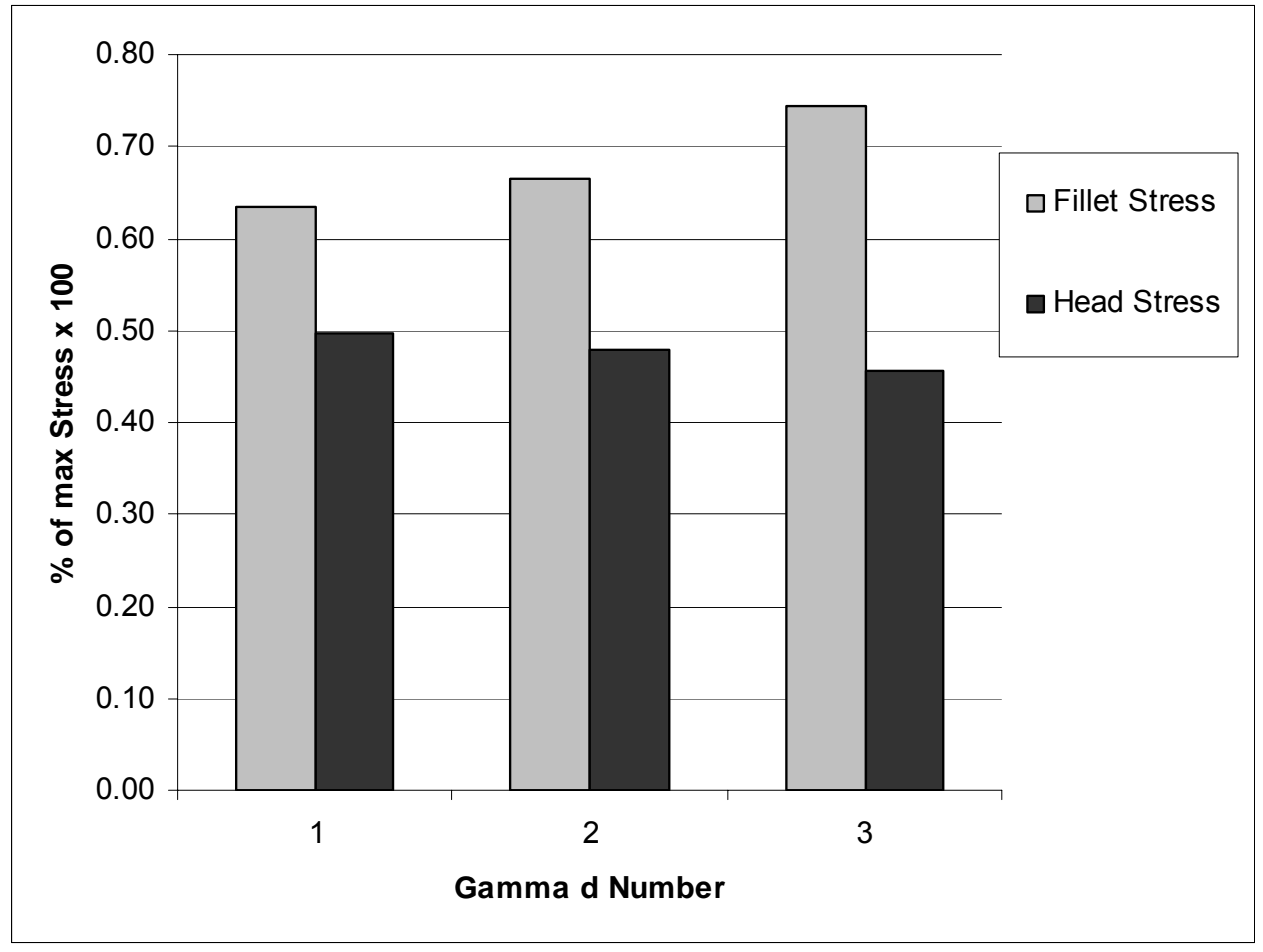

Figure 39 Percentage of stress for $\gamma_{d}$ for Constant $\gamma_{h 1}$ for load case 2

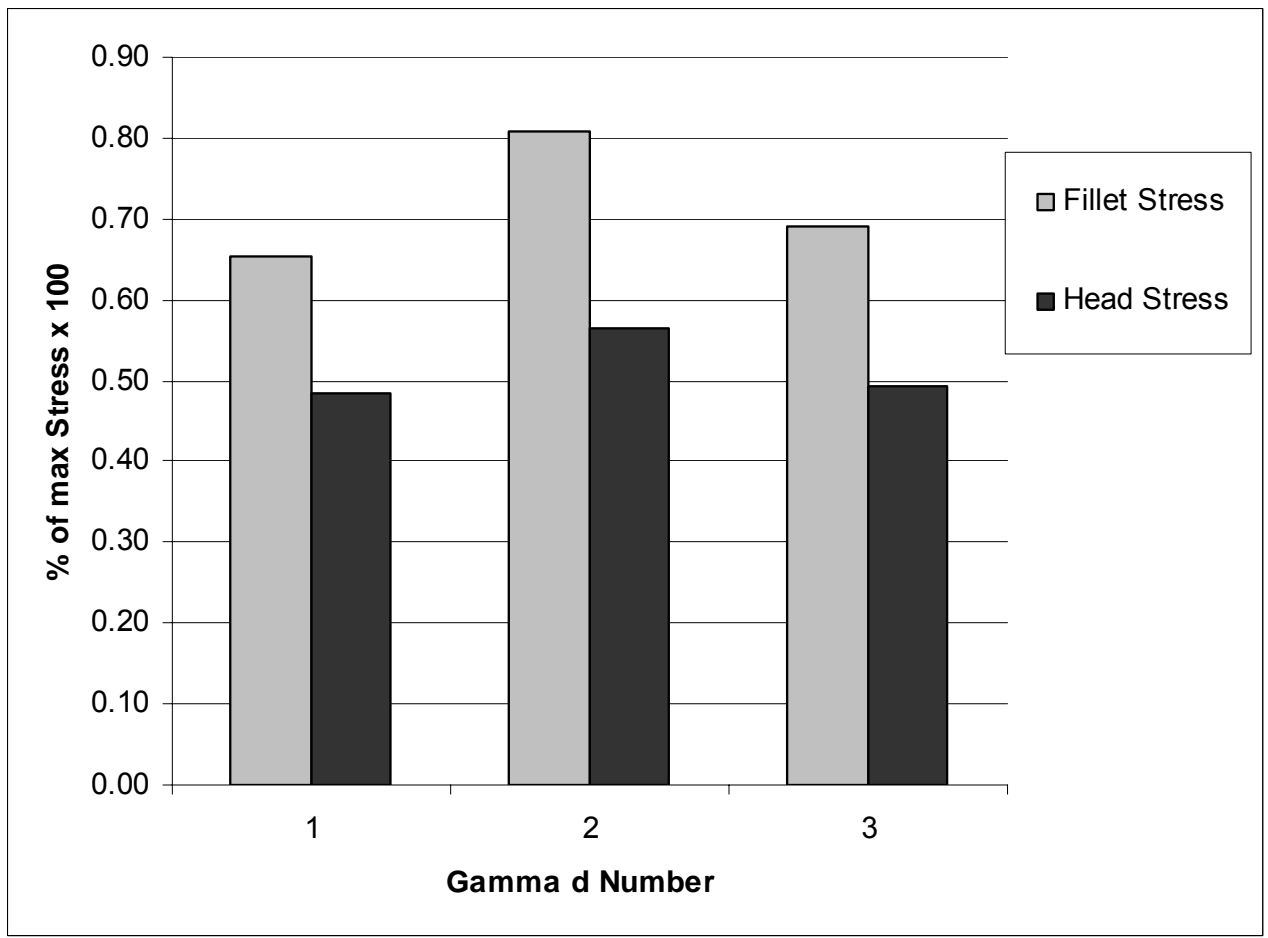

Figure 40 Percentage of stress for $\gamma_{d}$ for Constant $\gamma_{h 2}$ for load case 2 


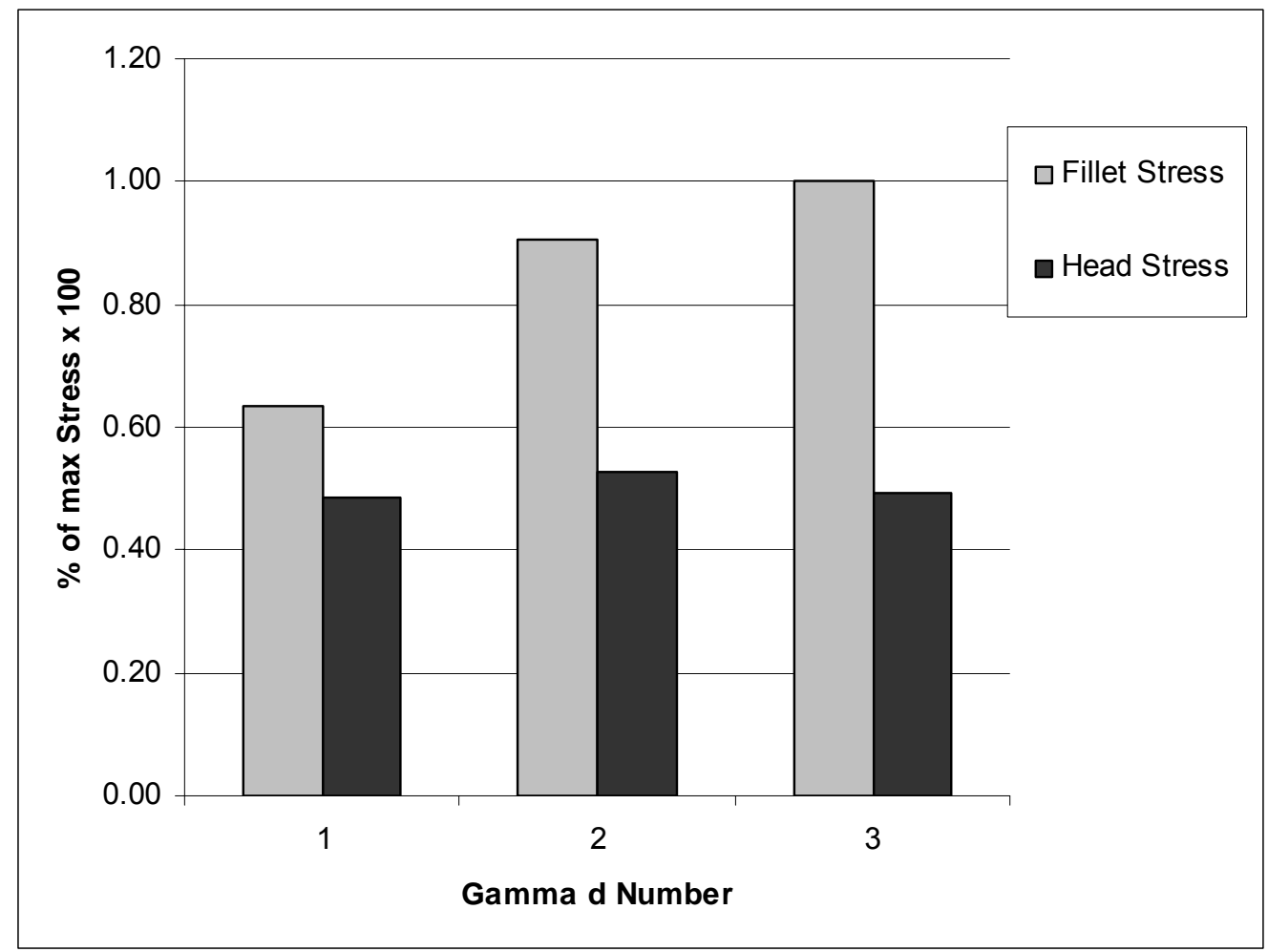

Figure 41 Percentage of stress for $\gamma_{d}$ for Constant $\gamma_{h 3}$ for load case 2

Figure 36 to Figure 41 can be combined into surface plots to for an even better understanding of the behavior of the microscrew under loading. The surface plot contains $\gamma_{d}$ and $\gamma_{h}$ values both plotted against their corresponding stresses in Figure 42. 


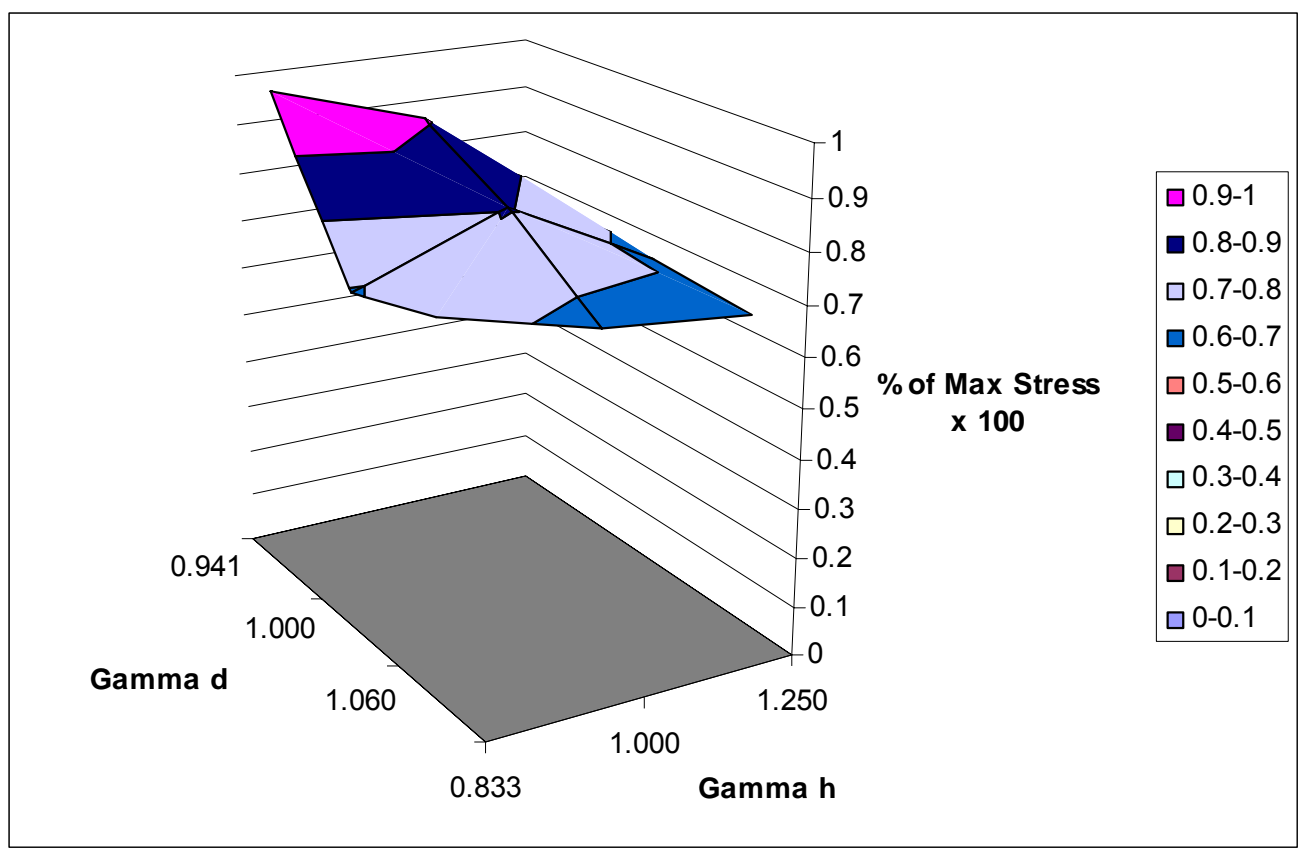

Figure $42 \gamma_{d}$ and $\gamma_{h}$ against percentage of max stress at the Microscrew Fillet for load case 2

A surface plot is created for the stress at the nodal location at the microscrew head in Figure 43 .

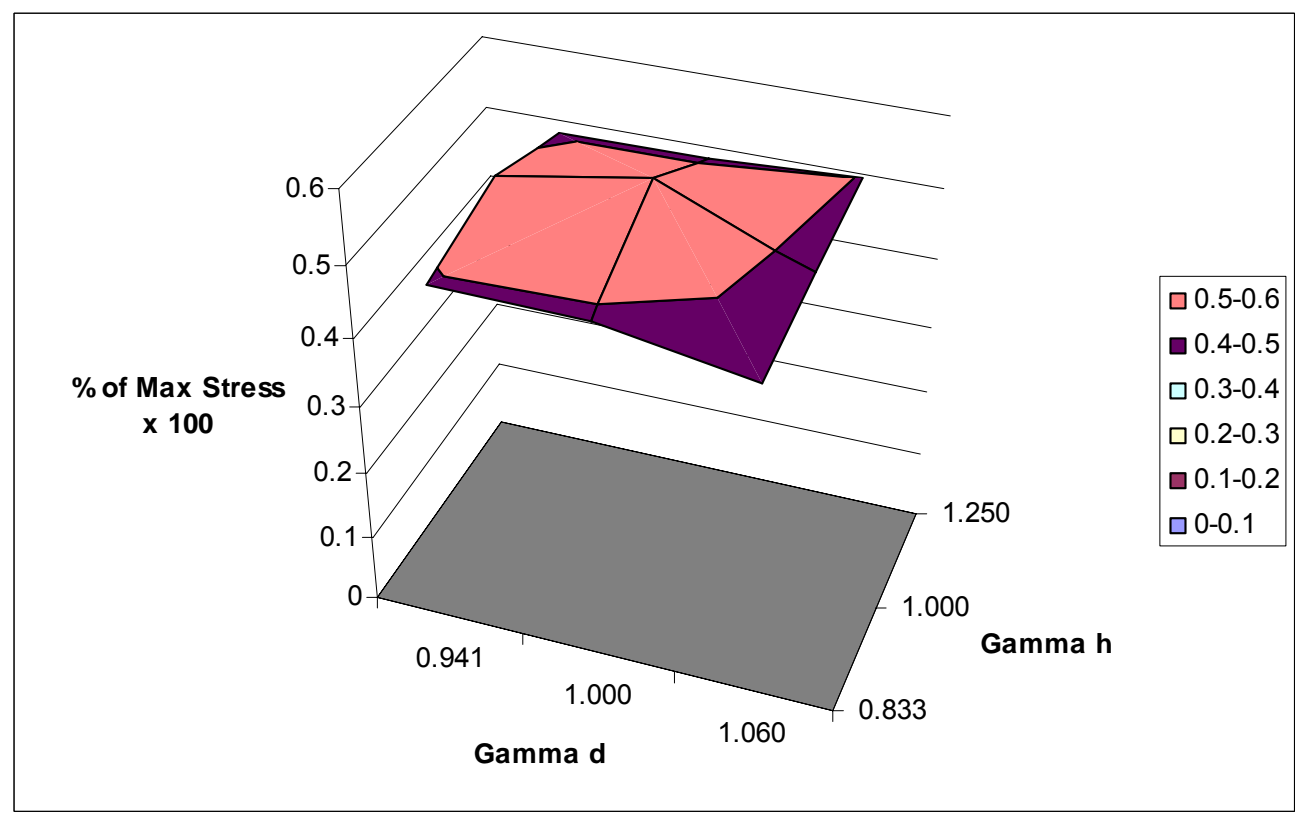

Figure $43 \gamma_{d}$ and $\gamma_{h}$ against percentage of max stress at the Microscrew Head for load case 2 


\subsection{Summary and Comparisons}

The tests performed on the torque to tension and nodal rotation to tension can be compared to calculate values and previous works. The torque to tension relationships closely mimicked the calculated values, but non-linearity in the ANSYS computational values existed.

Work done [7] showed a calculated nut rotation angle to bolt stress, Figure 3 for different friction coefficients with a standard M12 bolt with course threads. Figure 25, show similarities between the Finite Element Method approach and the calculated values. Differences in these analyses are the geometries of the fasteners. For this analysis a microscrew with properties taken from a 1-8 UNC bolt was used.

The stresses in the microscrew during the loading increments increased as the socket geometries were increased. The stress in the fillet increased proportionally with the load step increment while the stress in the head remained fairly constant. The stress found in the head is primarily from the deflection of the driver during tightening. The stress was highest along the top edge of the microscrew socket, and can lead to a deformation in the head. Though the stress in the head was high, failure in the fillet will occur first, which is the cause of the problem that exists. 


\section{Conclusions and Recommendations}

\subsection{Conclusions}

The purpose of the research was to determine a reason behind the premature failure of the microscrews during assembly. The nature of the 3ULR microscrew does not allow room for a very deep socket due to the shallow head. This geometry makes it rather difficult to create a socket size that would prevent a failure. The type of failure and the location led to a focus on the interface between the microscrew head and the shank. The material in this interface was significantly reduced when the socket diameter and the socket depth were increased. This increase in socket dimension created a situation where the furthest reach of the socket can in very close proximity to the fillet. As a result, very high stresses were found in this region.

The program written in APDL was found to be a very useful tool in performing the sensitivity analysis. The geometries were changed and loads were applied very easily without the burden of creating new models. Each of the models created were solved with small changes in parameters. The results from these changes were compared for the two load steps that were analyzed. As the parameters were increased to the point where the socket nearly pierced the fillet, it was found that consistent nonlinearity existed between the two load steps. It was determined that, due to the small size of the microscrew, even the slightest change in socket geometry caused the microscrew to fail.

In addition, high stress concentrations were found in the head of the microscrew. This stress was located directly behind the region of contact between the head and the driver assembly. It was determined that due to the tightening process the driver assembly 
deflects, causing tooth bending in the driver blades. This bending created a point-load situation on the leading edge of the microscrew socket, which created the high stresses. When these stresses were analyzed between the two loading cases, they were found to be relatively linear. The stress changed very little with the change in socket parameters and increased linearly when the load was increased.

The torque-to-tension and rotation-to-tension analyses proved useful in determining a relationship between clamping force and torque. The FEM analyses of these relationships validated the results given from ANSYS. The torque-to-tension analysis showed consistencies in the FEM analysis as well as the theoretical calculations. The rotation-to-tension analysis showed some consistency in linearity but the majority of the error can be related to friction not accurately depicted in calculations. Minor discrepancies existed in the numerical calculations from the analyses performed in FEM. The difference in values from the numerical and FEM analyses can be associated to the difference in model geometry. The numerical calculations were performed on a standard bolt of one inch diameter and eight threads per inch. The microscrew, though based off these dimensions, has a smaller shank diameter, which is equal to its root diameter. The rotation to tension analysis was compared to the findings of [7]. Though each of the ANSYS computational models was generally linear, there was a variation between the friction coefficients. The model without friction had a lower tension than the model with the highest friction coefficient. This could be associated with the high friction caused more stress in the cross section due to torsion which added to the Von Mises stress.

In conclusion ANSYS was used to modifying the socket geometry and simulate the affect of these modifications on the performance of the fastener. Data was extracted 
from these simulations to give a range of geometries to stop the microscrews from breaking. The data from the torque and rotation to tension analyses was verified by numerical computations and from previous works.

\subsection{Recommendations}

Further computational analysis could be used to analyze the mechanics of the microscrews for a wide variety of loadings. A full ANSYS license would allow an entire loading scenario set up with a fully threaded model and bulkhead as well as parts being clamped. These clamped parts and a nut or bulkhead, can have a stiffness varying that of the microscrew to accommodate different materials and friction coefficients. The programs written in the APDL code can be modified easily to model any desired geometry of head from a hexagonal geometry to a socket head cap screw-style.

Increasing the socket diameter and head depth can have a primary advantage of increasing the ease of which the microscrew "sticks" to the driver to hold it in place so that the microscrew can be used in an assembly. The microscrews are made from 302 Stainless Steel, which can become magnetic during cold working [11]. Slightly magnetic drivers can hold the microscrew in place during assembly, but due to some applications, such as micro-hard drives, this method would not be suitable for this particular use. A screw-starter screwdriver would be the best method in which to hold the microscrew

during assembly. One could be designed to hold the screw either with a type of spring clip or an adhesive layer for grip. 


\section{References}

[1] ANSYS Advanced Analysis Techniques Guide, Release 5.3, 1997, ANSYS Inc.

[2] ANSYS Command Reference Manual, Release 10.0 Documentation, 2005, ANSYS Inc.

[3] Bickford, John H., Nassar, Sayed, Handbook of Bolts and Bolted Joints, Marcel and Dekker, 1998

[4] Bretl, John L., Cook, Robert D., "Modeling the Load Transfer in Threaded Connections by the Finite Element Method", Int. J. for Numerical Methods in Engineering, Vol 14, 1979, pp 1359-1377.

[5] Cook, Robert D., Malkus, David S., Plesha, Michael E., Witt, Robert J. Concepts and Applications of Finite Element Analysis Fourth Ed. John Wiley \& Sons, 2002

[6] Englund, Richard B., Johnson, David H. "Finite Element Analysis of a Threaded Connection Compared to Experimental and Theoretical Research" Journal of Engineering Technology, Fall 1997, pp 42-46

[7] Fukuoka, Toshimichi, Takaki, Tomohiro, "Elastic Plastic Finite Element Analysis of Bolted Joint During Tightening Process" Journal of Mechanical Design, December 2003, Vol. 125 pp $823-830$

[8] Johnson, D.H., Englund, Robert B., McAnlis, Brian C., Sari, Kevin C. Colmbet, David, "Three-Dimensional Modeling of a Bolted Connection" FEA Consulting, Ohio CAE Inc. 2003 www.ohiocae.com/bolt.htm

[9] Lehnhoff, Terry F., Bunyard, Bradley A. "Bolt Thread and Head Fillet Stress Concentration Factors" December 2000, ASME Vol. 122, pp 180 - 185

[10] Lehnhoff, Terry F., Bunyard, Bradley A. "Effects of Bolt Threads on the Stiffness of a Bolted Joint" Journal of Pressure Vessel Technology, 2001 ASME Vol. 123, pp161- 165

[11] Metal Suppliers Online LLC. www.suppliersonline.com Material Property Data of 302 Stainless Steel.

[12] Motosh, N., "Development of Design Charts for Bolts Preloaded up to the Plastic Range" Journal of Engineering for Industry, Aug 1976 ASME pp 849 - 851 
[13] Nassar, Sayed A., Matin, Payam H., Barber, Gary C., "Thread Friction Torque in Bolted Joints" Journal of Pressure Vessel Technology, November 2005, ASME Vol. 127 , pp $387-39$

[14] Nassar, Sayed, A., El-Khiamy, H. Barber, G.C., Zou, Q., Sun, T.S., “An Experimental Study of Bearing and Thread Friction in Fasteners" Journal of Tribology, April 2005, ASME Vol. 127 pp $263-272$

[15] Papalambros, P.Y., Wilde, D.J., Principles of Optimal Design Modeling and Computation Cambridge University Press, 1988

[16] Shigley Joseph E., Mischke, Charles R., Budynas, Richard G., Mechanical Engineering Design $7^{\text {th }}$ Edition, McGraw Hill, 2004 


\section{Appendix A APDL Code For Parametric Sensitivity}

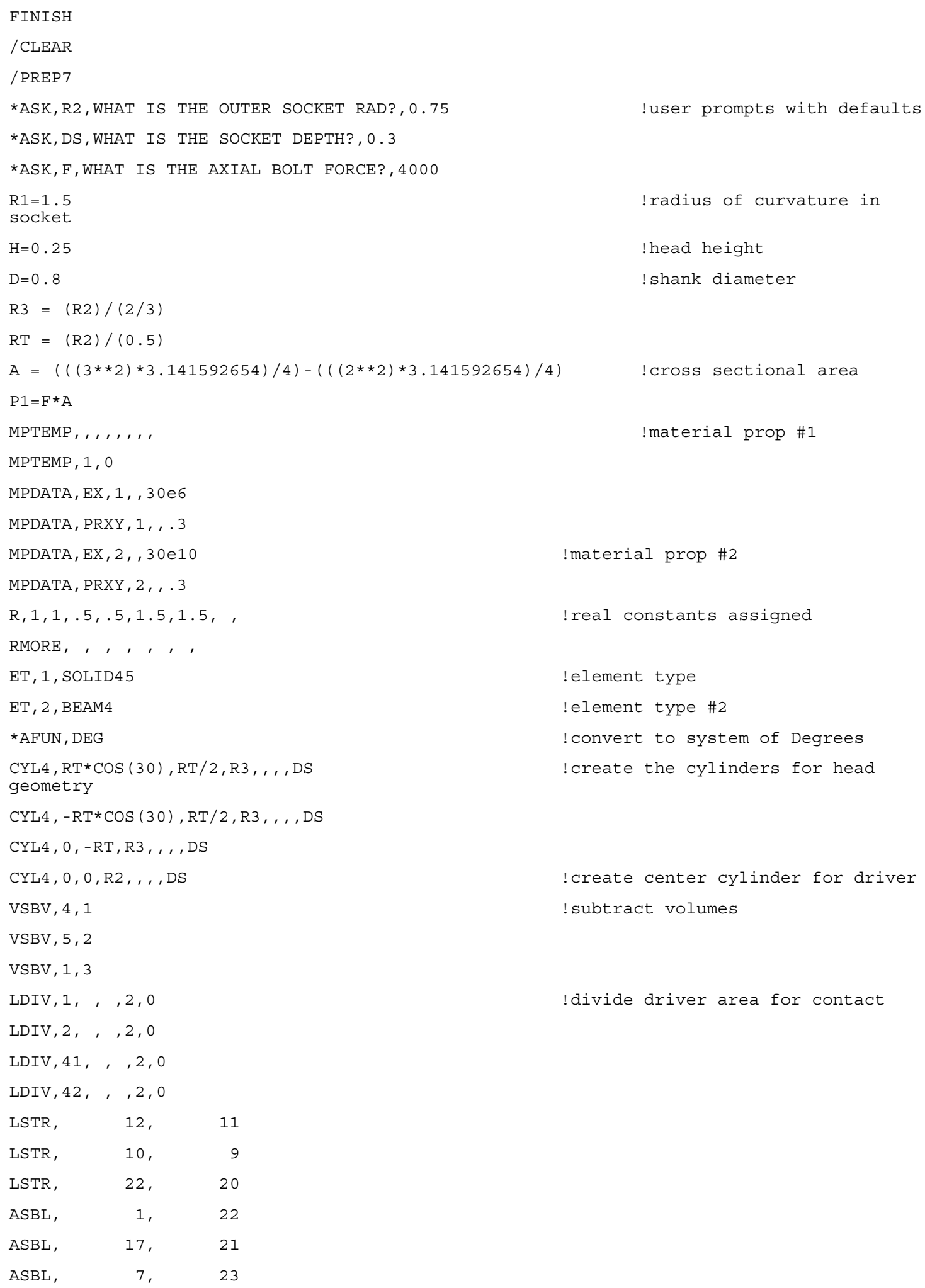




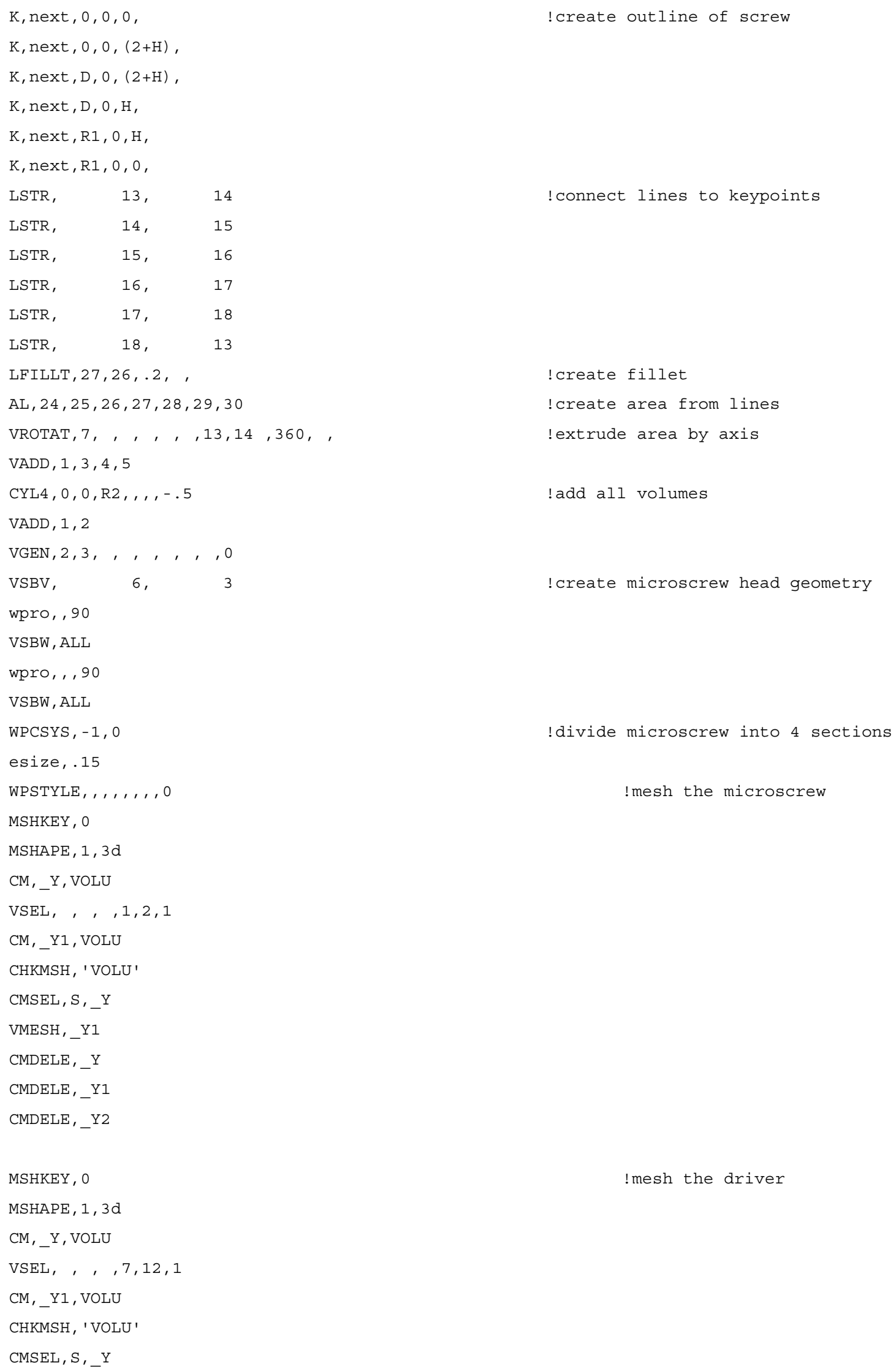




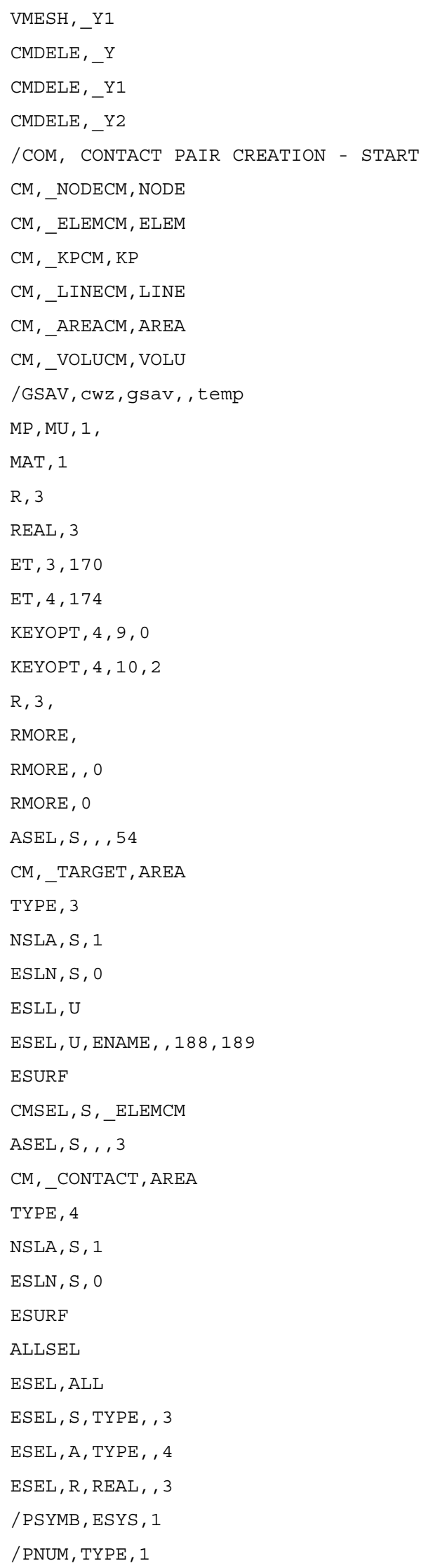




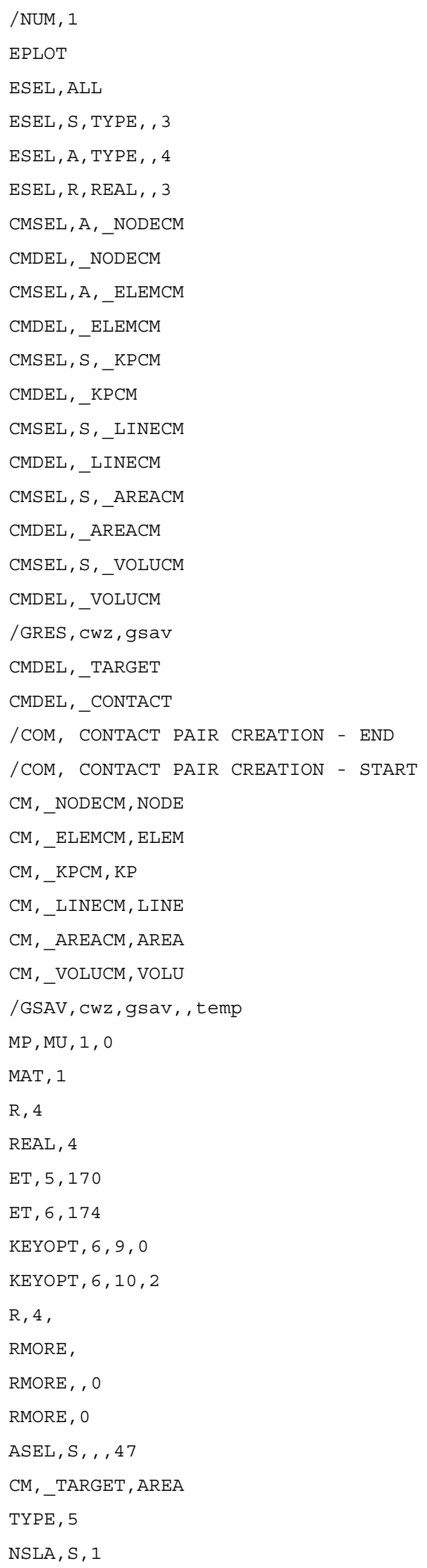


ESLN , S, 0

ESLL, U

ESEL , U, ENAME , , 188, 189

ESURF

CMSEL, S,_ELEMCM

! Generate the contact surface

ASEL , S , , , 9

CM,_CONTACT, AREA

TYPE, 6

NSLA, $S, 1$

ESLN , S , 0

ESURF

ALLSEL

ESEL, ALL

ESEL , S , TYPE , , 5

ESEL , A, TYPE, , 6

ESEL , R, REAL , , 4

/PSYMB, ESYS , 1

/PNUM, TYPE, 1

/NUM, 1

EPLOT

ESEL, ALL

ESEL , S, TYPE , , 5

ESEL , A, TYPE, , 6

ESEL , R, REAL , , 4

CMSEL, A,_NODECM

CMDEL, _NODECM

CMSEL, A, ELEMCM

CMDEL, _ELEMCM

CMSEL , S ,_KPCM

CMDEL, KRPM

CMSEL, S,_LINECM

CMDEL,_LINECM

CMSEL , S,_AREACM

CMDEL, _AREACM

CMSEL , S,_VOLUCM

CMDEL,_VOLUCM

/GRES, CWZ, gSav

CMDEL, _TARGET

CMDEL, CONTACT

/COM, CONTACT PAIR CREATION - END

/COM, CONTACT PAIR CREATION - START

CM,_NODECM, NODE

CM,_ELEMCM, ELEM

$\mathrm{CM}$,_KPCM, KP

CM,_LINECM, LINE

CM,_AREACM, AREA 


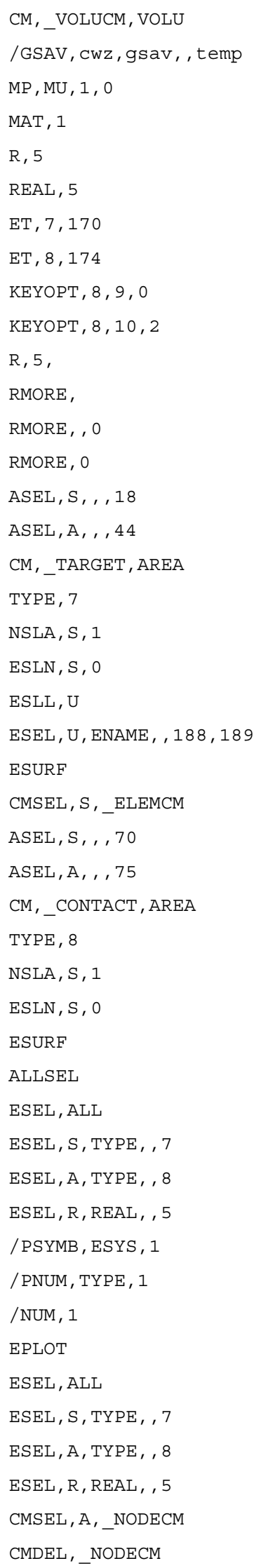




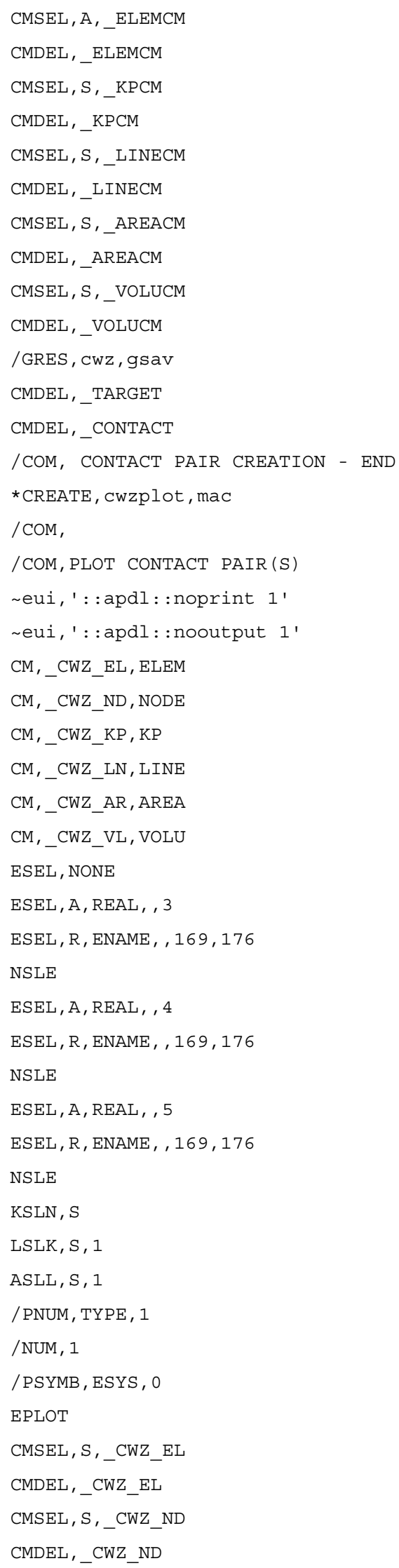




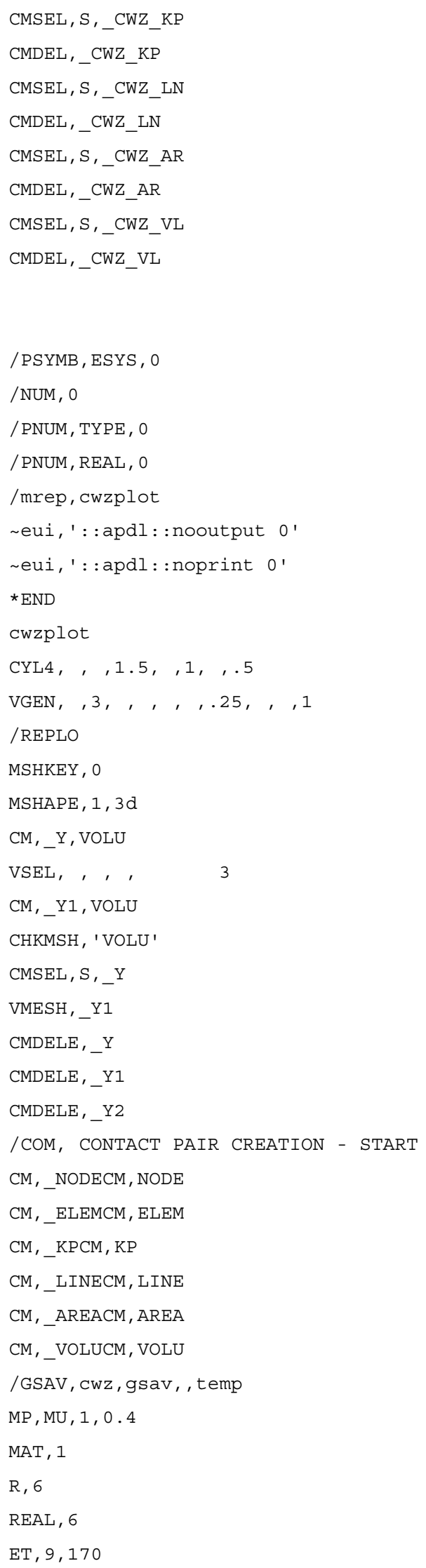


$\mathrm{ET}, 10,174$

KEYOPT, 10, 9,0

KEYOPT , 10, 10, 2

$R, 6$ ，

RMORE,

RMORE , , 0

RMORE, 0

! Generate the target surface

ASEL , S , , , 16

ASEL , A, , , 23

ASEL, A, , , 30

ASEL , A, , , 37

CM, TARGET, AREA

TYPE, 9

NSLA, $S, 1$

ESLN , S , 0

ESLL, U

ESEL , U, ENAME, , 188, 189

ESURF

CMSEL , S, ELEMCM

! Generate the contact surface

ASEL , $S, 1,1$

CM,_CONTACT , AREA

TYPE, 10

NSLA, S , 1

ESLN , S , 0

ESURF

ALLSEL

ESEL, ALL

ESEL , S , TYPE , , 9

ESEL , A, TYPE, , 10

ESEL , R, REAL , , 6

/PSYMB, ESYS , 1

/PNUM, TYPE, 1

/NUM, 1

EPLOT

ESEL, ALL

ESEL , S , TYPE , , 9

ESEL , A, TYPE, , 10

ESEL , R, REAL , , 6

CMSEL , A, NODECM

CMDEL，_NODECM

CMSEL, A,_ELEMCM

CMDEL，_ELEMCM

CMSEL, S, KPCM

CMDEL, _KPCM

CMSEL , S,_LINECM

CMDEL,_LINECM 


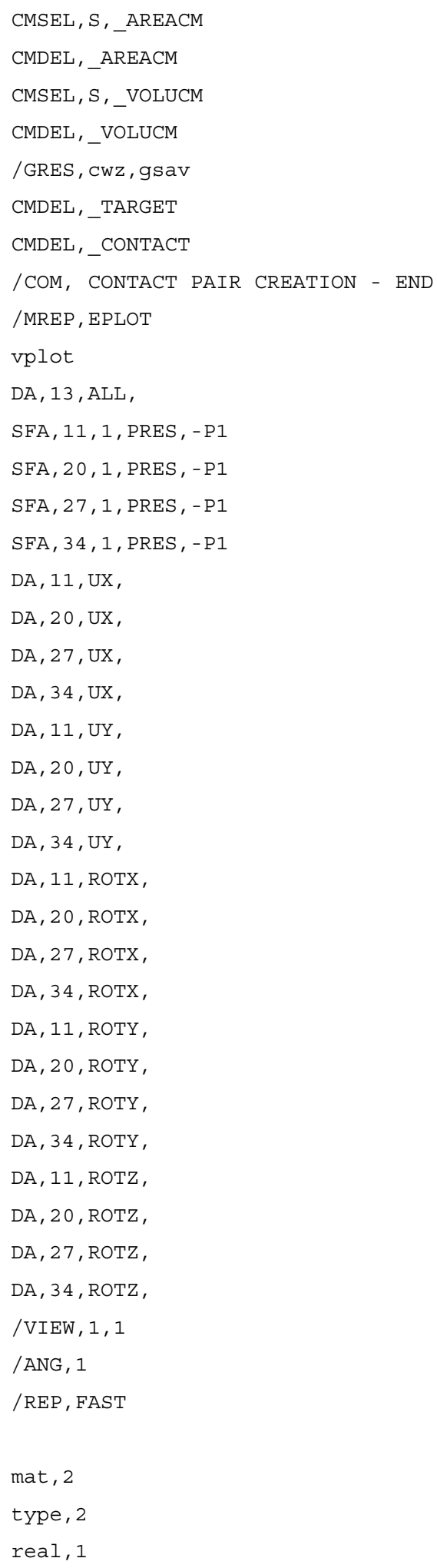




\section{Appendix B Von Mises Plots From the Parametric Analysis}

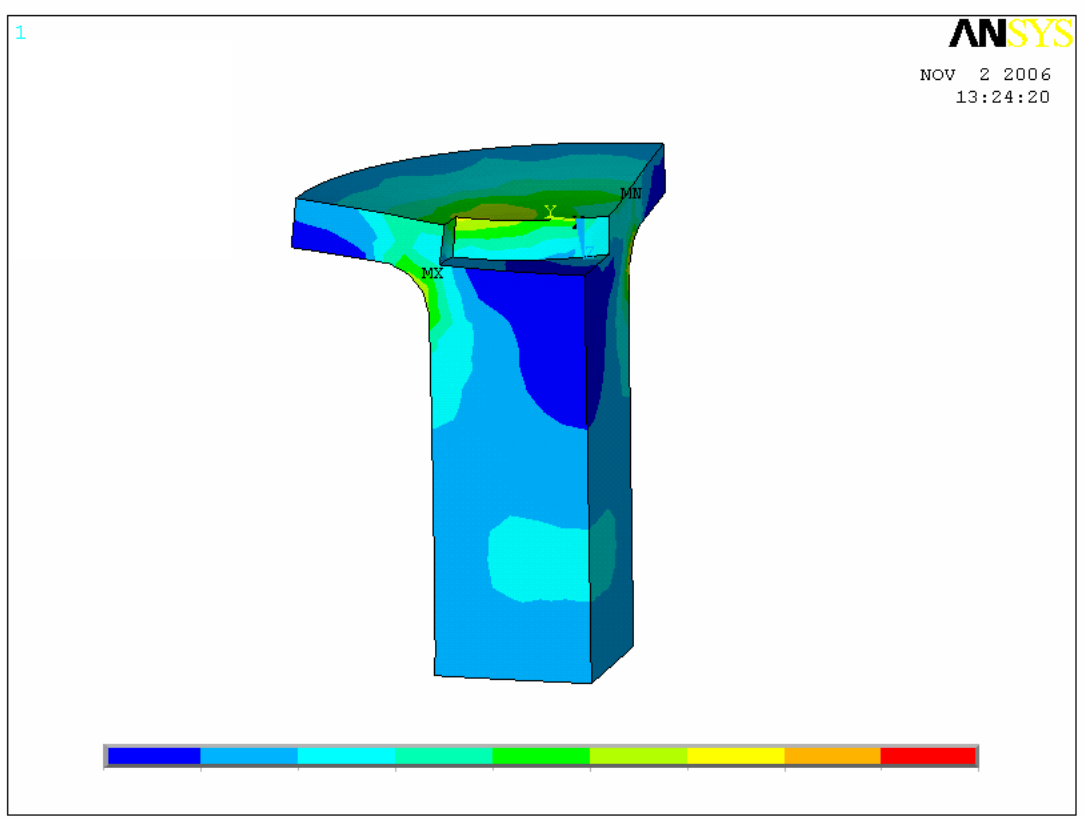

Figure 44 Von Mises stress for $\gamma_{\mathrm{d} 1} \gamma_{\mathrm{h} 1}$ for loading case 1

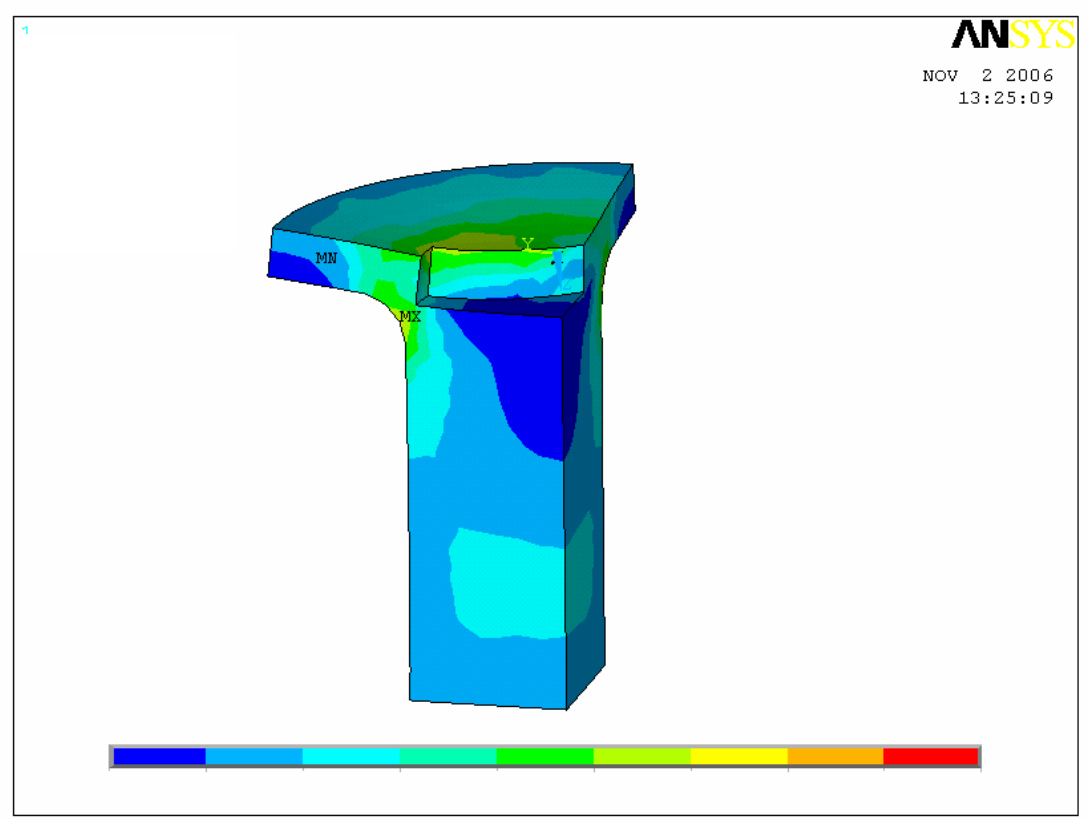

Figure 45 Von Mises stress for $\gamma_{\mathrm{d} 1} \gamma_{\mathrm{h} 2}$ for loading case 1 


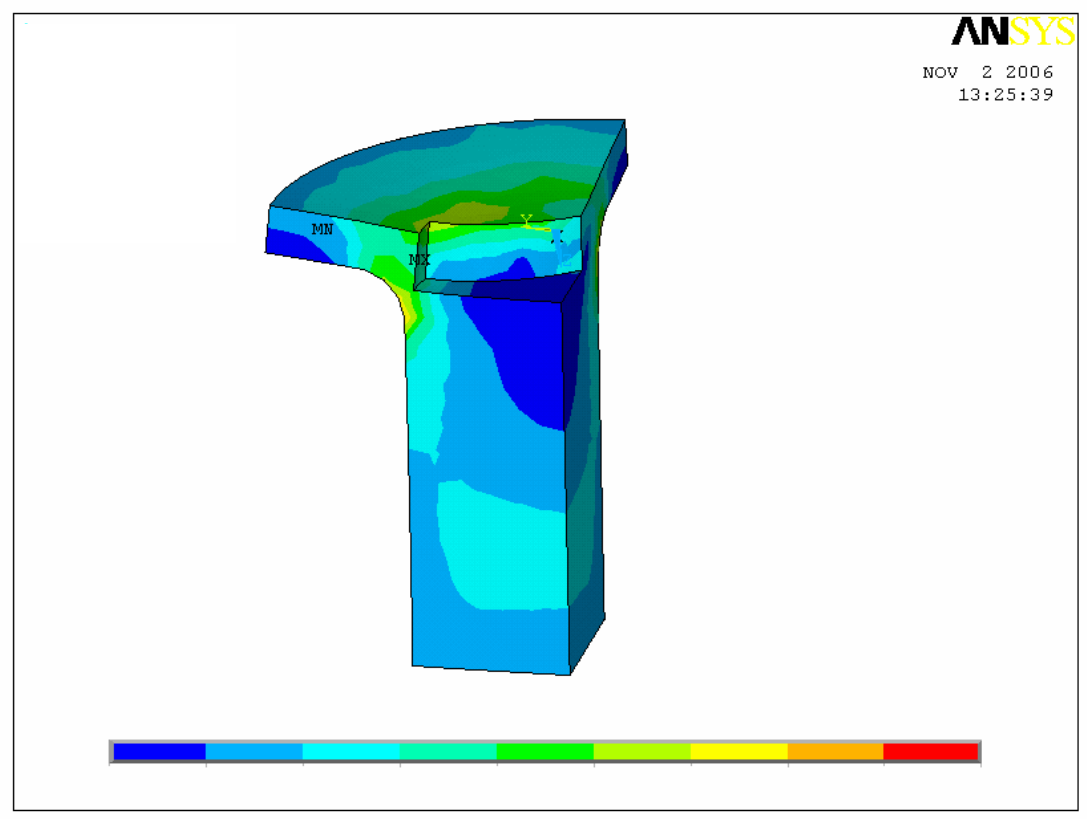

Figure 46 Von Mises stress for $\gamma_{\mathrm{d} 1} \gamma_{\mathrm{h} 3}$ for loading case 1

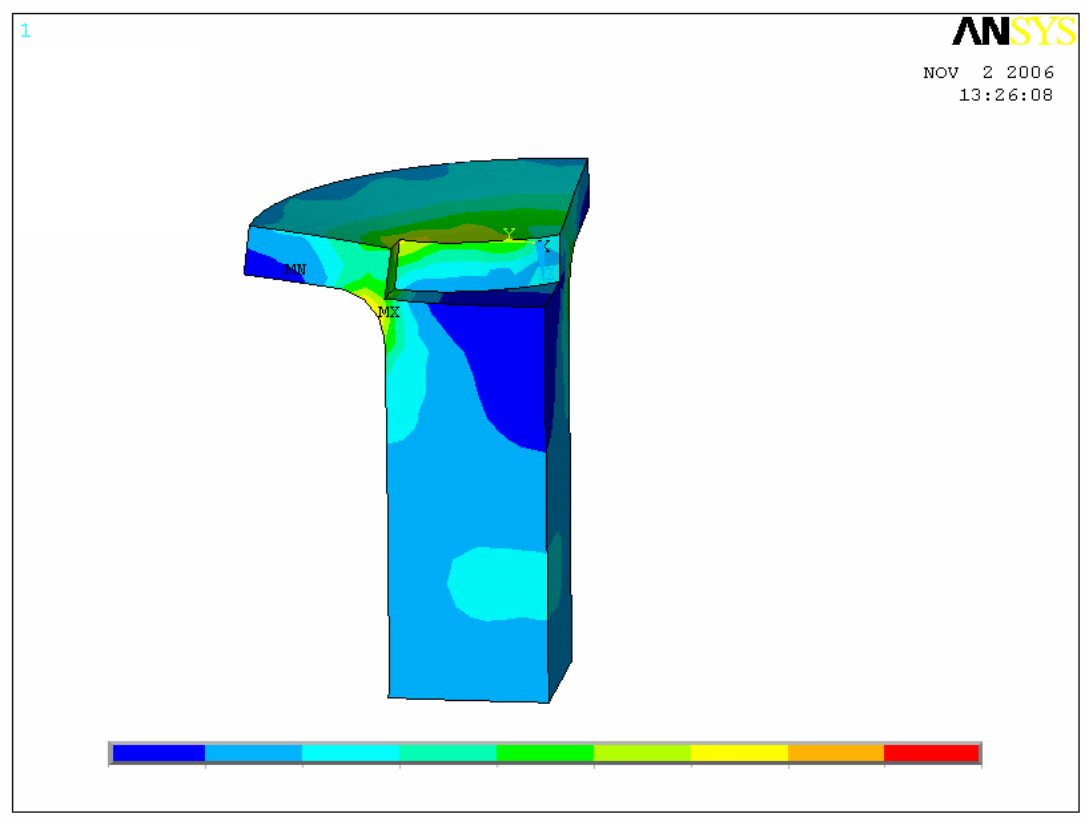

Figure 47 Von Mises stress for $\gamma_{\mathrm{d} 2} \gamma_{\mathrm{h} 1}$ for loading case 1 


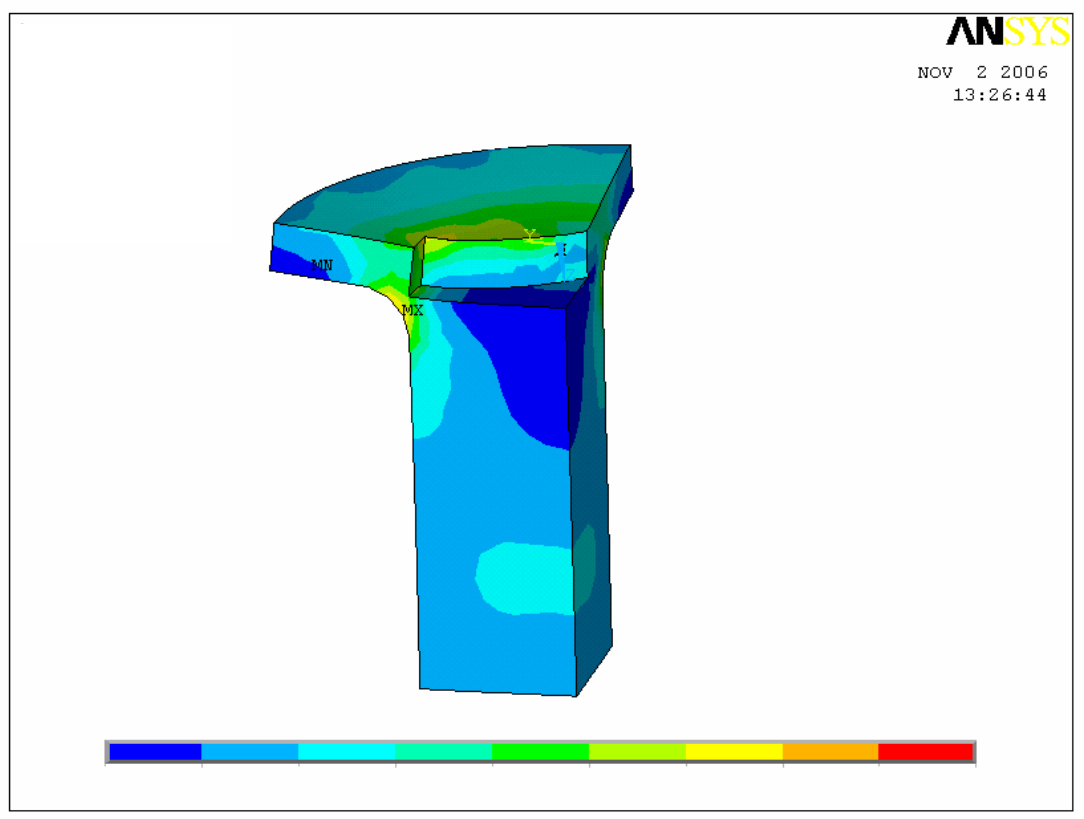

Figure 48 Von Mises stress for $\gamma_{\mathrm{d} 2} \gamma_{\mathrm{h} 2}$ for loading case 1

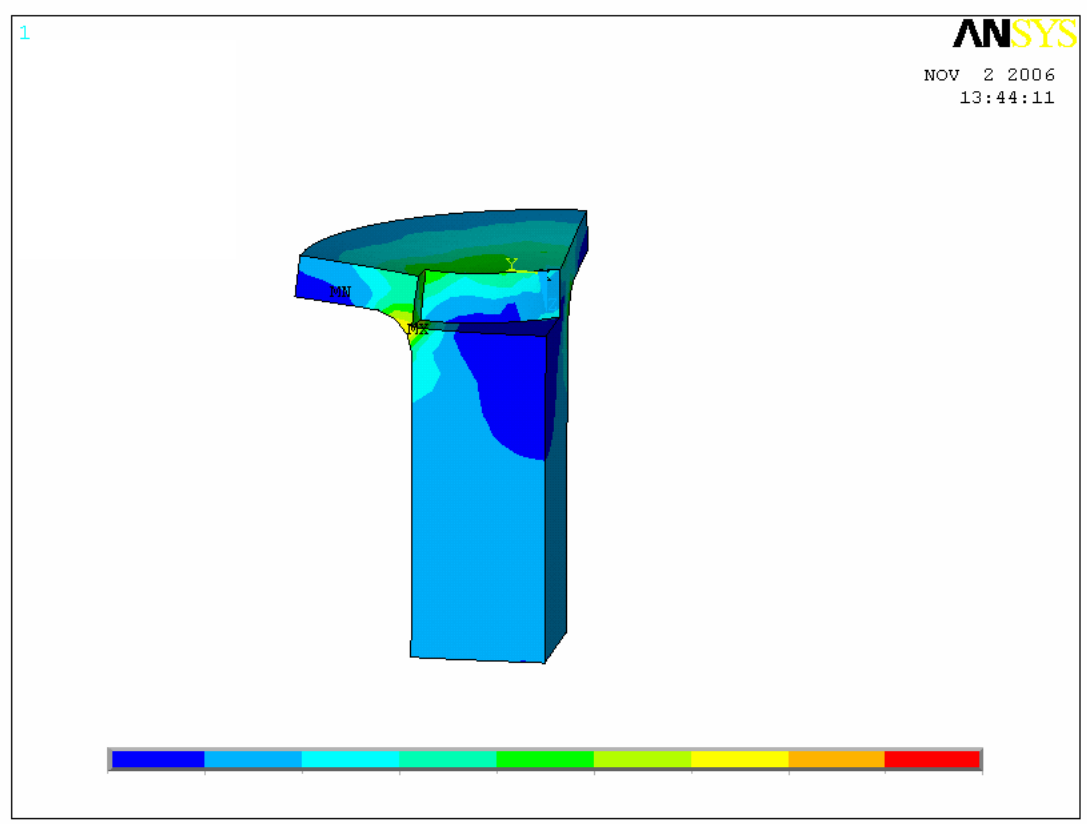

Figure 49 Von Mises stress for $\gamma_{\mathrm{d} 2} \gamma_{\mathrm{h} 3}$ for loading case 1 


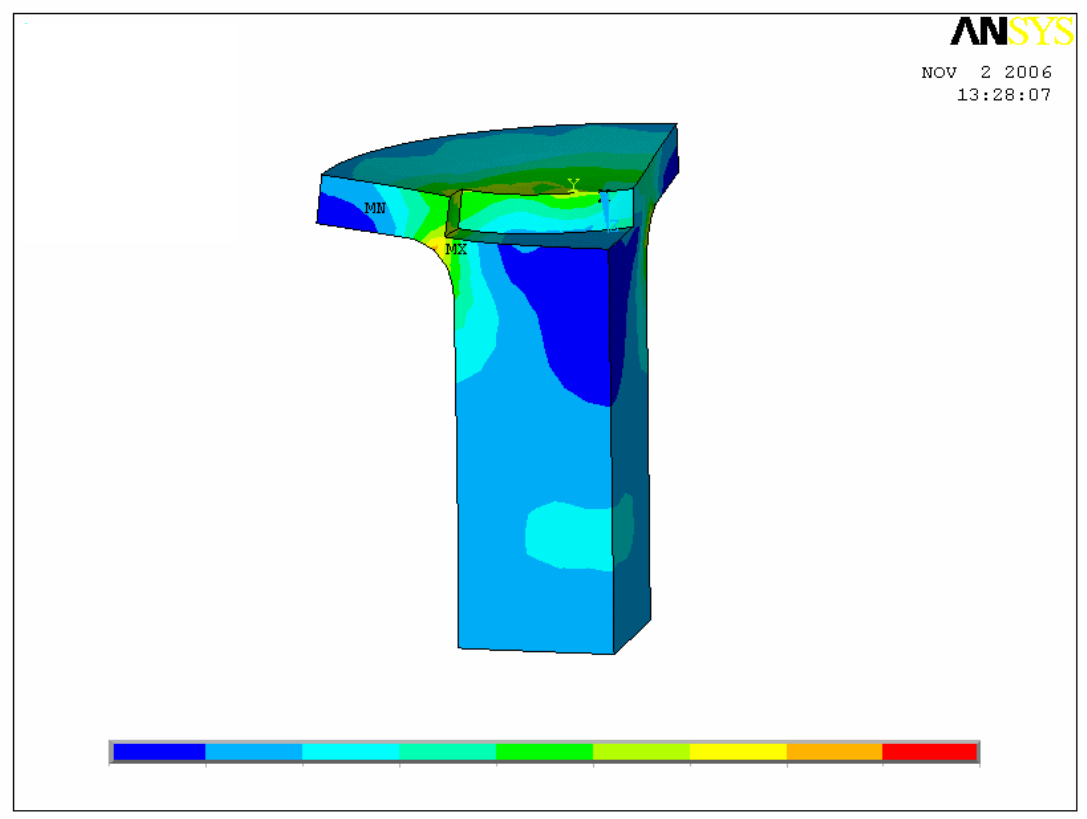

Figure 50 Von Mises stress for $\gamma_{\mathrm{d} 3} \gamma_{\mathrm{h} 1}$ for loading case 1

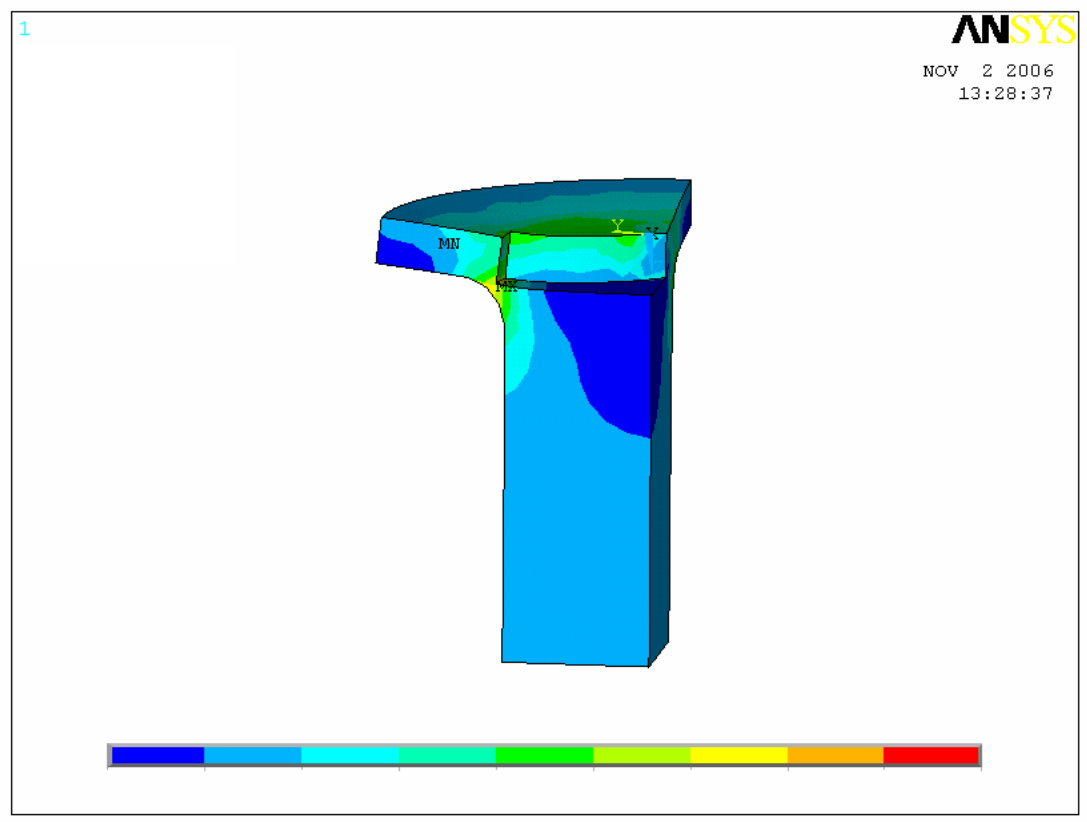

Figure 51 Von Mises stress for $\gamma_{\mathrm{d} 3} \gamma_{\mathrm{h} 2}$ for loading case 1 


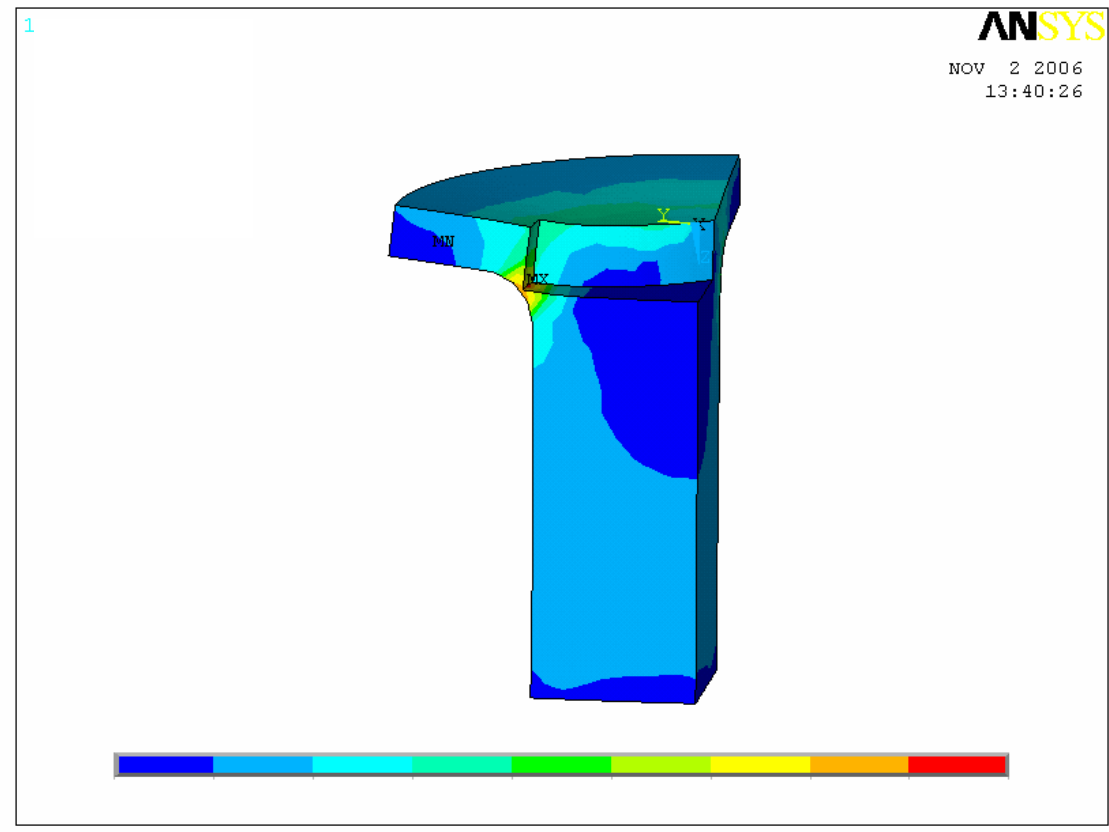

Figure 52 Von Mises stress for $\gamma_{\mathrm{d} 3} \gamma_{\mathrm{h} 3}$ for loading case 1

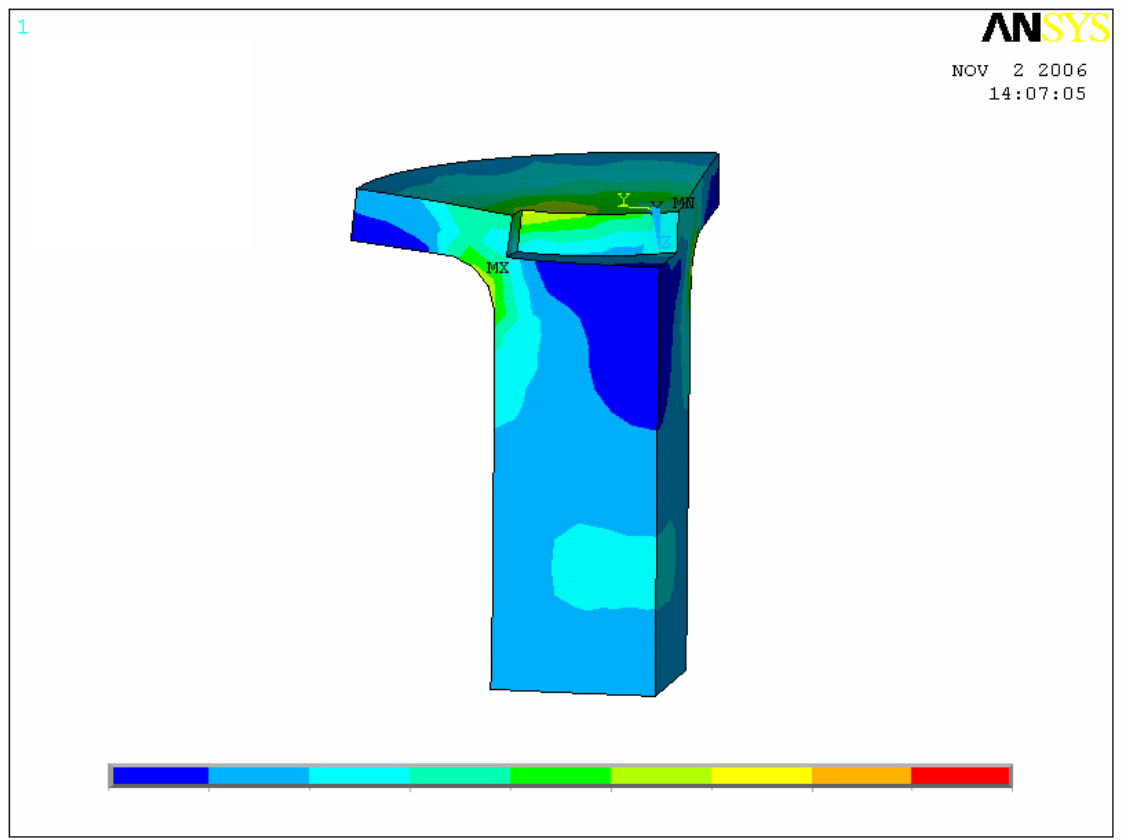

Figure 53 Von Mises stress for $\gamma_{\mathrm{d} 1} \gamma_{\mathrm{h} 1}$ for loading case 2 


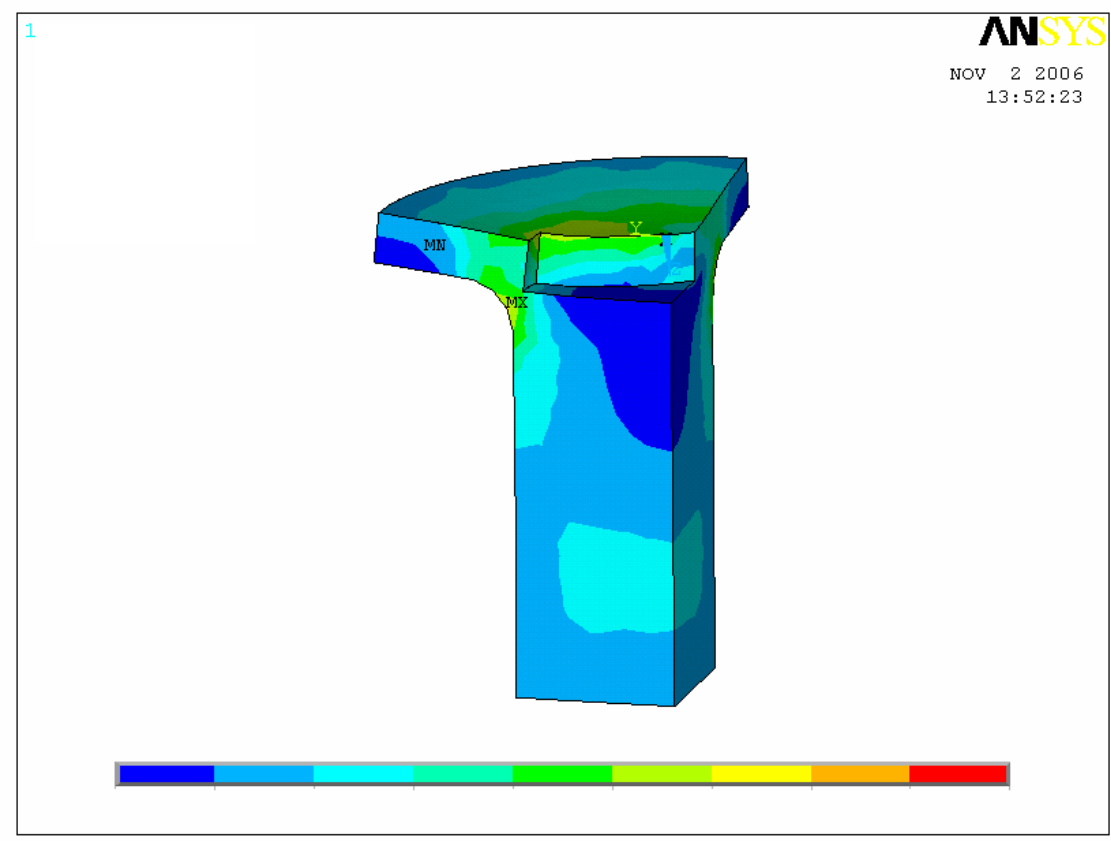

Figure 54 Von Mises stress for $\gamma_{\mathrm{d} 1} \gamma_{\mathrm{h} 2}$ for loading case 2

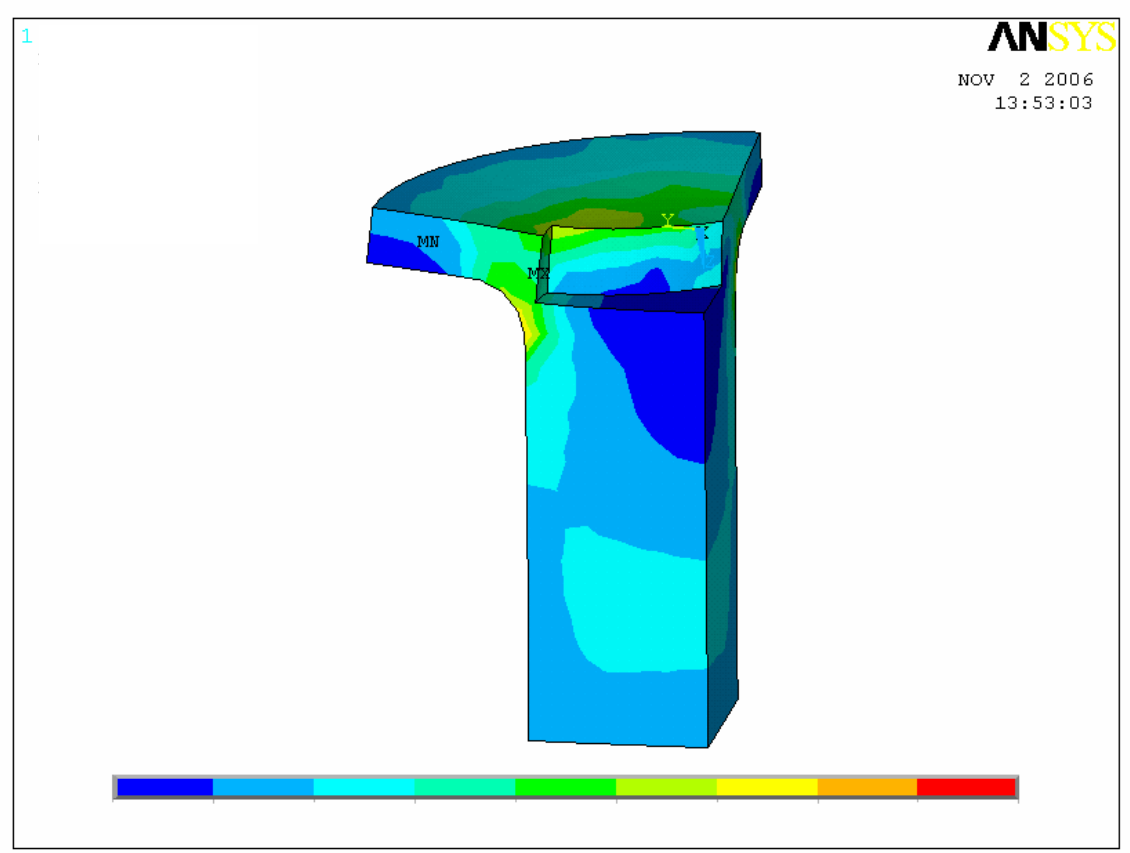

Figure 55 Von Mises stress for $\gamma_{\mathrm{d} 1} \gamma_{\mathrm{h} 3}$ for loading case 2 


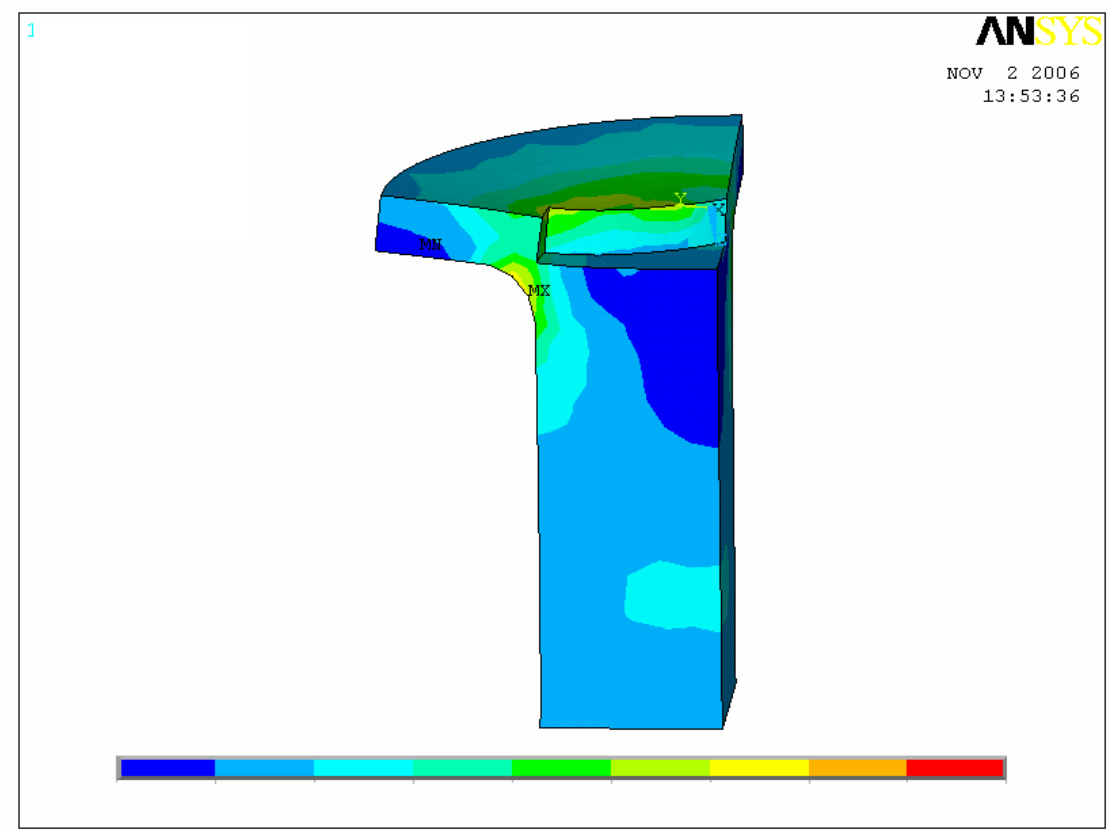

Figure 56 Von Mises stress for $\gamma_{\mathrm{d} 2} \gamma_{\mathrm{h} 1}$ for loading case 2

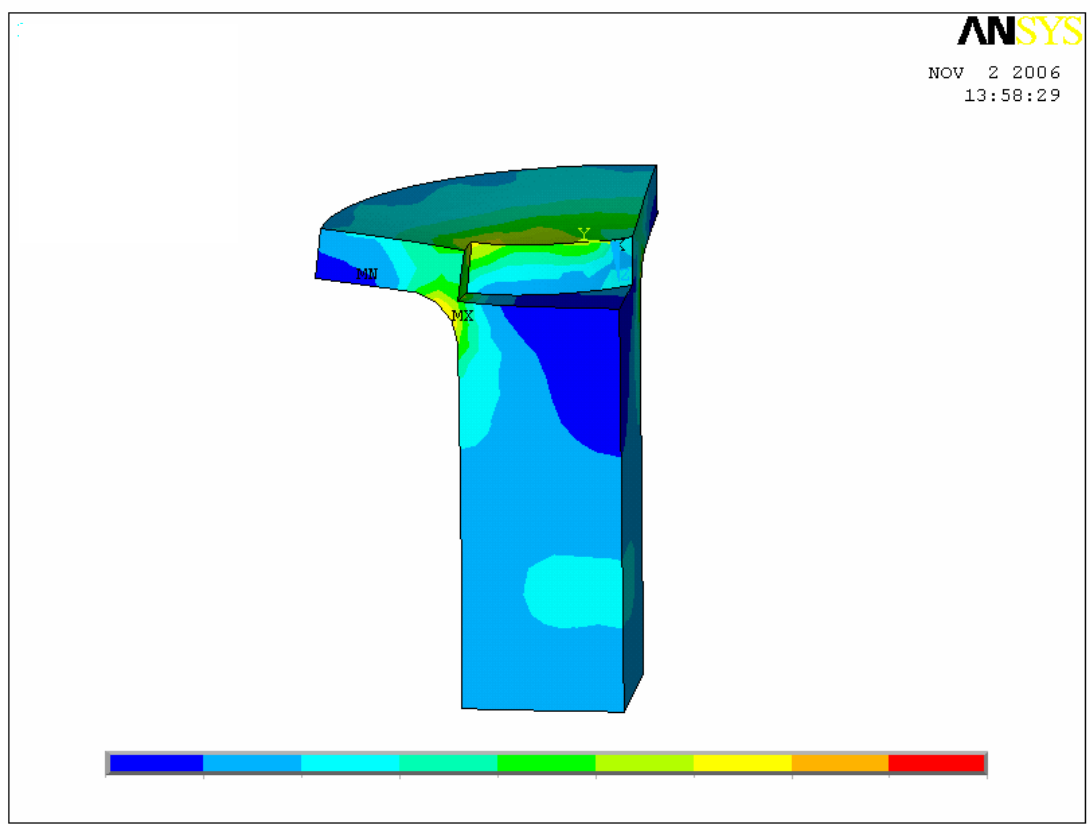

Figure 57 Von Mises stress for $\gamma_{\mathrm{d} 2} \gamma_{\mathrm{h} 2}$ for loading case 2 


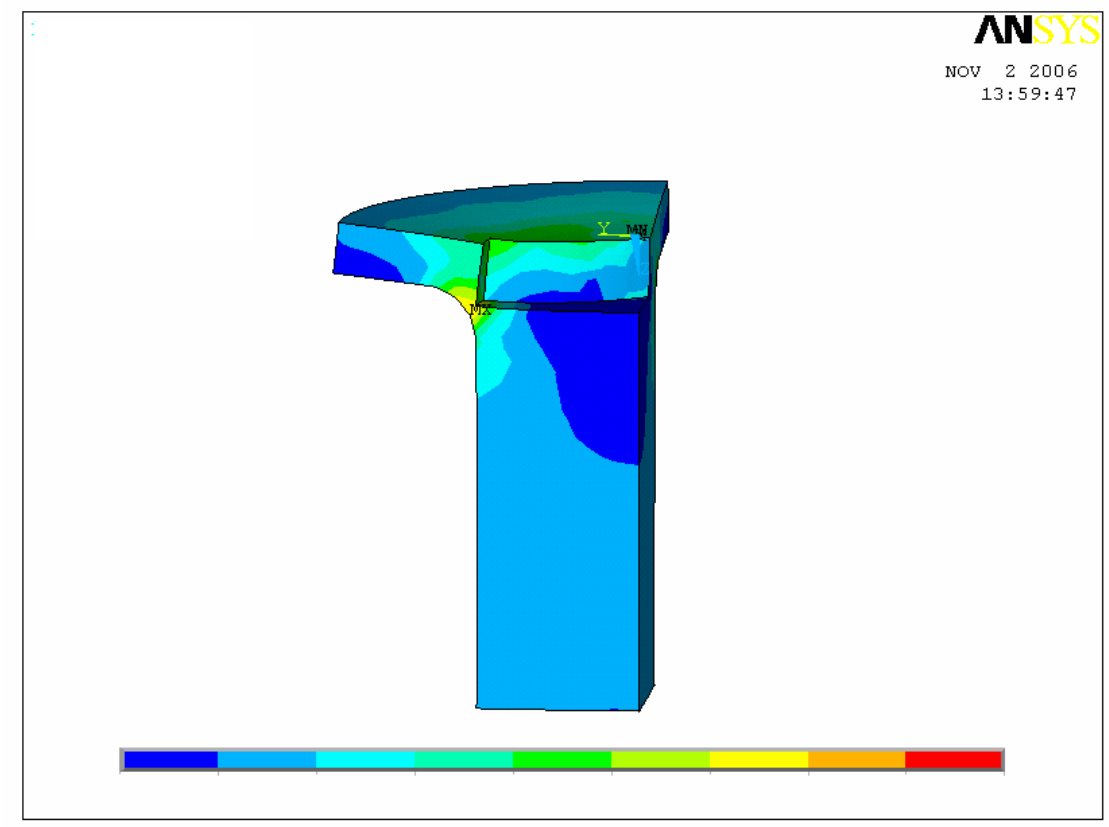

Figure 58 Von Mises stress for $\gamma_{\mathrm{d} 2} \gamma_{\mathrm{h} 3}$ for loading case 2

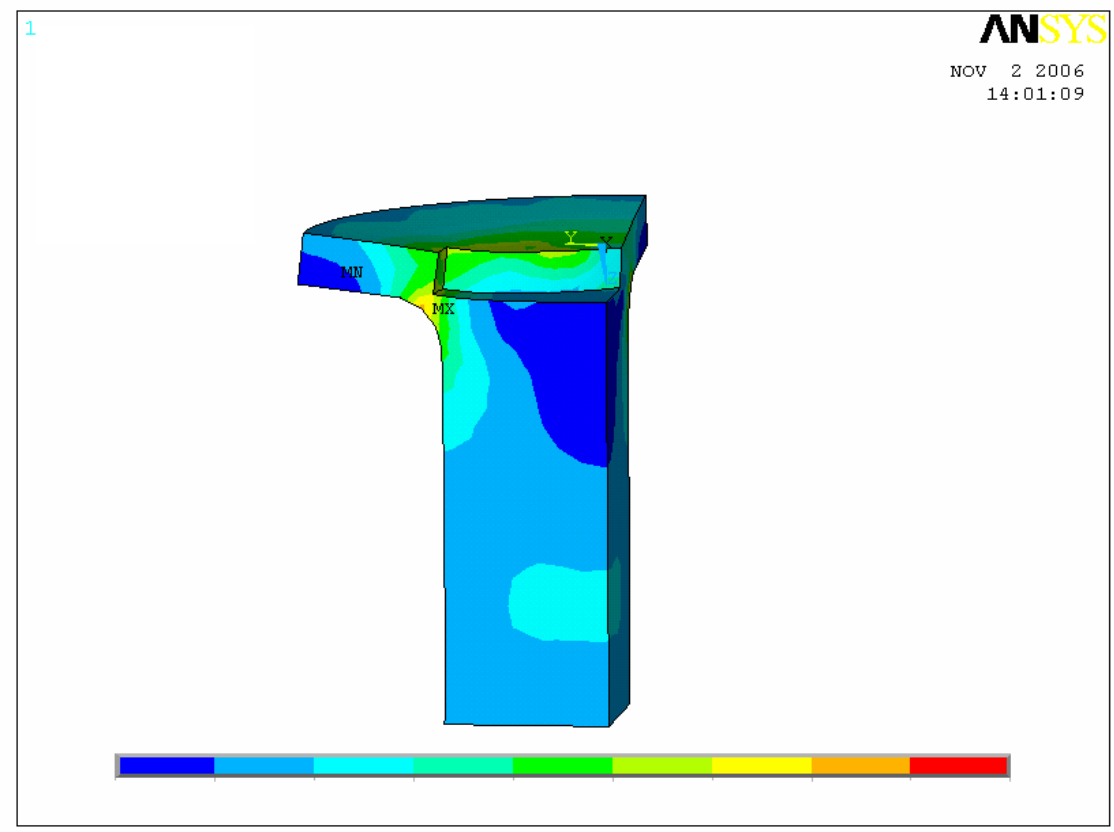

Figure 59 Von Mises stress for $\gamma_{\mathrm{d} 3} \gamma_{\mathrm{h} 1}$ for loading case 2 


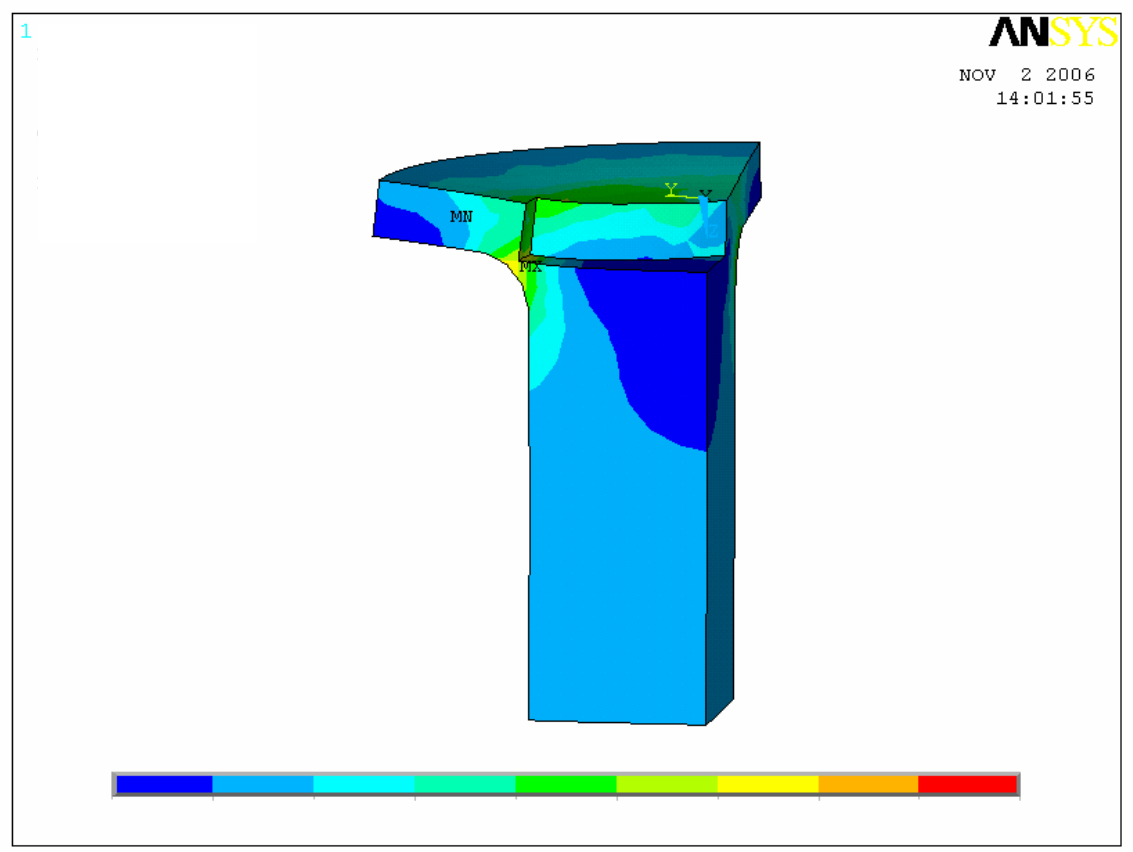

Figure 60 Von Mises stress for $\gamma_{\mathrm{d} 3} \gamma_{\mathrm{h} 2}$ for loading case 2

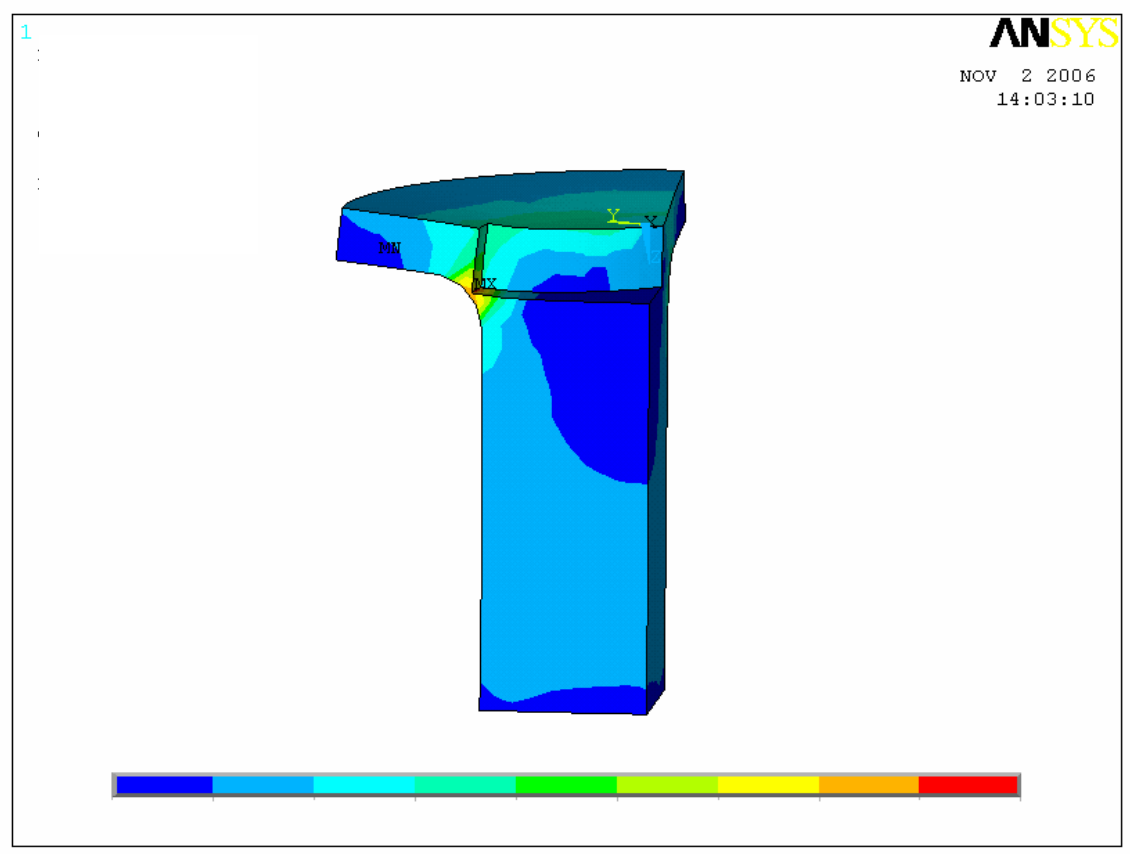

Figure 61 Von Mises stress for $\gamma_{\mathrm{d} 3} \gamma_{\mathrm{h} 3}$ for loading case 2 


\section{Appendix C Microscrew Schematic}
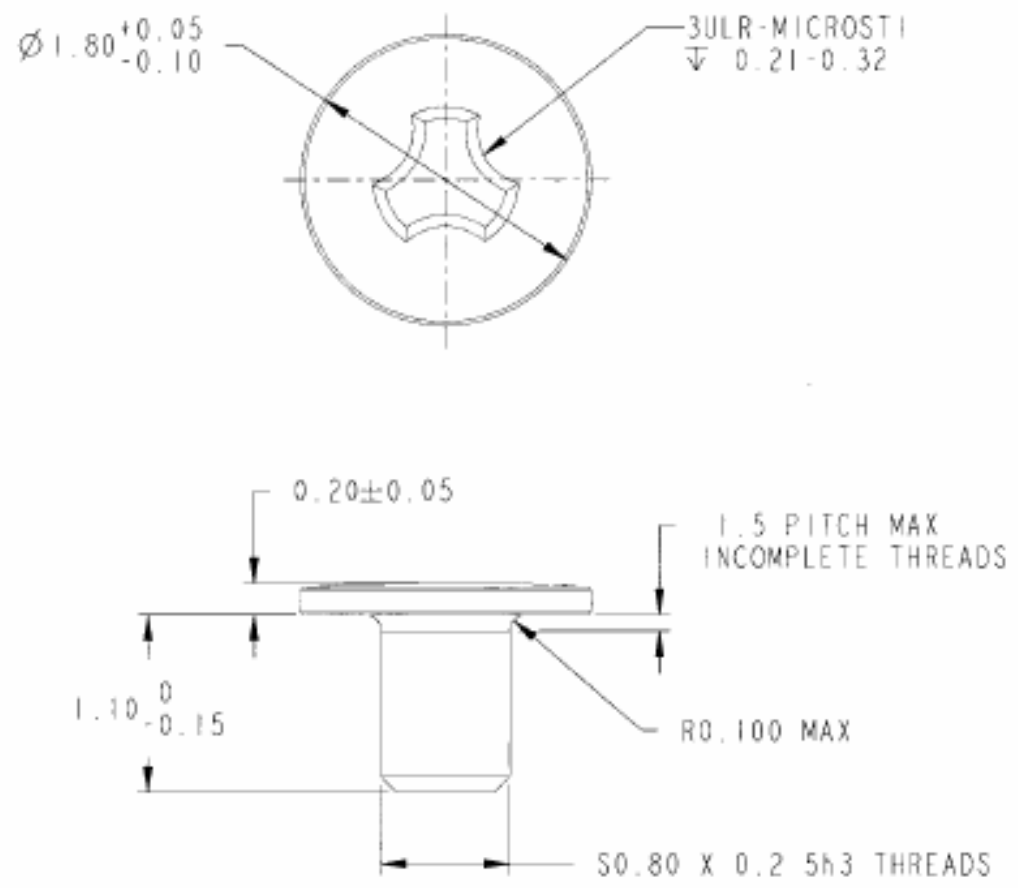

Figure 62 Microscrew schematic 